\title{
Transmission System Performance Analysis for High-Penetration Photovoltaics
}

Subcontract Report NREL/SR-581-42300

February 2008

S. Achilles, S. Schramm, and J. Bebic GE Global Research Niskayuna, New York 


\section{Transmission System Performance Analysis for High-Penetration Photovoltaics}

S. Achilles, S. Schramm, and J. Bebic GE Global Research

Niskayuna, New York

NREL Technical Monitor: Ben Kroposki

Prepared under Subcontract No. ADC-7-77032-01

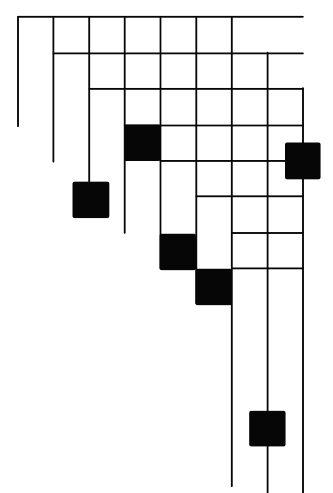




\section{NOTICE}

This report was prepared as an account of work sponsored by an agency of the United States government. Neither the United States government nor any agency thereof, nor any of their employees, makes any warranty, express or implied, or assumes any legal liability or responsibility for the accuracy, completeness, or usefulness of any information, apparatus, product, or process disclosed, or represents that its use would not infringe privately owned rights. Reference herein to any specific commercial product, process, or service by trade name, trademark, manufacturer, or otherwise does not necessarily constitute or imply its endorsement, recommendation, or favoring by the United States government or any agency thereof. The views and opinions of authors expressed herein do not necessarily state or reflect those of the United States government or any agency thereof.

Available electronically at http://www.osti.gov/bridge

Available for a processing fee to U.S. Department of Energy and its contractors, in paper, from:

U.S. Department of Energy

Office of Scientific and Technical Information

P.O. Box 62

Oak Ridge, TN 37831-0062

phone: 865.576 .8401

fax: 865.576 .5728

email: mailto:reports@adonis.osti.gov

Available for sale to the public, in paper, from:

U.S. Department of Commerce

National Technical Information Service

5285 Port Royal Road

Springfield, VA 22161

phone: 800.553 .6847

fax: 703.605.6900

email: orders@ntis.fedworld.gov

online ordering: http://www.ntis.gov/ordering.htm

This publication received minimal editorial review at NREL 


\section{Preface}

Now is the time to plan for the integration of significant quantities of distributed renewable energy into the electricity grid. Concerns about climate change, the adoption of state-level renewable portfolio standards and incentives, and accelerated cost reductions are driving steep growth in U.S. renewable energy technologies. The number of distributed solar photovoltaic (PV) installations, in particular, is growing rapidly. As distributed PV and other renewable energy technologies mature, they can provide a significant share of our nation's electricity demand. However, as their market share grows, concerns about potential impacts on the stability and operation of the electricity grid may create barriers to their future expansion.

To facilitate more extensive adoption of renewable distributed electric generation, the U.S. Department of Energy launched the Renewable Systems Interconnection (RSI) study during the spring of 2007. This study addresses the technical and analytical challenges that must be addressed to enable high penetration levels of distributed renewable energy technologies. Because integration-related issues at the distribution system are likely to emerge first for PV technology, the RSI study focuses on this area. A key goal of the RSI study is to identify the research and development needed to build the foundation for a high-penetration renewable energy future while enhancing the operation of the electricity grid.

The RSI study consists of 15 reports that address a variety of issues related to distributed systems technology development; advanced distribution systems integration; system-level tests and demonstrations; technical and market analysis; resource assessment; and codes, standards, and regulatory implementation. The RSI reports are:

- Renewable Systems Interconnection: Executive Summary

- Distributed Photovoltaic Systems Design and Technology Requirements

- Advanced Grid Planning and Operation

- Utility Models, Analysis, and Simulation Tools

- Cyber Security Analysis

- Power System Planning: Emerging Practices Suitable for Evaluating the Impact of High-Penetration Photovoltaics

- Distribution System Voltage Performance Analysis for High-Penetration Photovoltaics

- Enhanced Reliability of Photovoltaic Systems with Energy Storage and Controls

- Transmission System Performance Analysis for High-Penetration Photovoltaics

- Solar Resource Assessment

- Test and Demonstration Program Definition

- Photovoltaics Value Analysis

- Photovoltaics Business Models 
- Production Cost Modeling for High Levels of Photovoltaic Penetration

- Rooftop Photovoltaics Market Penetration Scenarios.

Addressing grid-integration issues is a necessary prerequisite for the long-term viability of the distributed renewable energy industry, in general, and the distributed PV industry, in particular. The RSI study is one step on this path. The Department of Energy is also working with stakeholders to develop a research and development plan aimed at making this vision a reality. 


\section{List of Acronyms}

ACL active current limit

AVR automatic voltage regulator

FC frequency droop control

GE General Electric

IEEE Institute of Electrical and Electronics Engineers

LVRT low-voltage ride-through

MPP maximum power point tracking

PLL phase-locked loop

PSLF positive sequence load flow

PSS power system stabilizer

PV photovoltaic 


\section{Executive Summary}

A combination of incentive programs, technology advancements, and further increases in prime energy costs could result in vast deployment of photovoltaics (PV) in power distribution systems. In such a scenario, power systems could be characterized by large quantities of generation embedded throughout the electric power system. Wind generation has been massively installed in some areas of the world (such as Spain and northern Germany) and has had a substantial impact on power system performance. For example, transmission faults that were previously characterized by short voltage sags can become significant system events with large power imbalance issues between control zones because a considerable amount of wind generation was disconnected during faults. Thus, wind generation technologies provide enhanced performance characteristics such as tolerance to voltage sags. Although PV generation is more distributed in nature than wind generation, many concerns about significant wind penetration are relevant to PV.

This research developed an understanding of the impact of significant PV penetration on transmission system reliability and performance. A simulation database was developed to allow analysis of system behavior and interactions with high levels of PV penetration under realistic system conditions. These explorations showed that for high PV penetration, the performance requirements for the PV units are stricter to keep similar reliability and performance. Also, the criterion to dispatch and commit conventional generation for high penetration of PV has a significant impact on system behavior.

The main observations associated with systems aspects with large penetration PV follow. (See Section 6 for more detail.)

- Unit commitment strategy has a significant impact on system performance at high PV penetration levels:

- System inertia and frequency regulation capabilities are reduced as conventional generation is de-committed.

- Thermal units could operate at less efficient load levels

- Reactive power support in the transmission system is reduced as conventional generation is de-committed.

- Dynamic stability of the system can be affected.

- Considerable dispatch flexibility of conventional generation is required to accommodate high-penetration PV.

- With substantial PV penetration that is compliant with IEEE $1547,{ }^{1}$ there is considerable reduction in system reliability caused by extensive loss of PV generation during transmission faults.

- PV generation could provide primary frequency control for frequency excursions above nominal without significantly reducing energy production.

\footnotetext{
${ }^{1}$ IEEE 1547 Standard for Interconnecting Distributed Resources with Electric Power Systems, 2003.
} 
- Anti-islanding schemes of PV can affect the oscillatory stability of the bulk power system.

The main observations on PV potential performance are:

- The low-voltage ride-through capability of PV would reduce the negative impact on system reliability of high-penetration PV.

- Even if the PV stays connected during and after a system fault, voltage sags are prone to cause prolonged PV power output reductions.

The simulation work presented in this report focused on system performance after electrical faults and power imbalances caused by generation trips. Other aspects of PV integration that were not analyzed with simulations in this effort, but are considered relevant, follow. (For more detail see Section 6.)

- The commitment of fewer regulating units to accommodate PV generation increases the requirement of load-following reserve in the system and for individual units. Additionally, the variability of PV generation may also increase load-following requirements.

- The implementation of voltage control on individual PV systems is challenging. There is potential for undesirable interactions between PV systems connected to the same feeder and phase and between PV systems and other voltage-regulating devices.

Based on the analysis and observations, we recommend that future research in this area:

- Develop models that are accurate enough to estimate aggregated behavior of PV systems for system planning. The behavior of aggregated PV during and after faults is most relevant. Converter technology and control can result in considerable differences between systems.

- Develop guidelines for enhancing transmission planning databases to accommodate such models, including aggregated representation of medium- and low-voltage networks.

- Improve understanding and provide guidelines to quantify the performance and economic impact of PV penetration on regulation and load-following requirements.

- Develop methodologies for estimating the required flexibility of the generation assets to meet regulation and load-following requirements; in particular, the requirements for generating units to ramp production up or down and to stop and start.

- Develop a unit commitment and dispatch strategy for conventional units in systems with high-penetration PV. The proposed strategy should include reliability requirements, operational costs, regulation, and load-following costs. The use of PV forecasts in unit commitment is also instrumental to increase the value of PV generation for high penetration. The approach may require that part of the unit scheduling be done a few hours in advance (instead of 24 to 48 hours currently required) to improve PV production forecast accuracy. Extending such research to systems with PV and wind generation is also recommended. 
- Provide guidance to quantify the value in terms of performance and the economic benefits of potentially mitigating measures of PV power variability (modifications of control zone constraints, flexible conventional generation, centralized and local energy storage, forecast, etc.). These guidelines could be applied to different systems and generation resources. Extending such research to systems with PV and wind generation is also recommended.

- Develop methods to reliably forecast PV generation at regional levels.

- Develop methods to estimate the actual PV generation to help with system operation.

- Develop active anti-islanding schemes or tuning guidelines that do not affect regional system performance.

- Develop strategy and specification of PV voltage control.

Develop potential remuneration mechanisms for ancillary services associated with voltage support of PV. 


\section{Table of Contents}

List of Figures

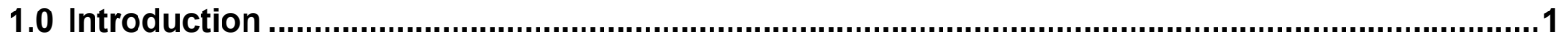

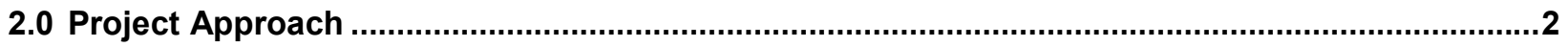

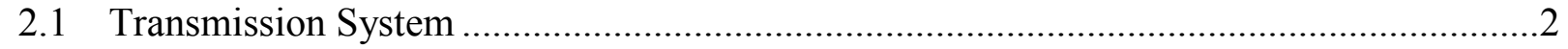

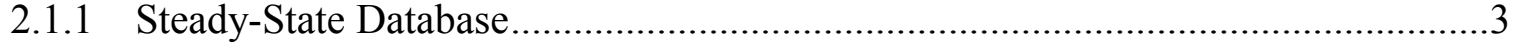

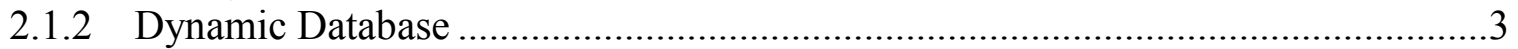

2.1.3 Validation Runs ................................................................................... 4

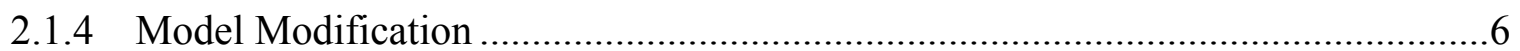

2.2 Aggregated PV Representation........................................................................... 7

2.2.1 Photovoltaic Module Representation ............................................................10

2.2.2 Boost Converter ......................................................................................... 11

2.2.3 Active Power Control ................................................................................... 11

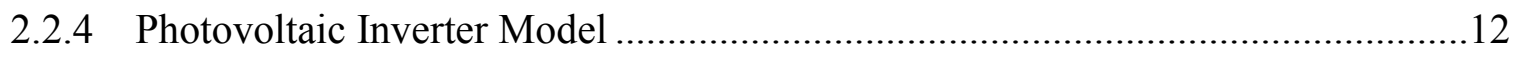

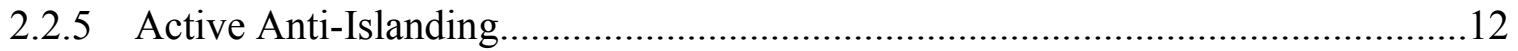

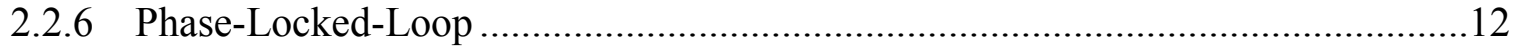

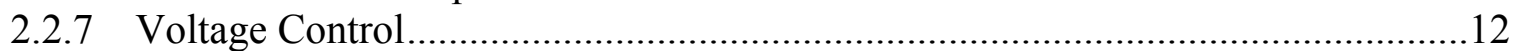

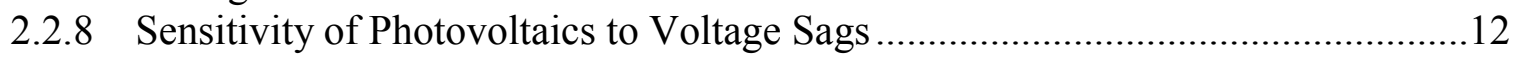

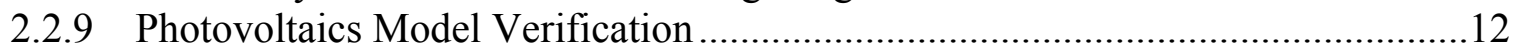

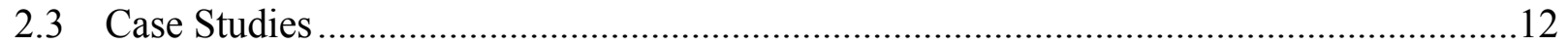

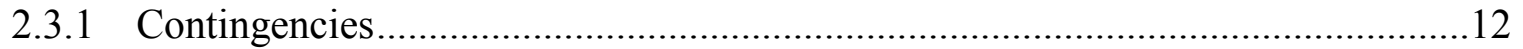

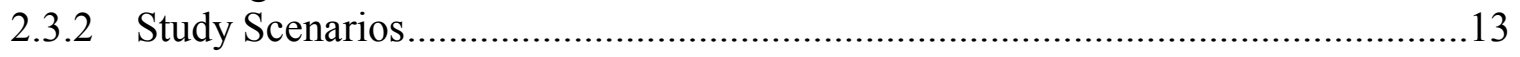

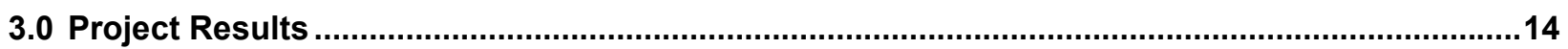

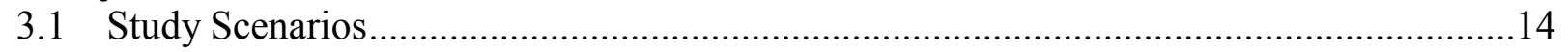

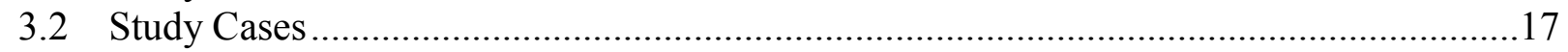

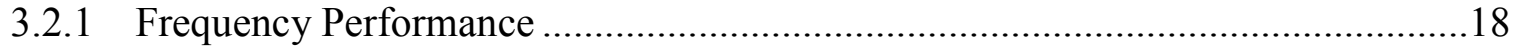

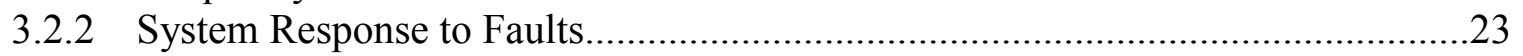

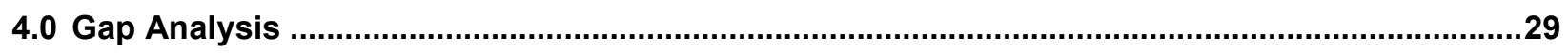

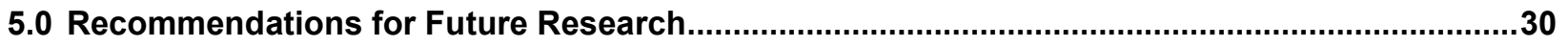

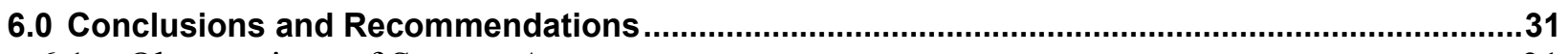

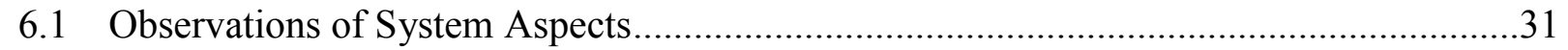

6.2 Observations of Photovoltaics Potential Performance ................................................32

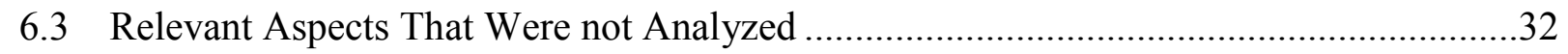

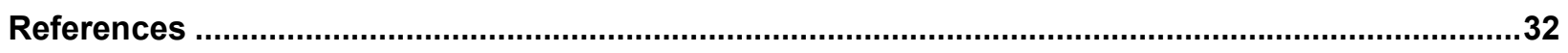

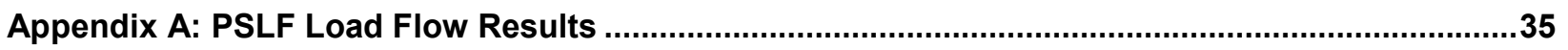

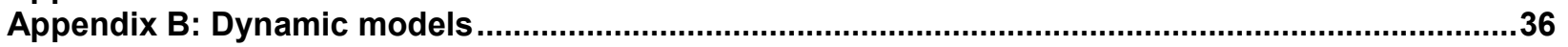

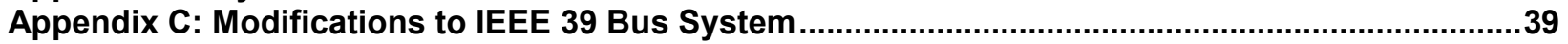

Appendix D: Single Line Diagrams of Starting Scenarios ...........................................................41

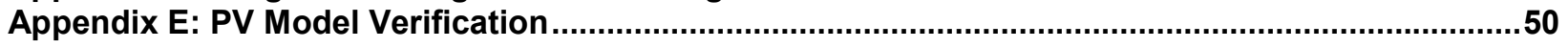




\section{List of Figures}

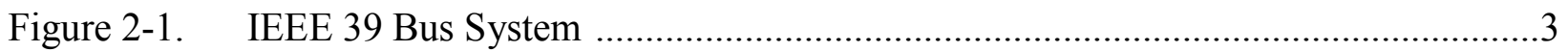

Figure 2-2. Rotor angle plot [deg] of the IEEE 39 benchmark model ....................................

Figure 2-3. Rotor angle deviation to Gen1(39) Gen10 (30), Gen2(31), Gen3(32),

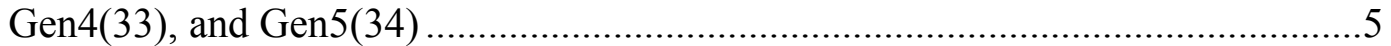

Figure 2-4. Rotor speed plot [PU\%], IEEE 39 benchmark model ........................................5

Figure 2-5. Rotor Speed Plot [PU\%] - Gen1(39), Gen10 (30), Gen2(31), Gen3(32),

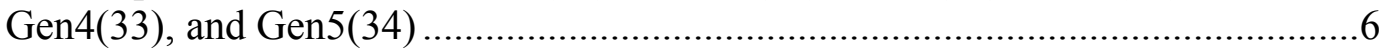

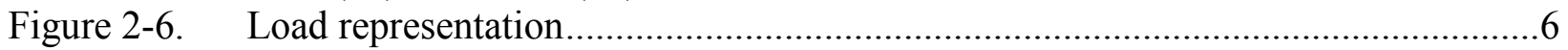

Figure 2-7. Generic PV inverter arrangement considered for dynamic model........................... 8

Figure 2-8. Block diagram representation of aggregated PV generation model ........................9

Figure 2-9. Block diagram representation of aggregated PV generation model for

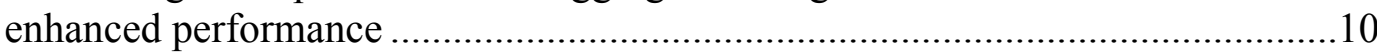

Figure 2-10. Normalized PV-module characteristic implemented in the PV-dynamic model...11

Figure 3-1. Summary of scenarios................................................................................16

Figure 3-2. Generation trip and lower load cases. Scenarios s2 (red), s6 (green), and s8

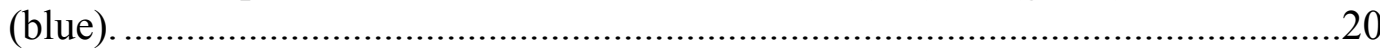

Figure 3-3. Generation trip and high load cases. Scenarios s1 (red), s5 (green), and s7

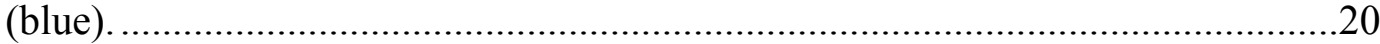

Figure 3-4. Generation trip and low load cases. Scenarios s2 (red) and s6r with frequency control and reserve in PV generation (green). ......................................................21

Figure 3-5. Load trip and low load cases. Scenarios s2 (red), s6 with PV acc to IEEE 1547 (green), and s6 without PV disconnection on overfrequency (blue). ....................23

Figure 3-6. Peak load cases with different PV characteristics. Case 1 (red), case 5 (green), case 11 (blue), and case 17 (black). ....................................................................26

Figure 3-7. Lower load cases with different PV characteristics. Case 2 (red), case 12 (green), case 18 (blue), and case 24 (black).........................................................26

Figure 3-8. Peak load cases with different unit-commitment strategies. Case 1 (red), case 11 (green), and case 13 (blue)...........................................................................27

Figure 3-9. Peak load cases with different anti-islanding settings. Case 29 (red), case 29 with three times higher anti-islanding gain (green), and case 29 with five times higher gain (blue) ....................................................................................27

Figure 3-10. Power reduction of PV generation during and after faults (PV LVRT) ................28

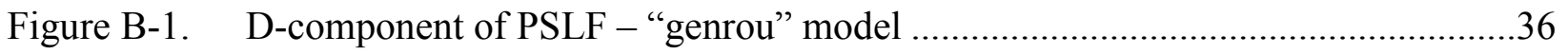

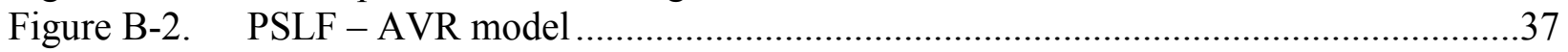

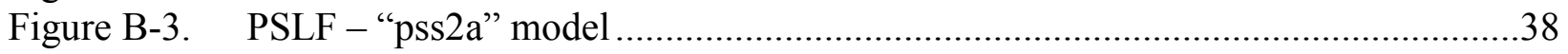

Figure B-4. PSLF - "wlwscc" load model polynomial representation .......................................38

Figure D-1. Scenario s1 peak load (IEEE benchmark load). No PV generation.........................42

Figure D-2. Scenario s2 low load (50\% of peak). No PV generation. .......................................43

Figure D-3. Scenario s3 peak (plus 30\%). 30\% PV generation. ………......................................4

Figure D-4. Scenario s4 low load plus 30\%. 30\% PV generation.........................................45

Figure D-5. Scenario s5 peak load. 30\% PV generation. Conventional generation decommitted. 
Figure D-6. Scenario s6 low load. 30\% PV generation. Conventional generation decommitted.

Figure D-7. Scenario s7 peak load. 30\% PV generation. Conventional generation not decommitted.

Figure D-8. Scenario s8 low load. 30\% PV generation. Conventional generation not decommitted.

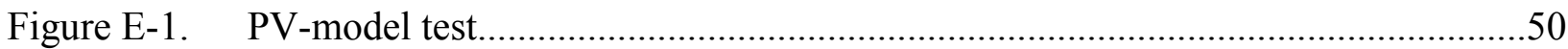

Figure E-2. MPP-tracking response to a step change in solar irradiation.................................51

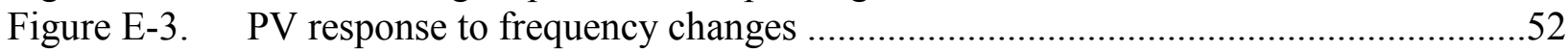

Figure E-4. PV response to frequency changes with initial reserve ........................................53

Figure E-5. Response to voltage reference step change.........................................................54

Figure E-6. Response to voltage reference step change, slower settings .................................55

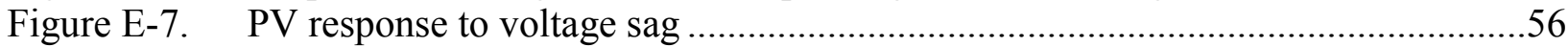

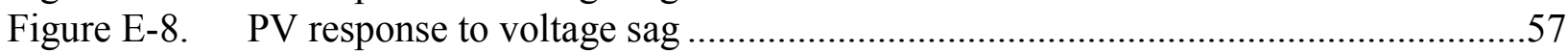

Figure E-9. PV response to voltage sag without fast DC link voltage control .........................58

Figure E-10. PV islanding without active anti-islanding ......................................................5

Figure E-11. PV islanding with active anti-islanding ............................................................60

Figure E-12. PV islanding with active anti-islanding and voltage control ...............................61

Figure E-13. PV islanding with active anti-islanding and slower voltage control......................62

Figure E-14. PV islanding with active anti-islanding (higher gain) and slower voltage control 


\section{List of Tables}

Table 2-1. Impedances of Load Model Extension in per Unit of Transformer Rating ..............7

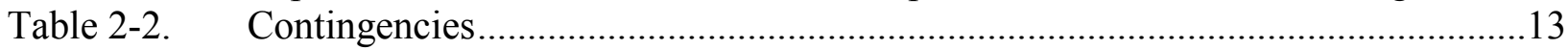

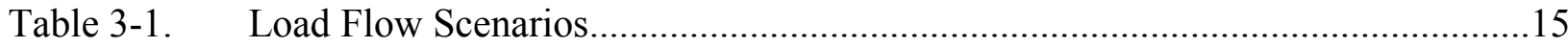

Table 3-2. Active Power Data of Different Scenarios............................................................15

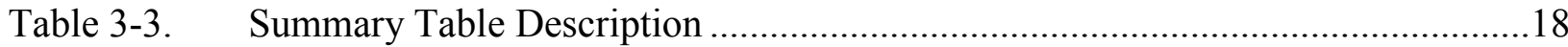

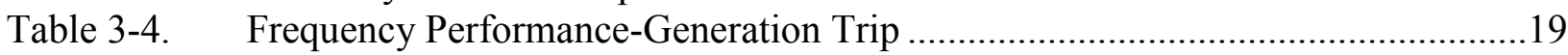

Table 3-5. Frequency Performance-Load Trip ..................................................................2

Table 3-6. System Response to Short and Severe Faults .......................................................24

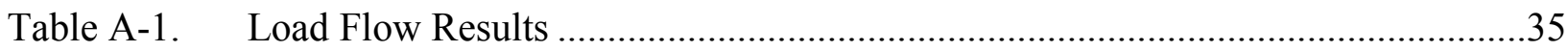

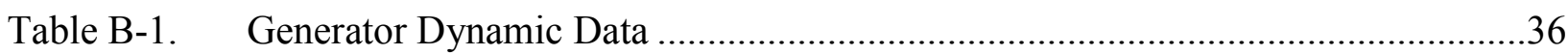

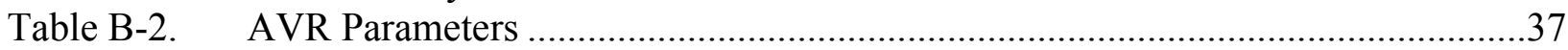

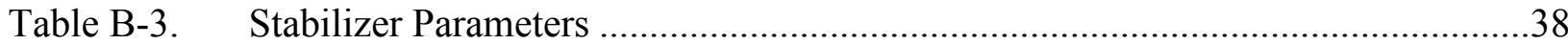

Table C-1. Load Flow Result of Extended Model...................................................................

Table C-2. Modified Governor Mbase Values.......................................................................... 


\subsection{Introduction}

A combination of incentive programs, technology advancements, and a further increase in prime energy costs could result in a vast deployment of PV in future power distribution systems. In such a scenario, power systems could be characterized by large quantities of generation embedded throughout the electric power system. Wind generation that has been massively installed in some areas of the world (such as Spain and northern Germany) has had a substantial impact on power system performance and therefore should be examined when planning for high-penetration PV scenarios. For example, transmission faults that were previously characterized by short voltage sags became significant system events with large power imbalance issues between control zones because of the considerable amount of wind generation that was disconnected during the faults. Thus, wind generation technologies provided the enhanced performance required as the penetration increased, such as tolerance to voltage sags. Although PV generation is more distributed in nature than wind generation, many concerns about significant wind penetration are relevant to PV.

This research developed an understanding of the impact of significant PV penetration on transmission system reliability and performance. A simulation database was developed to allow analysis of system behavior and interactions with high levels of PV penetration under realistic system conditions. These explorations showed that for high PV penetration, the performance requirements for the PV units are stricter to keep similar reliability and performance. Also, the criterion to dispatch and commit conventional generation for high penetration of PV has a significant impact on system behavior.

Section 2 presents the simulation database and describes the developed aggregated PV model. It also includes a short description of scenarios and contingencies. Section 3 presents the results of load flow calculations and time simulations. The results are summarized in tables and plots are presented to support the conclusions. Sections 4, 5, and 6 state the needs in the industry to phase in high-penetration PV, the conclusions of this effort, and the recommended research programs in the area of transmission planning and high PV penetration. 


\subsection{Project Approach}

The potential impact of high levels of PV penetration was assessed by using stability simulations of a transmission system with different levels of penetration in the simulation environment: General Electric (GE) Positive Sequence Load Flow (PSLF). The transmission system data are based on an Institute of Electrical and Electronic Engineers (IEEE) benchmark system. Section 0 describes the database and its implementation on GE PSLF. This section also presents the modifications performed on the IEEE benchmark system to apply PV generation and adapt the database to the purpose of this effort.

The characteristics of the PV generation had a significant impact on the results. The analysis performed considered different behaviors of the PV systems. An ad-hoc simulation model was developed to represent the dynamic behavior of aggregated PV for technology assumptions such as IEEE 1547 compliance, voltage control, active power control, lowvoltage ride-through (LVRT), and sensitivities to voltage sags.

Various starting scenarios and contingencies were considered to evaluate voltage and frequency performance with different PV characteristics and levels of PV penetration and load.

\subsection{Transmission System}

The transmission system database selected for this analysis is based on the IEEE 39 Bus System [1]. The system was implemented in the simulation environment GE PSLF for load flow and time simulations analysis.

Figure 2-1 presents a one-line diagram of the system [1]. 


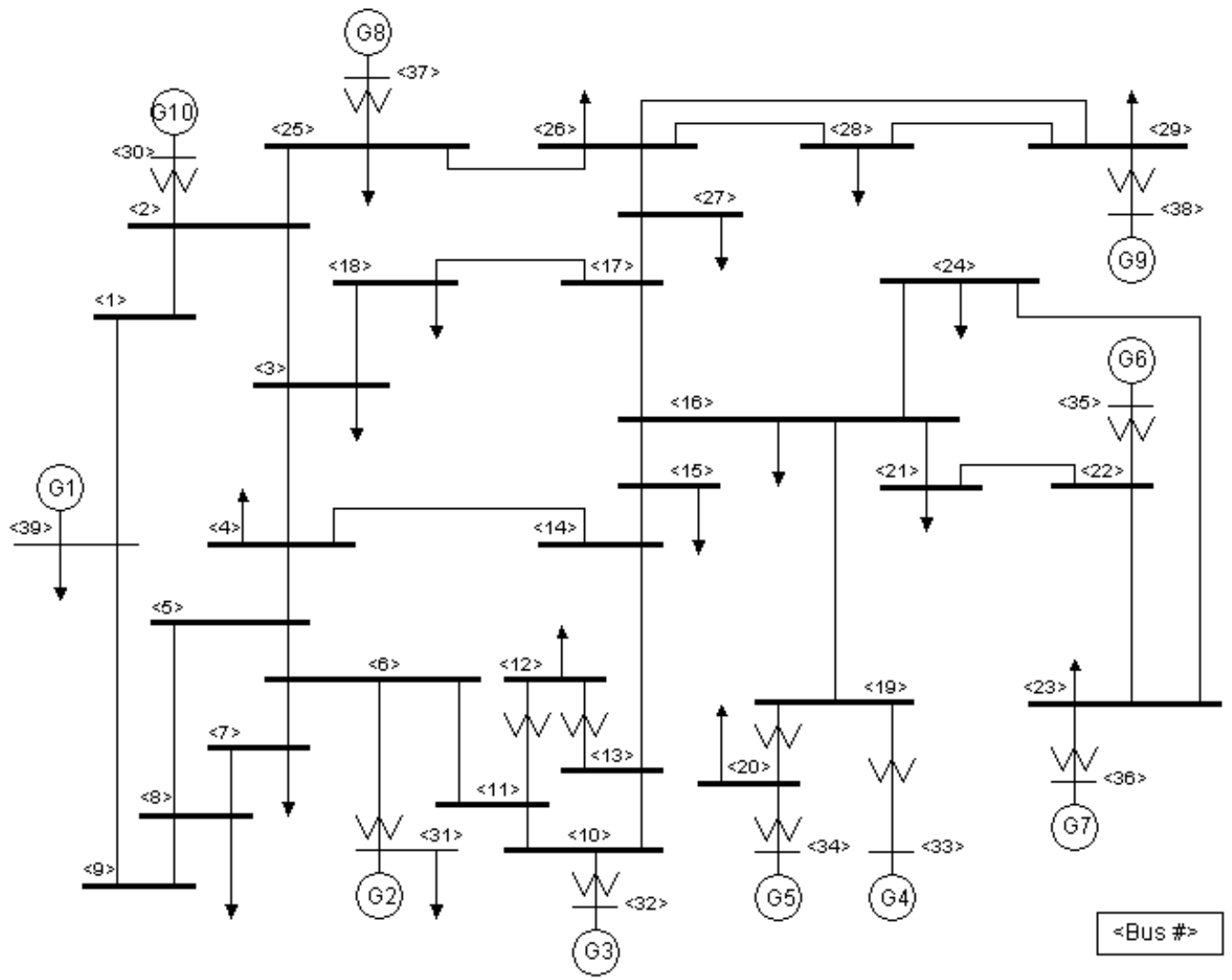

Figure 2-1. IEEE 39 Bus System [1]

Generator 1 connected to bus 39 represents a neighboring transmission system. The rest of the generators represent generating stations.

Some modifications were made to the system model presented in [1] to adapt the model to the needs of this effort. In particular, the load representation was modified to better represent the impact of PV connected at the distribution level.

\subsubsection{Steady-State Database}

Data in [1] were used to create a load flow database in GE PSLF. The load flow results of the GE PSLF match well with the reported voltages of the benchmark system in [1]. Appendix A shows the comparison of results.

\subsubsection{Dynamic Database}

Information in [1] was used to set up a dynamic database in PSLF. The selected PSLF models and parameters are presented in Appendix B. Reference [1] provides generator, automatic voltage regulator (AVR), and power system stabilizer (PSS) dynamic data. Governor models were added in PSLF to allow analysis of frequency events. Reference [1] does not indicate generator ratings and all generator parameters are expressed in per unit of the system base. Generator ratings were calculated to achieve physically meaningful transient reactances. Generators in [1] are represented with a fourth-order machine model; PSLF 
models include subtransient components based on typical values. The benchmark system [1] considers constant mechanical torque. Loads are treated as constant impedance loads.

\subsubsection{Validation Runs}

A fault at bus 16 was simulated for validation. The solid fault is applied at $t=0.5$ seconds and cleared 0.2 seconds later. Figure 2.2 and Figure 2.4 present rotor angle and speed results from [1] and Figure 2.3 and 2.5 from PSLF for comparison. Scales of PSLF plots coincide with plots extracted from [1]. Results match well.
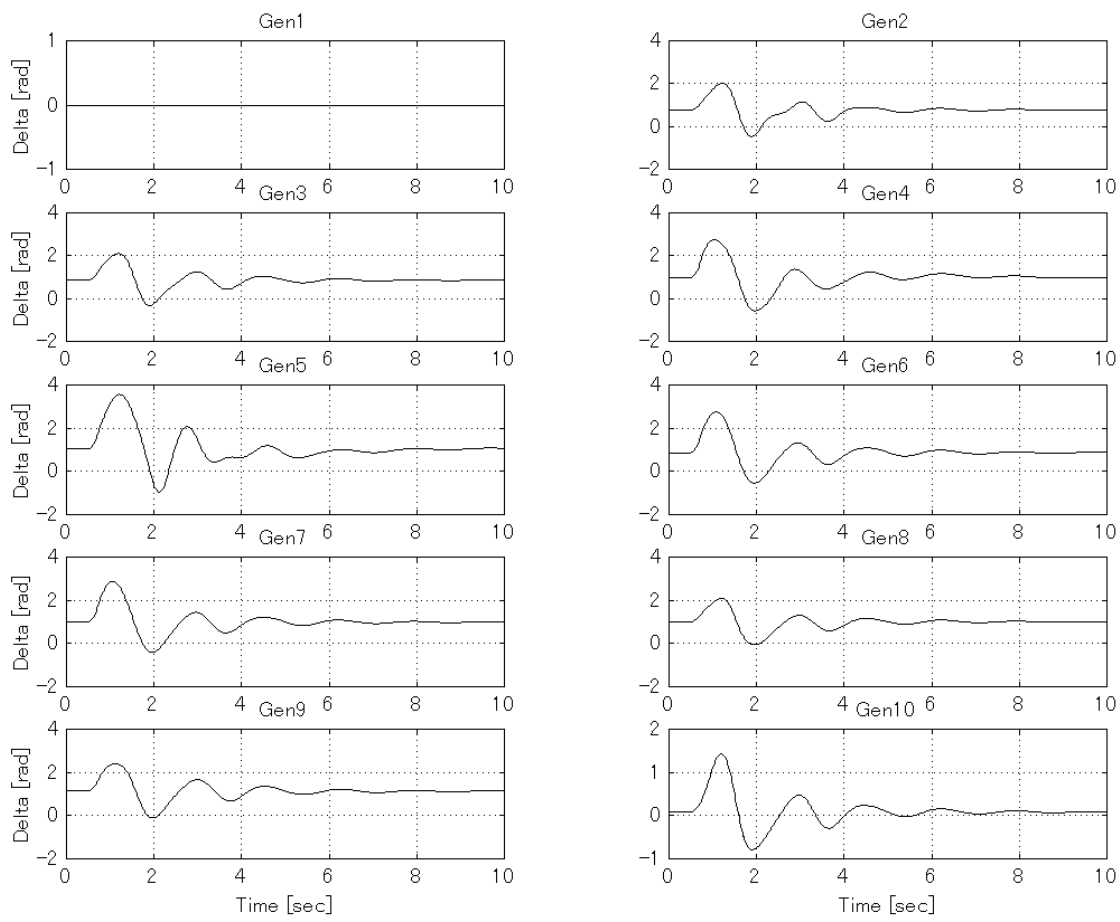

Figure 2-2. Rotor angle plot [deg] of the IEEE 39 benchmark model [1] 

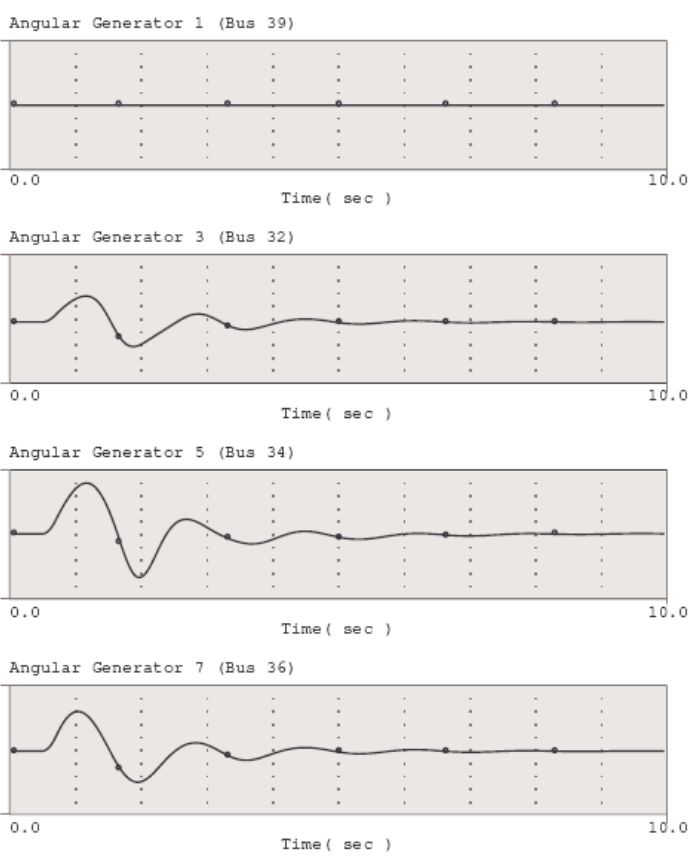
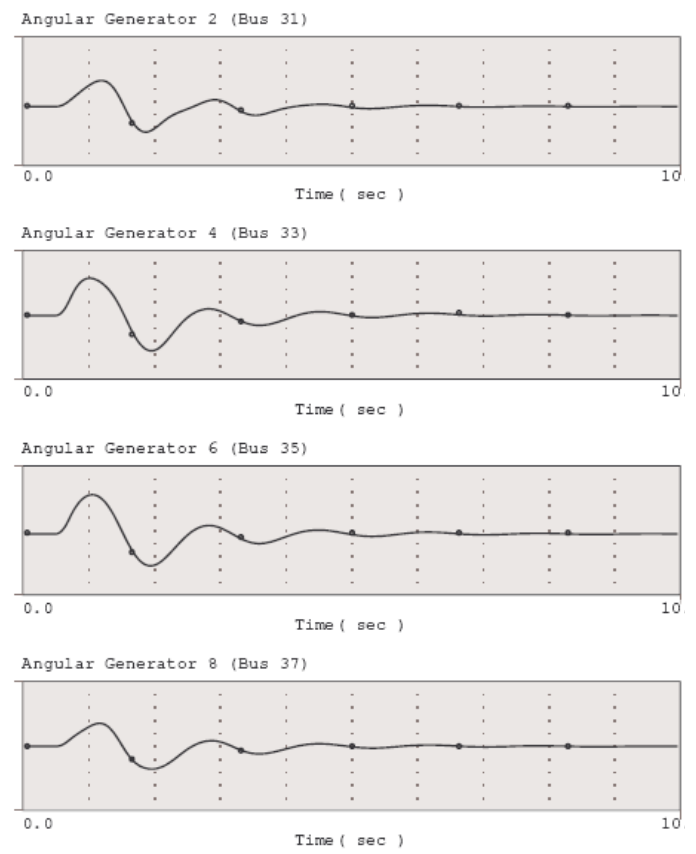

Figure 2.3. Rotor angle deviation to Gen1(39) (acting as swing bus in this example). Gen10 (30), Gen2(31), Gen3(32), Gen4(33), and Gen5(34)
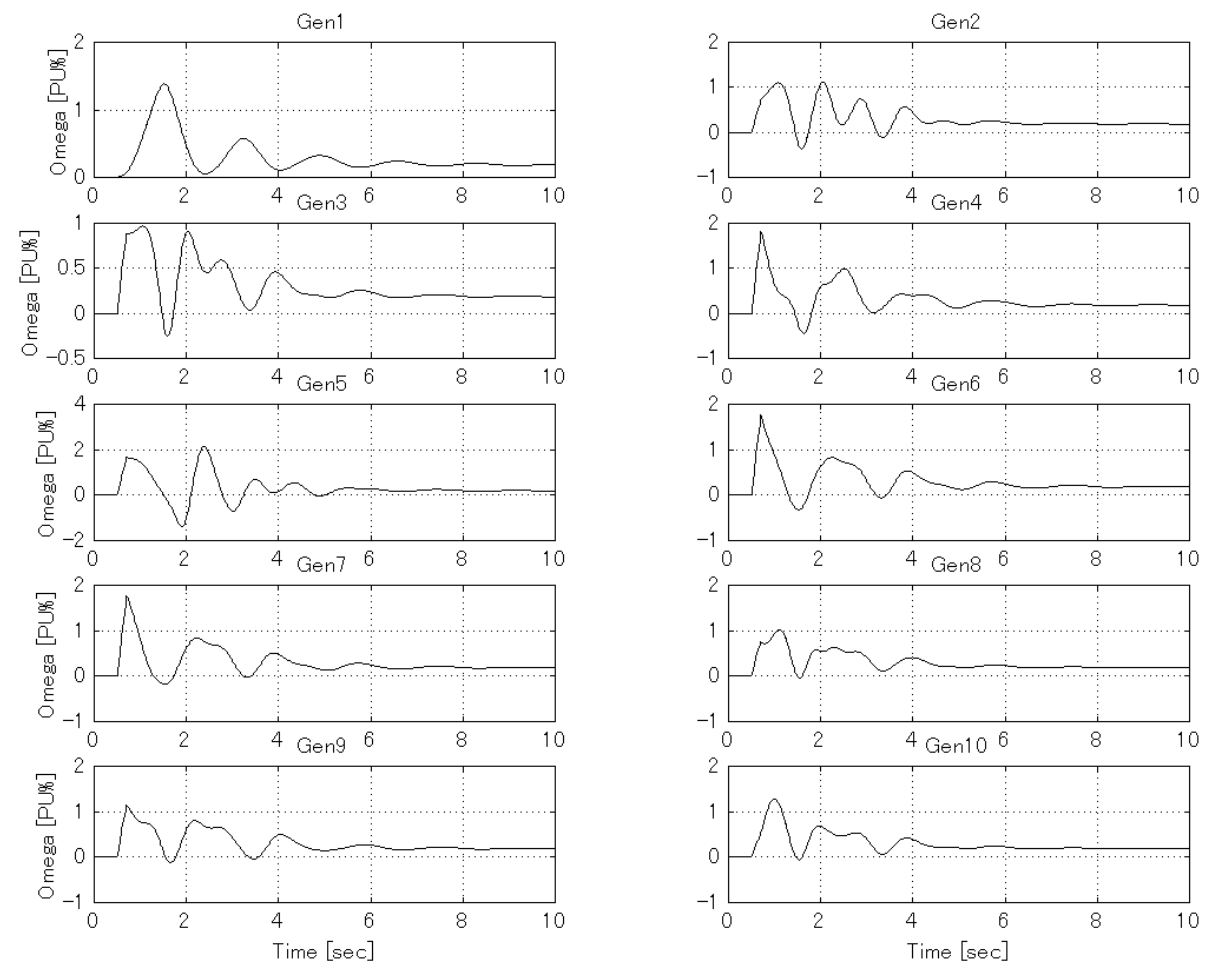

Figure 2-4. Rotor speed plot [PU\%], IEEE 39 benchmark model [1] 


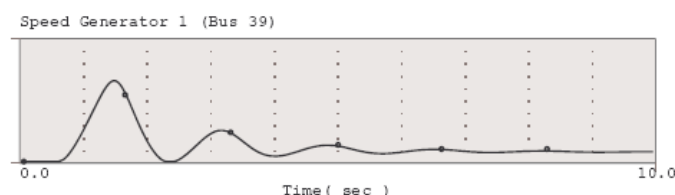

Timel sec 1

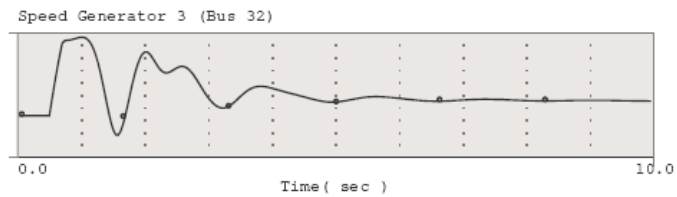

Time $($ sec $)$
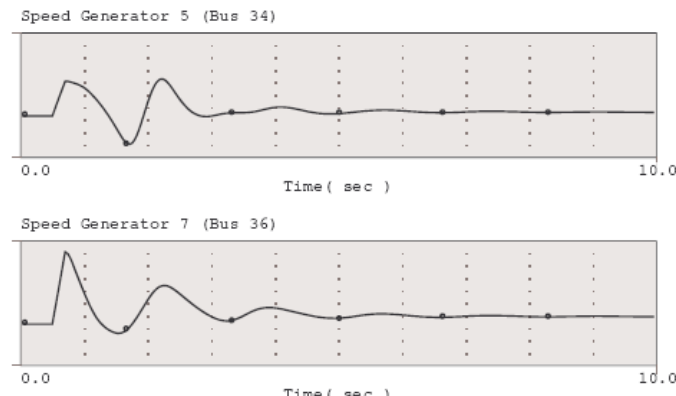
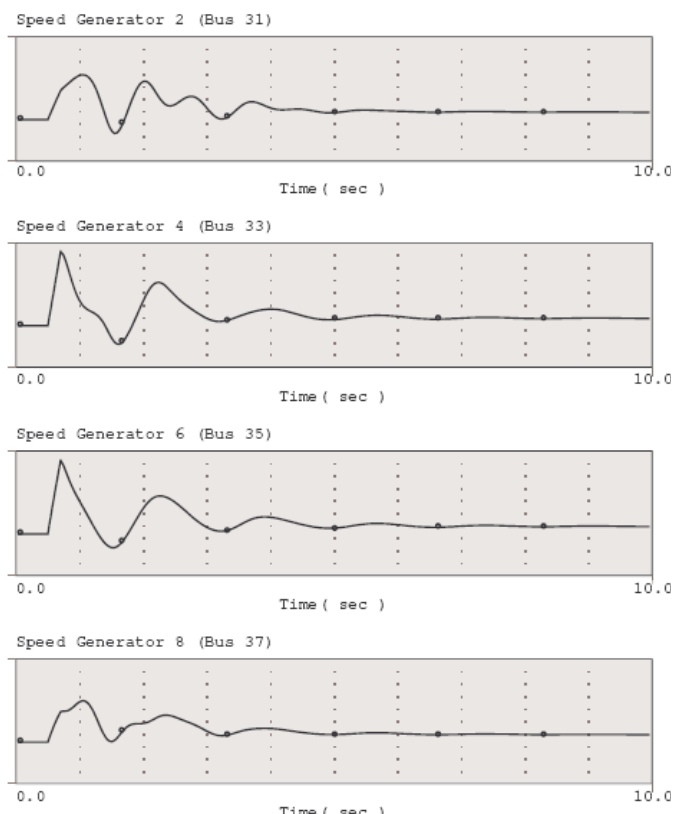

Figure 2-5. Rotor Speed Plot [PU\%] - Gen1(39), Gen10 (30), Gen2(31), Gen3(32), Gen4(33), and Gen5(34)

\subsubsection{Model Modification}

\subsubsection{Load busses}

In the original benchmark system, loads are connected to high-voltage buses. The load representation for this effort was modified to include two levels of voltage transformation, medium-voltage capacitor compensation, and feeder impedances. Each load transformer incorporated represents an aggregate of parallel load transformers.

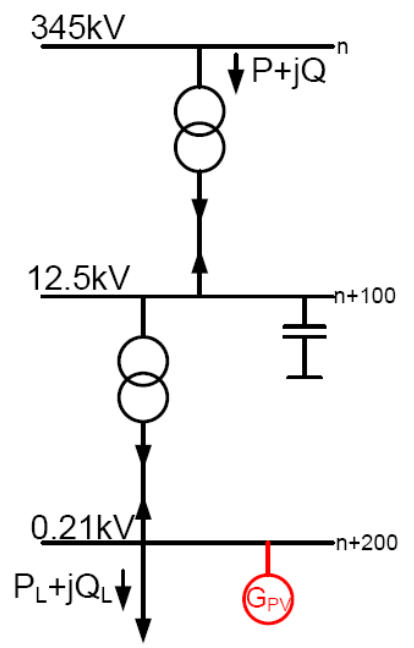

Figure 2-6. Load representation 
Figure 2-6 shows the enhanced load model. The load was moved to the low-voltage bus. Medium-voltage capacitors were sized to obtain about the same reactive power in the highvoltage bus ( $\mathrm{Q}$ in the figure).

Table 2-1 indicates impedances considered on a transformer base. The transformer impedances in the database are used to represent transformer and cable impedances. All PV generation in the low-voltage system fed from a high-voltage bus is represented with a single generator $\left(G_{p v}\right)$ connected to the low-voltage bus.

Table 2-1. Impedances of Load Model Extension in per Unit of Transformer Rating

\begin{tabular}{|c|c|c|c|c|c|c|c|}
\hline \multicolumn{4}{|c|}{ Low Voltage } & \multicolumn{4}{c|}{ Medium Voltage } \\
\hline \multicolumn{2}{|c|}{ Transformer } & \multicolumn{2}{c|}{ Line/Cable } & \multicolumn{2}{c|}{ Transformer } & \multicolumn{2}{c|}{ Line/Cable } \\
\hline $\mathrm{R}$ & $\mathrm{X}$ & $\mathrm{R}$ & $\mathrm{X}$ & $\mathrm{R}$ & $\mathrm{X}$ & $\mathrm{R}$ & $\mathrm{X}$ \\
\hline 0 & 0.05 & 0.1 & 0.1 & 0 & 0.07 & 0.01 & 0.03 \\
\hline
\end{tabular}

Load flow results after extending the model are indicated in Appendix C. The results on the high-voltage distribution line are within $0.6 \%$ compared with the benchmark model.

\subsubsection{Governors}

To enable meaningful analysis of frequency transients, turbine-governor models were included for all generators. Also, the generator bases were adapted when required to allow reasonable levels of rotating reserve in the simulations. Governor model structure and parameters are presented in Appendix C.

\subsection{Aggregated PV Representation}

As described in Section 2.6, PV generation is represented at low-voltage load buses. A single generator is used to represent all PV generators connected at a low-voltage bus of the equivalent transformers. A dynamic model for the equivalent PV generator was created as part of this effort. The model includes a number of features of commercial systems and some that are not common.

The generic PV inverter arrangement in Figure 2-7 was used to derive the dynamic model. The grid converter is controlled to keep the direct current link $\left(V_{D C}\right)$ constant. The reactive power of the converter can be controlled as long as the current capability of the components is not exceeded. In present systems, the reactive power is kept constant, equal to zero, despite the potential to control it. The duty cycle of the boost converter switch $\mathrm{S}$ is controlled to apply the desired DC voltage at the PV module $\left(V_{P V}\right)$. In present systems, the duty cycle of switch $\mathrm{S}$ is controlled to track the point of operation that extracts maximum power from the PV modules. Assumptions associated with the model are:

- $\quad$ Single-phase PV modules are aggregated and represented as a single three-phase source.

- All dynamics faster than a fundamental frequency cycle were neglected (the typical approach for transient stability simulations).

- PV systems periodically perform screenings of the relationship between current and voltage. The simulation model does not incorporate these phenomena.

- All magnitudes are normalized. 


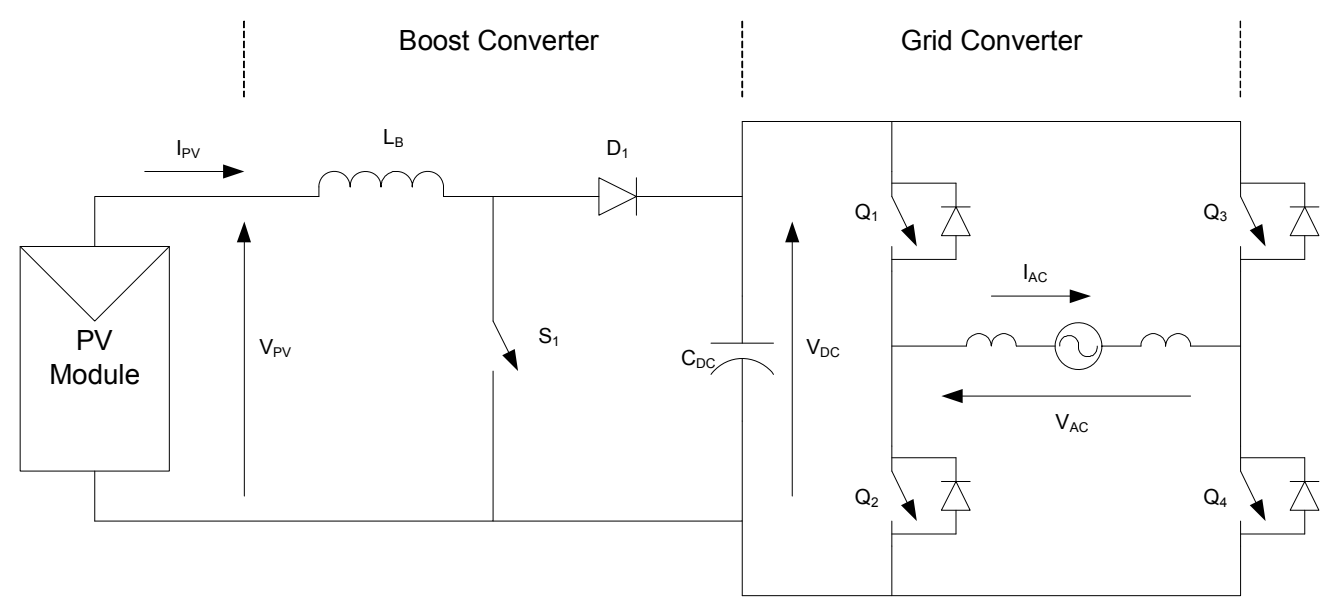

Figure 2-7. Generic PV inverter arrangement considered for dynamic model

The proposed simulation model for transient stability of aggregated standard PV systems is presented in Figure 2-8. The model includes:

- PV panel power as a function of applied dc voltage $V_{P V}$. Two irradiation levels are considered.

- Simplified representation of the maximum power point (MPP) tracking. The representation is designed to replicate power output fluctuations caused by MPP operation during or after system disturbances, and does not capture implementation details of actual MPP tracking algorithms.

- Over- and undervoltage and frequency disconnection according to IEEE 1547

- Current source representation of inverter

- Fixed power factor (unity)

- Phase-locked loop (PLL).

Another model, presented in Figure 2-9, was also created to incorporate additional control capabilities to assess their impact for high PV penetration levels. The model also includes:

- Terminal voltage control

- Frequency droop control and active power reserve

- Inverter current limitation control

- Active anti-islanding.

The next sections describe the different blocks of these diagrams. 


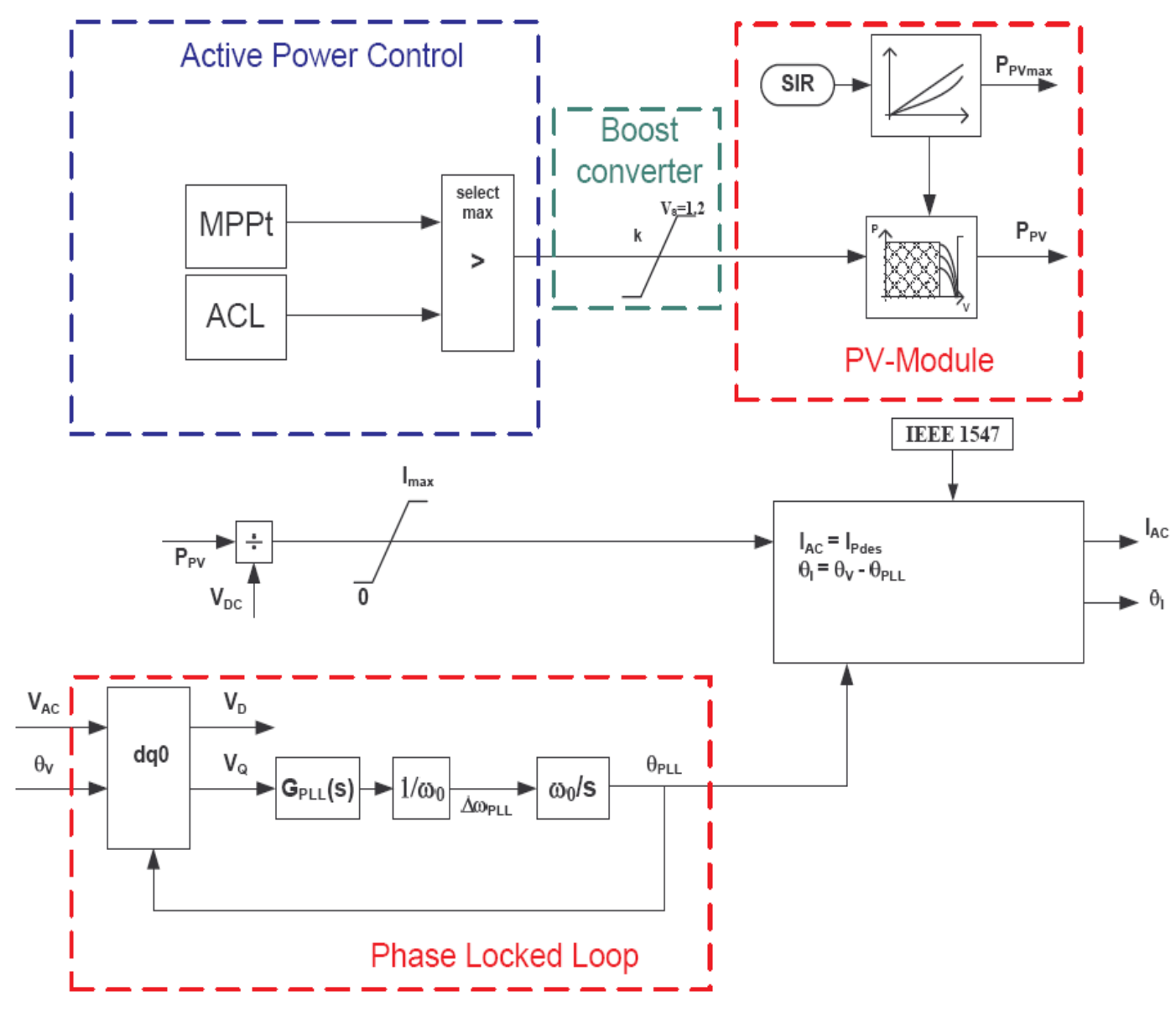

Figure 2-8. Block diagram representation of aggregated PV generation model 


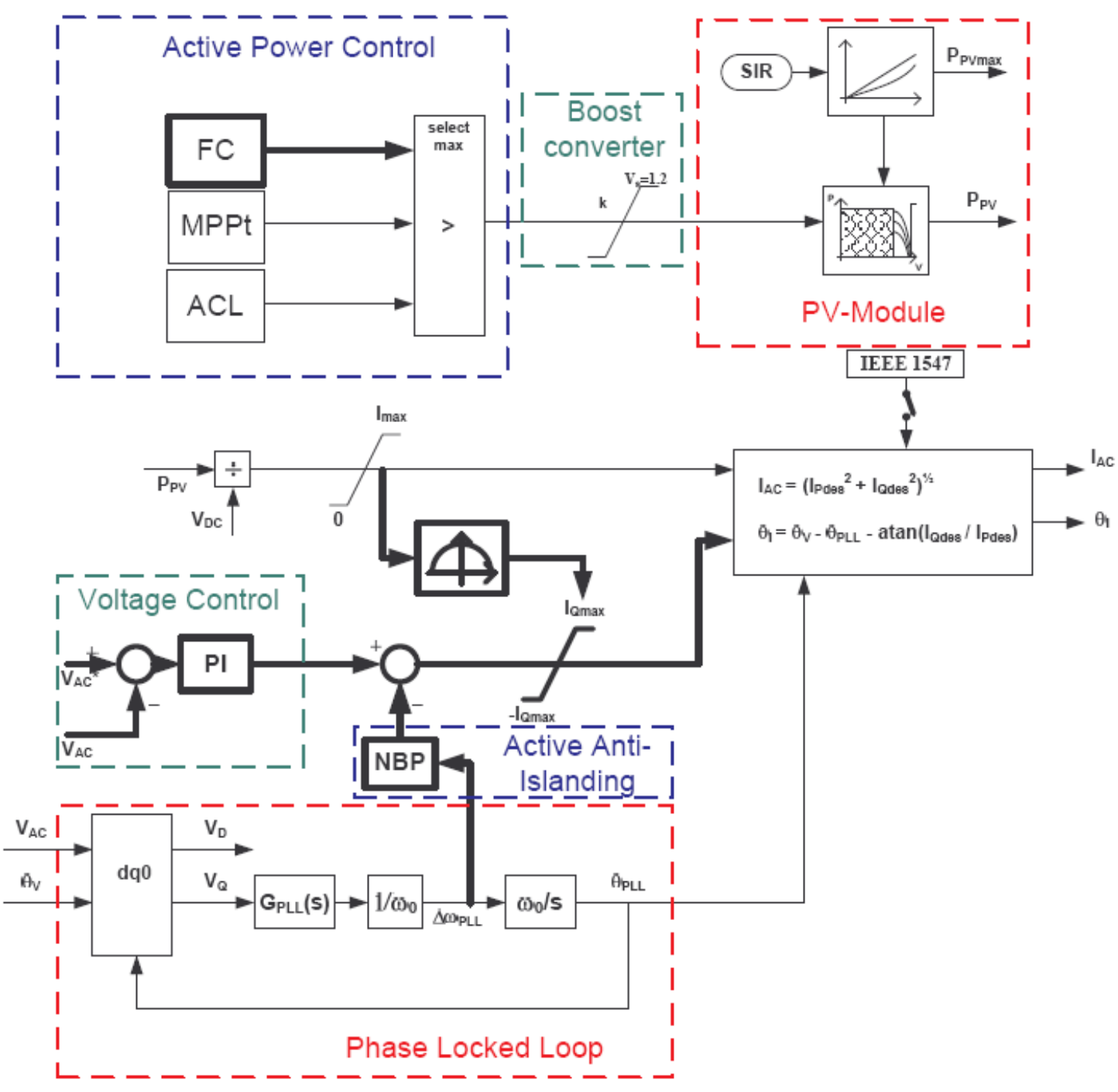

Figure 2-9. Block diagram representation of aggregated PV generation model for enhanced performance

\subsubsection{Photovoltaic Module Representation}

The PV module is represented with an algebraic transfer function between DC voltage and power output. The function consists of a sixth-order polynomial equation and was obtained for two solar irradiation levels (see Figure 2-10). For each irradiation level there is an MPP for a DC voltage $V_{P V}$ of about $1 \mathrm{pu}$.

In present systems, the module is operating close to the MPP voltage. In this effort, different operating conditions are explored to support the transmission system operation. Under normal operating conditions, the module is assumed to operate with DC voltages between the MPP voltage (1 pu) and the open circuit voltage (about $1.2 \mathrm{pu}$ ). This region of operation is preferred, to avoid high direct currents in switching operations, e.g., caused by faults. 


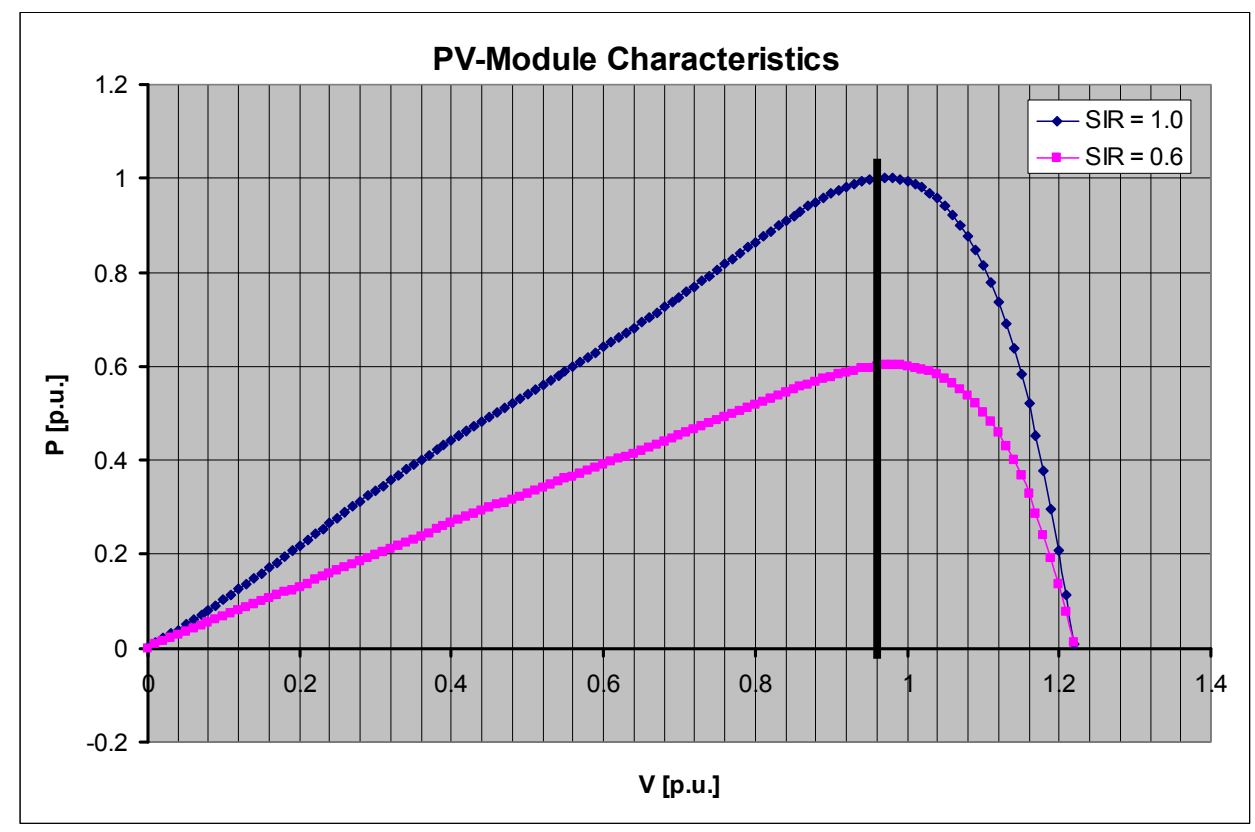

Figure 2-10. Normalized PV-module characteristic implemented in the PV-dynamic model

Temperature dependence of the module was not considered relevant for this study.

\subsubsection{Boost Converter}

The boost converter is assumed to have a limited duty cycle. The limits applied in the model are associated with the maximum ratio between the voltages $V_{P V}$ and $V_{D C}$ in Figure 2-7.

\subsubsection{Active Power Control}

The active power control includes three different control loops (Figure 2-9) and has as an output the desired ratio between the voltages $V_{P V}$ and $V_{D C}$ (Figure 2-7). A maximum selector is used to select the control loop governing the operation. As indicated in Section 2.2.1, the module will be normally operated in the region above the MPP voltage. Hence, selecting the maximum voltage request results in the lowest produced power. The three control loops and the boost converter limit are implemented to ensure smooth transitions between control loops and avoids wind-ups. The three control loops are:

- MPP tracking, indicated as MPPt in Figure 2-8 and Figure 2-9. This consists of a simplified representation of an actual MPP loop with the objective of capturing the relatively slow power output variations caused by this control.

- Active current limit, indicated as ACL in Figure 2-8 and Figure 2-9. This loop is intended to limit the module active power when the current capability of the inverter is reached (or exceeded). This control loop will only be active during the voltage sags and when the PV generation is not tripped.

- Frequency droop control and active power reserve, indicated as FC in Figure 2-9. This control option was not considered for all simulations. It includes a frequency signal to allow PV generation to perform frequency control and to be dispatched with primary reserve. 


\subsubsection{Photovoltaic Inverter Model}

The PV inverter is represented as a current source. The dynamics of the current control loops are neglected and the control current references are assumed to be equal to the currents. The active current component is set depending on the active power of the PV module. This simple approach is associated with the assumptions that the inverter losses are neglected and that the inverter controls the DC voltage $V_{D C}$ with high bandwidth. The reactive current component is set to zero or by the voltage control. The effect of phase jumps on the inverter operation (for example during faults or fault clearings) is considered using the error between the actual phase of the inverter AC voltage and the PLL angle.

The inverter model also includes the under- and overvoltage and frequency disconnection criteria according to IEEE 1547. This function was disabled in some simulation cases.

\subsubsection{Active Anti-Islanding}

An active anti-islanding loop was incorporated in the PV model. The scheme considered has the frequency measurement of the PLL as an input and acts on the reactive power signal of the converter. The loop includes a band pass filter to avoid noise injection and permanent reactive power modifications caused by frequency changes of normal system operation.

\subsubsection{Phase-Locked-Loop}

The phase-locked-loop is represented to allow for RMS voltage input and with a typical structure and tuning. Filtering and angle compensations are neglected.

\subsubsection{Voltage Control}

The voltage control loop was not considered in all simulations, as it is considered optional. The plug-in controller sets the reactive current component based on the AC voltage measurement. The bandwidth of the control is set relatively slow. No voltage drooping was considered. When this control is not active, the reactive current is set to zero.

\subsubsection{Sensitivity of Photovoltaics to Voltage Sags}

More economical (but less efficient) PV systems do not have boost converters (see Figure 27). In such systems, the DC link voltage is applied to the PV modules and controlled with an MPP tracking to maximize energy capture. The power output of such systems is expected to be more sensitive to terminal voltage fluctuations. Some simulation cases were performed considering the sensitivity to voltage variations of such systems.

\subsubsection{Photovoltaics Model Verification}

The models in Figure 2-8 and Figure 2-9 were implemented in GE PSLF. A number of simulations were performed in a simple system to verify the behavior of the model under different disturbances and with different control options. The primary results are presented in Appendix E.

\subsection{Case Studies}

\subsubsection{Contingencies}

The contingencies simulated are presented in Table 2-2. The bus numbers correspond to numbering presented in the one-line diagram of Figure 2-1. 
Table 2-2. Contingencies

\begin{tabular}{|c|l|}
\hline Contingency & \multicolumn{1}{|c|}{ Description } \\
\hline G1 & Disconnection from neighbor transmission system. \\
\hline L1 & Large load disconnection. \\
\hline F3 & Fault at bus 16. Voltage sag to 0\%. 100ms clearing of 16-17 line. \\
\hline
\end{tabular}

\subsubsection{Study Scenarios}

Different starting points were considered for the simulations to account for:

- Different load levels

- Different PV penetration

- Different unit commitment strategy

- Different primary reserve distribution 


\subsection{Project Results}

\subsection{Study Scenarios}

Different load flow scenarios were considered as a starting point for time simulations. Table 3-1 describes the scenarios considered. Single line diagrams of the scenarios are presented in Appendix D.

The benchmark system presented in Section 2.1 was assumed to be a peak load operating condition and was used as scenario s1.

Variations of this scenario were produced to account for behavior of the system under the following conditions and operating rules:

- Peak (s1, s3, s5, and s7) and moderate load (s2, s4, s6, and s8)

- With (s3 to s8) and without (s1 and s2) PV generation

- Maintaining dispatch and commitment to accommodate PV generation (s3 and s4)

- Modifying dispatch and commitment to accommodate PV generation (s5 to s8)

- PV generation with and without power reserve for frequency support.

Scenario s2 assumes a 50\% load reduction with respect to s1. Generation units 3, 4, 6, and 10 were de-committed. This implies that a good degree of flexibility was assumed in the generation portfolio. The scenarios that include PV (s3 to s8) assume total PV generation rating of $30 \%$ of the peak load $(1.8 \mathrm{GW})$. The different combinations associated with load level and assumptions resulted in different penetration levels with respect to system load (Table 3-1).

Consistent with Ye et al. [3], the peak scenario s3 assumed that PV takes the load increase over future years. That is, the load was increased to match the PV generation. Scenario 4 was similarly created using scenario s2 (low load) as a reference. In these two scenarios, the conventional generation remained unchanged.

Peak scenarios s5 and s7 have the same load as s1. Conventional generation was hence displaced to accommodate PV generation. Similarly, low-load scenarios s6 and s8 have the same load as s2. In scenarios s5 and s6 units are de-committed with respect to scenarios s1 and s2 (without PV) to accommodate PV generation. However, units are not de-committed to accommodate PV generation in scenarios s7 and s8.

These sets of scenarios present the extreme cases of how the system could be operated depending on the availability of PV production forecast for unit commitment. Specifically, scenarios s5 and s6 assume that accurate forecast of PV generation is considered in the unit commitment, and scenarios s7 and s8 assume that no PV production forecast is considered in the unit commitment.

An additional set of scenarios with power reserve in PV was created. Cases with PV generation (s3 to s8) were modified to accommodate $5 \%$ power reserve in the PV systems. 
Table 3-1. Load Flow Scenarios

\begin{tabular}{|l|l|l|c|}
\hline & Filename & Scenario & $\begin{array}{l}\text { PV Generation } \\
\text { (\% of load) }\end{array}$ \\
\hline s1 & nrel_If_s1.sav & $\begin{array}{l}\text { Peak load (IEEE benchmark load). No } \\
\text { PV generation. }\end{array}$ & 0 \\
\hline s2 & nrel_If_s2.sav & $\begin{array}{l}\text { Low load (50\% of peak). No PV } \\
\text { generation. }\end{array}$ & 0 \\
\hline s3 & nrel_If_s3.sav & Peak (plus 30\%). 30\% PV generation. & 23 \\
\hline s4 & nrel_ff_s4.sav & Low load plus 30\%. 30\% PV generation. & 37 \\
\hline s5 & nrel_If_s5.sav & $\begin{array}{l}\text { Peak load. 30\% PV generation. } \\
\text { Conventional generation de-committed. }\end{array}$ & 30 \\
\hline s6 & nrel_ff_s6.sav & $\begin{array}{l}\text { Low load. 30\% PV generation. } \\
\text { Conventional generation de-committed. }\end{array}$ & 60 \\
\hline s7 & nrel_If_s7.sav & $\begin{array}{l}\text { Peak load. 30\% PV generation. } \\
\text { Conventional generation not de- } \\
\text { committed. }\end{array}$ & 30 \\
\hline s8 & nrel_If_s8.sav & $\begin{array}{l}\text { Low load. 30\% PV generation. } \\
\text { Conventional generation not de- } \\
\text { committed. }\end{array}$ & 60 \\
\hline
\end{tabular}

Table 3-2 presents, for each scenario, the power of conventional generation $\left(P_{\text {gen }}\right), \mathrm{PV}$ generation $\left(P_{P V}\right)$, power transferred from neighbor areas $\left(P_{\text {trans }}\right)$, total load $\left(P_{\text {load }}\right)$, and system losses $\left(P_{\text {loss }}\right)$. Additionally, Figure 3-1 presents the power production portion of conventional units, PV, and transfer power for the scenarios.

Table 3-2. Active Power Data of Different Scenarios

\begin{tabular}{|c|c|c|c|c|c|}
\hline & $\begin{array}{c}\mathbf{P}_{\text {gen }} \\
(\mathbf{M W})\end{array}$ & $\begin{array}{c}\mathbf{P}_{\mathbf{P V}} \\
(\mathbf{M W})\end{array}$ & $\begin{array}{c}\mathbf{P}_{\text {Trans }} \\
\text { (MW) }\end{array}$ & $\begin{array}{c}\mathbf{P}_{\text {Load }} \\
\text { (MW) }\end{array}$ & $\begin{array}{c}\mathbf{P}_{\text {loss }} \\
\text { (MW) }\end{array}$ \\
\hline s1 & 5543 & 0 & 1080 & 6089 & 533 \\
\hline $\mathbf{s 2}$ & 3002 & 0 & 200 & 3044 & 158 \\
\hline $\mathbf{s 3}$ & 5589 & 1826 & 1080 & 7916 & 580 \\
\hline s4 & 3033 & 1826 & 200 & 4871 & 188 \\
\hline s5 & 4348 & 1826 & 200 & 6089 & 285 \\
\hline s6 & 1274 & 1826 & 0 & 3044 & 56 \\
\hline $\mathbf{s 7}$ & 3768 & 1826 & 756 & 6089 & 261 \\
\hline $\mathbf{s 8}$ & 1203 & 1826 & 40 & 3044 & 25 \\
\hline
\end{tabular}




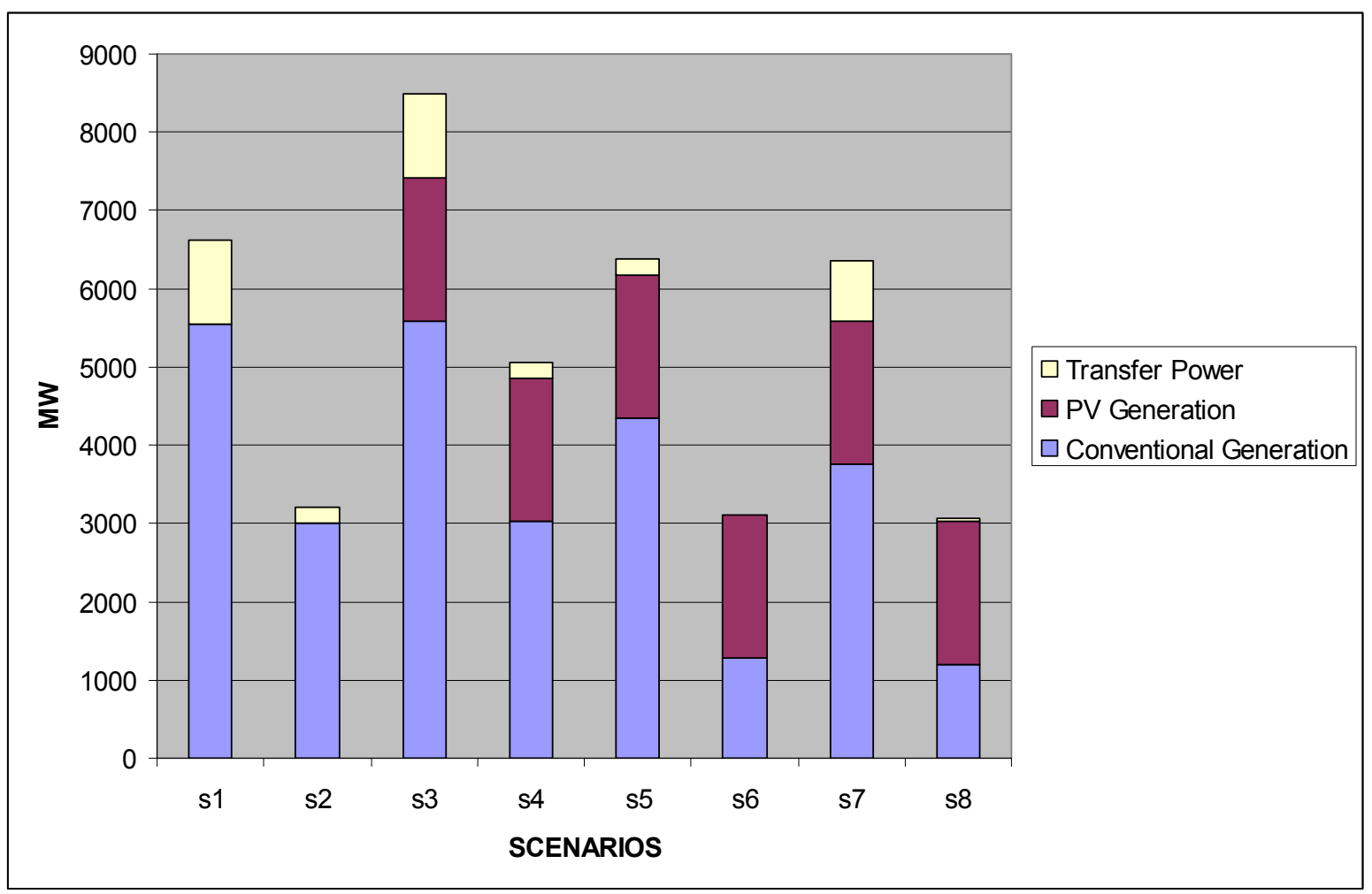

Figure 3-1. Summary of scenarios

In all scenarios, tap changers of medium-voltage transformers were adjusted to keep voltages within $\pm 0.05 \mathrm{pu}$. These are observations from load flow analysis of the system with PV penetration:

- Transmission losses are lower with increased PV generation because PV is connected closer to the loads than conventional generation (comparison of scenarios s1 with s5 and s2 with s6). Distribution losses are not represented in detail.

- Accommodating high PV generation during low load is challenging for unit commitment and dispatch. Lower load scenarios s2, s6, and s8 assume that units can be de-committed during lower load periods. If units cannot be de-committed because of operational constraints or cost implications, it would not be possible to accommodate all PV generation and dispatch units above technical minimums. In scenario $\mathrm{s} 8$ the same unit commitment as in $\mathrm{s} 2$ was considered, but units were dispatched lower to accommodate high PV generation. The technical minimum assumed for all units is $20 \%$. In most systems there are units with technical minimums higher than $20 \%$, accommodating PV generation will then not be possible without de-committing more conventional generation or reducing the PV generation.

- Scenario s6 has only a few conventional units in service. Thus, a significant part of the transmission system is without voltage support. 


\subsection{Study Cases}

Summary tables are presented in next sections to show results of the simulations. The values presented in the summary tables in this section are described in Table 3-3. The description column in the summary tables indicates the following variations:

- No PV. Cases without PV generation.

- IEEE 1547. Conventional PV (Figure 2-8) with disconnection criteria according to IEEE 1547. Undervoltage clearing times set to maximum allowed in this standard.

- Frequency Control. PV with frequency control and MPP tracking operation.

- Frequency Control, $5 \%$ reserve. PV with frequency control and with 5\% up-reserve.

- No Overfrequency Trips. Conventional PV (Figure 2-8) without overfrequency disconnection.

- Undervoltage Trip. Conventional PV (Figure 2-8) with disconnection criteria according to IEEE 1547. Undervoltage clearing times set below maximum allowed in this standard.

- LVRT. Capability of PV generation. PV is assumed to be able to ride through the applied faults without tripping. Current capability limitations of PV converters are observed during and after faults (Figure 2-9).

- Voltage Control. PV with voltage control as presented in Figure 2-9.

- Anti-Islanding. PV with active anti-islanding (Figure 2-9).

- $30 \%$ Motor Load. Load model was modified to account for motor loads.

Key plots are presented in next sections. The complete set of plots for all cases (more than 1000 pages) is not included in this report. An appendix of plots is available on request. 
Table 3-3. Summary Table Description

\begin{tabular}{|c|c|}
\hline Column & Description \\
\hline $\mathrm{fmax}[\mathrm{Hz}]$ & Maximum frequency \\
\hline $\mathrm{fmin}[\mathrm{Hz}]$ & Minimum frequency \\
\hline fss [Hz] & Final steady state frequency \\
\hline $\mathrm{dfmax}[\mathrm{Hz} / \mathrm{s}]$ & $\begin{array}{l}\text { Maximum absolute value of derivative of frequency } \\
\text { with respect to time. }\end{array}$ \\
\hline tdfmax [sec] & Time of maximum derivative of frequency \\
\hline V16 (max) [pu] & Maximum per unit voltage at transmission bus 16 \\
\hline v16 (min) [pu] & Minimum per unit voltage at transmission bus 16 \\
\hline v16ss [pu] & $\begin{array}{l}\text { Final steady state per unit voltage at transmission } \\
\text { bus } 16\end{array}$ \\
\hline t16rec [sec] & $\begin{array}{c}\text { Time required for voltage at bus } 16 \text { to recover } \\
\text { (above } 0.8 \mathrm{pu} \text { ) after a fault }\end{array}$ \\
\hline Initial PV [MW] & Initial PV generation \\
\hline PV end [MW] & PV generation at the end of the simulation. \\
\hline Loss : & $\begin{array}{c}\text { Loss of synchronism of units. "0" means no unit lost } \\
\text { synchronism, "1" means at least one unit lost } \\
\text { synchronism. }\end{array}$ \\
\hline
\end{tabular}

\subsubsection{Frequency Performance}

\subsubsection{Generation Trip}

Disconnection from a neighboring transmission system was simulated to assess the impact of $\mathrm{PV}$ on frequency performance. The disconnection results in a deficit of generating power of $540 \mathrm{MW}$ in peak load cases (s1, s3, s5, and s7) and $200 \mathrm{MW}$ in the lower load cases (s2, s4, s6, and s8). As a reference, the system peak load is $5.4 \mathrm{GW}$ and the lower load is $2.7 \mathrm{GW}$. For these simulations, the generator G1 (Figure 2-1) connected to bus 39 was split into two generators (G1 and G11) to represent the connection to two neighboring systems. The initial generation of the disconnected generator (G1) was set to obtain the desired power imbalance. Table 3-4 presents a summary of the results and the run cases. The cases include all starting scenarios and different PV behaviors. 
Table 3-4. Frequency Performance-Generation Trip

\begin{tabular}{|c|c|c|c|c|c|c|c|c|c|}
\hline & CASE & Scen & Description & $\begin{array}{l}\text { fmax } \\
{[\mathrm{Hz}]}\end{array}$ & $\mathrm{fmin}[\mathrm{Hz}]$ & fss $[H z]$ & $\begin{array}{l}\mathrm{dfmax} \\
{[\mathrm{Hz} / \mathrm{s}]}\end{array}$ & $\begin{array}{c}\text { tdfmax } \\
{[\mathrm{sec}]}\end{array}$ & Comment \\
\hline 1 & REGI_s1_g1_npv & $\mathrm{s} 1$ & No PV & 60.00 & 59.42 & 59.97 & 0.26 & 1.93 & 0 \\
\hline 2 & REGI_s2_g1_npv & s2 & No PV & 60.00 & 59.67 & 59.96 & 0.12 & 1.83 & 0 \\
\hline 3 & REGI s3 g1 $\mathrm{mp}$ & s3 & IEEE1547 & 60.00 & 59.46 & 59.94 & 0.24 & 1.93 & 0 \\
\hline 4 & REGI_s4_g1_mp & s4 & IEEE1547 & 60.00 & 59.67 & 59.93 & 0.12 & 1.83 & 0 \\
\hline 5 & REGI_s5_g1_mp & s5 & IEEE1547 & - & 43.06 & - & - & - & collapse \\
\hline 6 & REGI_s6_g1_mp & s6 & IEEE1547 & 60.00 & 59.39 & 59.92 & 0.18 & 1.05 & 0 \\
\hline 7 & REGI_s7_g1_mp & s7 & IEEE1547 & 60.04 & 59.39 & 59.88 & 0.26 & 1.93 & 0 \\
\hline 8 & REGI_s8_g1_mp & s8 & \begin{tabular}{|l} 
IEEE1547 \\
\end{tabular} & 60.06 & 59.70 & 59.92 & 0.12 & 1.73 & 0 \\
\hline 9 & REGI_s3r_g1_fc & $s 3 r$ & $\begin{array}{c}\text { Frequency Control. 5\% } \\
\text { reserve }\end{array}$ & 60.00 & 59.52 & 59.90 & 0.23 & 1.93 & 0 \\
\hline 10 & REGI_s4r_g1_fc & $s 4 r$ & $\begin{array}{c}\begin{array}{c}\text { Frequency Control. 5\% } \\
\text { reserve }\end{array} \\
\end{array}$ & 60.00 & 59.76 & 59.92 & 0.10 & 1.83 & 0 \\
\hline 11 & REGI_s5r_g1_fc & $s 5 r$ & $\begin{array}{c}\text { Frequency Control. 5\% } \\
\text { reserve }\end{array}$ & 60.00 & 59.40 & 59.89 & 0.29 & 2.03 & 0 \\
\hline 12 & REGI_s6r_g1_fc & $s 6 r$ & $\begin{array}{c}\begin{array}{c}\text { Frequency Control. } 5 \% \\
\text { reserve }\end{array} \\
\end{array}$ & 60.00 & 59.57 & 59.94 & 0.16 & 1.05 & 0 \\
\hline 13 & REGI_s7r_g1_fc & s7r & $\begin{array}{c}\begin{array}{c}\text { Frequency Control. 5\% } \\
\text { reserve }\end{array} \\
\end{array}$ & 60.03 & 59.46 & 59.84 & 0.24 & 1.83 & 0 \\
\hline 14 & REGI_s8r_g1_fc & s8r & $\begin{array}{c}\begin{array}{c}\text { Frequency Control. 5\% } \\
\text { reserve }\end{array} \\
\end{array}$ & 60.02 & 59.77 & 59.91 & 0.11 & 1.63 & 0 \\
\hline
\end{tabular}

The observations from these cases follow:

- The cases where PV displaced conventional generation (5 and 6) had worse performance than the cases without PV (1 and 2). The low-load case (6) with PV resulted in a frequency minimum that was significantly lower than the case without PV (2) because the system inertia is lower. The steady-state frequency value is also negatively affected because fewer units perform frequency control (Figure 3-2). In the high-load case with PV (5), the event is further aggravated because PV generation trips at $59.3 \mathrm{~Hz}$, per IEEE 1547 (Figure 3-3). The system collapses in the simulation. In a real event, significant frequency load shedding would operate.

- If units are committed ignoring PV generation, the frequency performance is similar with (7 and 8) and without PV (1 and 2) because the system inertia is the same and the up reserve is even higher.

- Frequency control of PV improves the steady-state frequency variations. The maximum frequency excursion and the maximum rate of change of frequency are not significantly improved, because of the relatively slow regulating response assumed for PV. Figure 3-4 presents a comparison of a run without PV and with PV and frequency control. 


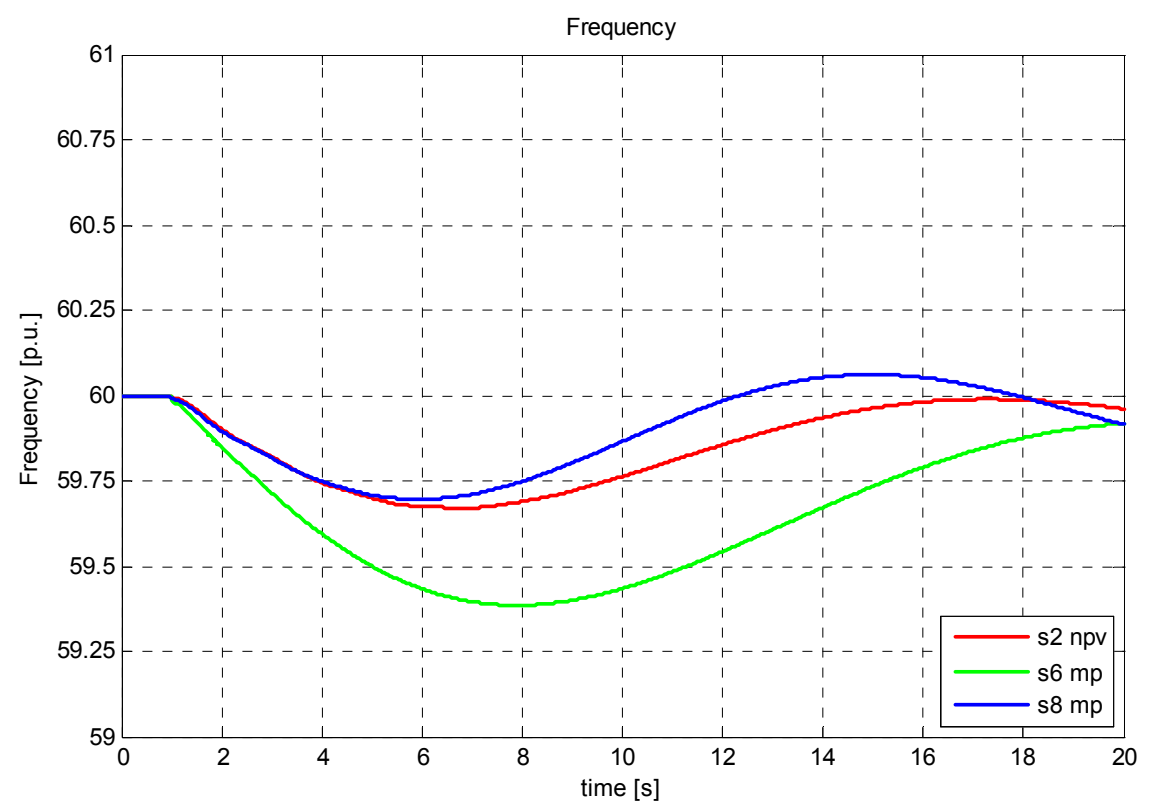

Figure 3-2. Generation trip and lower load cases. Scenarios s2 (red), s6 (green), and s8 (blue).

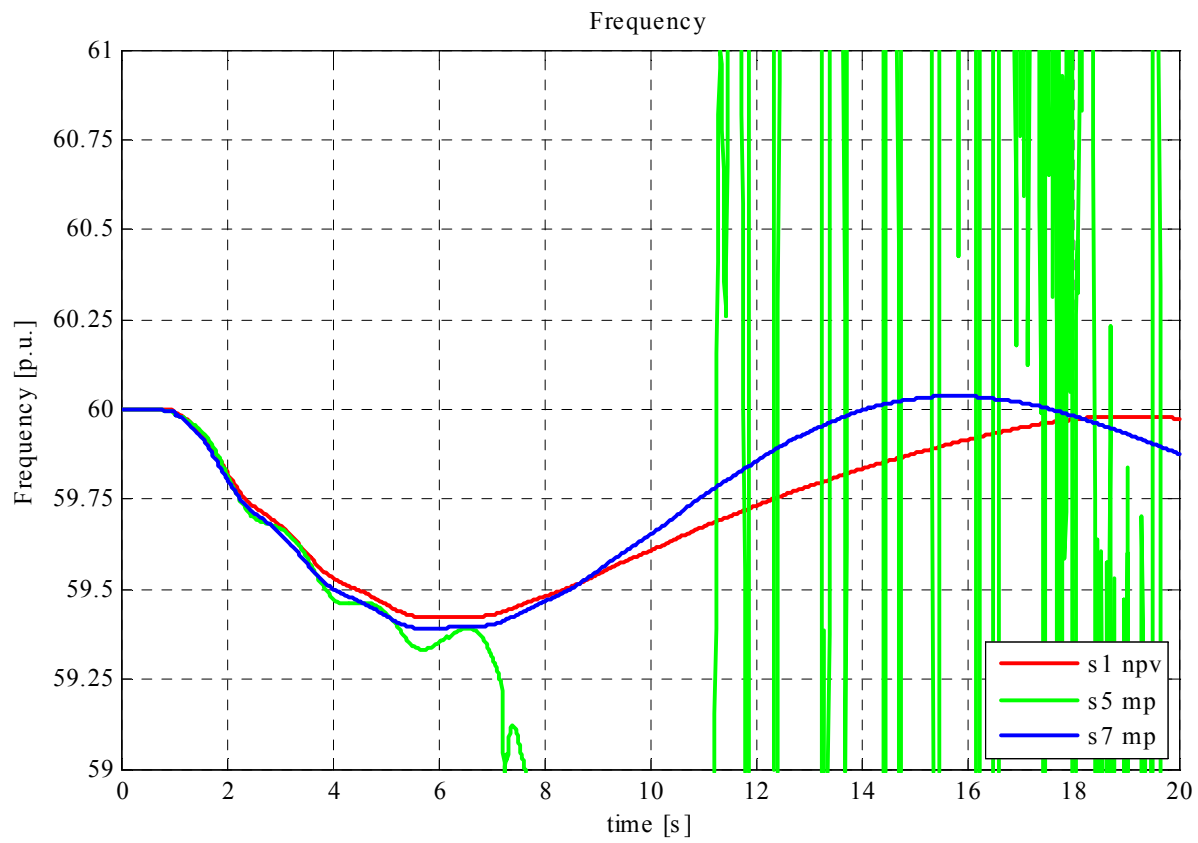

Figure 3-3. Generation trip and high load cases. Scenarios s1 (red), s5 (green), and s7 (blue). 


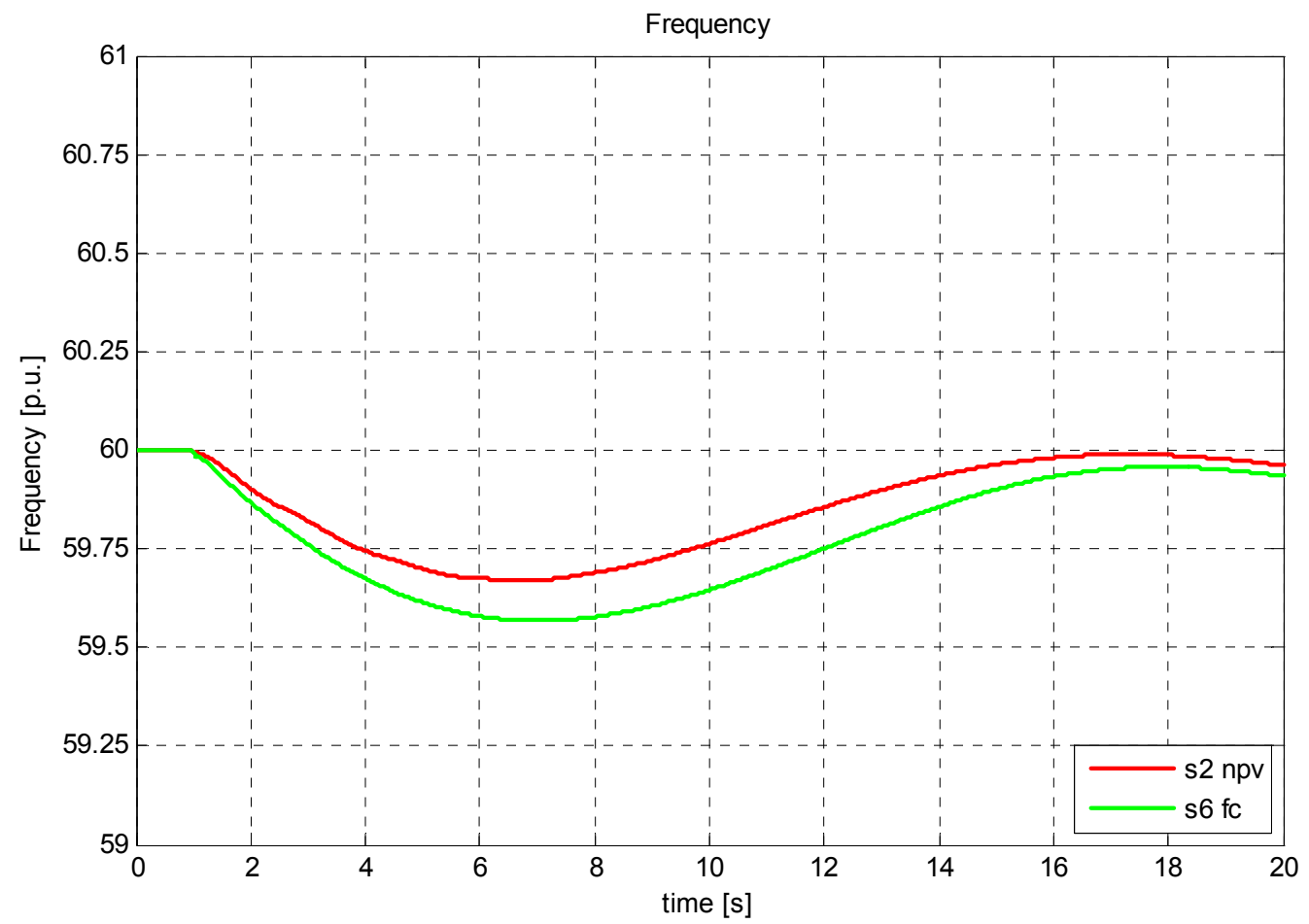

Figure 3-4. Generation trip and low load cases. Scenarios s2 (red) and s6r with frequency control and reserve in PV generation (green).

\subsubsection{Load Trip}

Disconnection of a large load was simulated to assess the impact of PV on frequency performance. The disconnection results in generating power in excess of about $500 \mathrm{MW}$ in peak load cases (s1, s5, and s7) and $250 \mathrm{MW}$ in the lower load cases (s2, s6, and s8). In cases $\mathrm{s} 3$ and s4 the imbalance is $30 \%$ larger.

Table 3-5 presents a summary of the results and the run cases. The cases include all starting scenarios and different PV behavior. 
Table 3-5. Frequency Performance-Load Trip

\begin{tabular}{|c|c|c|c|c|c|c|c|c|c|}
\hline CASE & Scen & Description & $\begin{array}{l}\text { fmax } \\
{[\mathrm{Hz}]}\end{array}$ & $\mathrm{fmin}[\mathrm{Hz}]$ & fss [Hz] & $\begin{array}{c}\text { dfmax } \\
{[\mathrm{Hz} / \mathrm{s}]}\end{array}$ & $\begin{array}{c}\text { tdfmax } \\
\text { [sec] }\end{array}$ & $\begin{array}{c}\text { Initial PV } \\
{[\mathrm{MW}]}\end{array}$ & $\begin{array}{c}\text { PV end } \\
{[\mathrm{MW}]}\end{array}$ \\
\hline REGI_s1_I1_npv & $\mathrm{s} 1$ & No PV & 60.55 & 59.99 & 60.04 & 0.22 & 1.83 & 0 & 0 \\
\hline REGI_s2_I1_npv & s2 & No PV & 60.44 & 60.00 & 60.05 & 0.13 & 1.83 & 0 & 0 \\
\hline REGI_s3_I1_mp & s3 & IEEE1547 & 60.37 & 60.00 & 60.05 & 0.27 & 1.83 & 1827 & 1496 \\
\hline REGI_s4_I1_mp & s4 & IEEE1547 & 60.51 & 59.53 & 59.72 & 0.42 & 5.53 & 1827 & 1220 \\
\hline REGI_s5_I1_mp & s5 & IEEE1547 & 60.50 & 59.75 & 59.96 & 0.23 & 1.83 & 1827 & 1334 \\
\hline REGI_s6_I1_mp & s6 & IEEE1547 & 60.30 & 60.00 & 60.11 & 0.58 & 2.43 & 1827 & 1639 \\
\hline REGI_s7_I1_mp & s7 & IEEE1547 & 60.50 & 59.65 & 60.04 & 0.26 & 5.53 & 1827 & 1274 \\
\hline REGI_s8_I1_mp & s8 & IEEE1547 & 60.31 & 59.96 & 59.99 & 0.11 & 1.83 & 1827 & 1827 \\
\hline REGI_s3e_I1_mpl & s3 & $\begin{array}{l}\text { no overfrequency } \\
\text { trips }\end{array}$ & 60.65 & 60.00 & 60.06 & 0.27 & 1.83 & 1827 & 1827 \\
\hline REGI_s4e_I1_mpl & s4 & $\begin{array}{l}\text { no overfrequency } \\
\text { trips }\end{array}$ & 60.59 & 60.00 & 60.13 & 0.19 & 1.73 & 1827 & 1827 \\
\hline REGI_s5e_I1_mpl & s5 & $\begin{array}{l}\text { no overfrequency } \\
\text { trips }\end{array}$ & 60.59 & 60.00 & 60.06 & 0.23 & 1.83 & 1827 & 1827 \\
\hline REGI_s6e_I1_mpl & s6 & $\begin{array}{l}\text { no overfrequency } \\
\text { trips }\end{array}$ & 60.62 & 60.00 & 60.32 & 0.13 & 1.63 & 1827 & 1827 \\
\hline REGI_s7e_I1_mpl & s7 & $\begin{array}{l}\text { no overfrequency } \\
\text { trips }\end{array}$ & 60.53 & 59.98 & 60.04 & 0.21 & 1.83 & 1827 & 1827 \\
\hline REGI_s8e_I1_mpl & s8 & $\begin{array}{l}\text { no overfrequency } \\
\text { trips }\end{array}$ & 60.31 & 59.96 & 59.99 & 0.11 & 1.83 & 1827 & 1827 \\
\hline REGI_s3_I1_fc & s3 & Frequency Control & 60.52 & 60.00 & 60.17 & 0.26 & 1.83 & 1827 & 1827 \\
\hline REGI_s4_I1_fc & s4 & Frequency Control & 60.42 & 60.00 & 60.17 & 0.18 & 1.73 & 1827 & 1827 \\
\hline REGI_s5_I1_fc & s5 & Frequency Control & 60.45 & 60.00 & 60.15 & 0.22 & 1.83 & 1827 & 1827 \\
\hline REGI_s6_I1_fc & s6 & Frequency Control & 60.36 & 60.00 & 60.17 & 0.12 & 1.63 & 1827 & 1827 \\
\hline REGI_s7 I1_fc & s7 & Frequency Control & 60.42 & 60.00 & 60.14 & 0.21 & 1.73 & 1826.9 & 1826.9 \\
\hline REGI_s8_I1_fc & s8 & Frequency Control & 60.25 & 60.00 & 60.07 & 0.11 & 1.73 & 1826.9 & 1826.9 \\
\hline
\end{tabular}

The observations from these cases follow:

- In cases with PV with IEEE 1547 disconnection criteria (cases 3 to 8), the main impact of PV is associated with trips for frequency higher than $60.5 \mathrm{~Hz}$. In these cases, the maximum frequency excursions are generally better than in cases without PV (cases 1 and 2) because of the generation trip. The trip of PV causes a considerable frequency drop in cases where major PV generation is disconnected.

- In cases with PV, without overfrequency disconnection and with reduced unit commitment (cases 11 and 12), the reduced number of units on frequency control and the reduced inertia result in higher over-frequencies. Figure 3-5 shows the resulting frequency for the case without PV (red) and for the case with a reduced number of regulating units in the system (blue).

- Frequency regulation has a modest impact on the final frequency. 


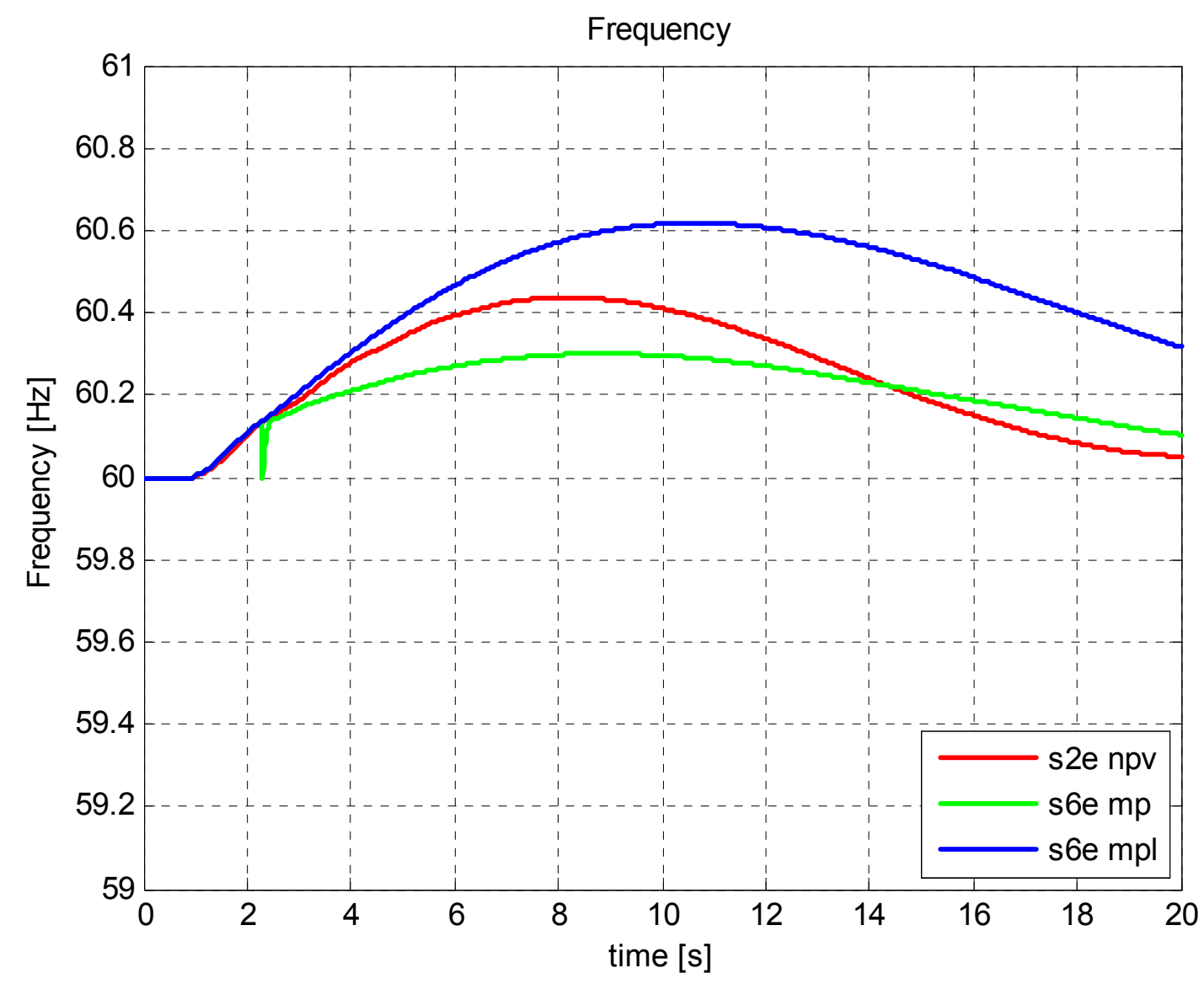

Figure 3-5. Load trip and low load cases. Scenarios s2 (red), s6 with PV acc to IEEE 1547 (green), and $\mathbf{6} 6$ without PV disconnection on overfrequency (blue).

\subsubsection{System Response to Faults}

A solid fault at the bus 16 end of the 16-17 line was simulated; $100 \mathrm{~ms}$ clearing of 16-17 line was assumed. Table 3-6 presents a summary of the results. The cases include all starting scenarios and different PV behavior. Steady-state and dynamic frequency excursions $\left(f_{\min }\right.$ and $\left.f_{s s}\right)$ below $59 \mathrm{~Hz}$ are highlighted in red in the table. Overvoltages above $1.1 \mathrm{pu}\left(\mathrm{V} 16_{\max }\right)$ and steady state voltages $\left(\mathrm{V} 16_{\mathrm{ss}}\right)$ lower than $0.9 \mathrm{pu}$ are also highlighted in red. 
Table 3-6. System Response to Short and Severe Faults

\begin{tabular}{|c|c|c|c|c|c|c|c|c|c|c|c|c|c|c|c|}
\hline \# & CASE & Scen & Cont & Description & $\begin{array}{l}\text { fmax } \\
{[\mathrm{Hz}]}\end{array}$ & $\begin{array}{c}\mathrm{fmin} \\
{[\mathrm{Hz}]}\end{array}$ & $\begin{array}{r}\text { fss } \\
{[\mathrm{Hz}]}\end{array}$ & $\begin{array}{c}\mathrm{dfmax} \\
{[\mathrm{Hz} / \mathrm{s}]}\end{array}$ & $\begin{array}{c}\text { tdfmax } \\
{[\mathrm{sec}]}\end{array}$ & $\begin{array}{c}\mathrm{V} 16 \\
(\mathrm{max}) \\
{[\mathrm{pu}]}\end{array}$ & $\begin{array}{c}\mathrm{v} 16 \\
\text { (min) } \\
{[\mathrm{pu}]}\end{array}$ & $\begin{array}{l}\text { v16ss } \\
\text { [pu] }\end{array}$ & $\begin{array}{l}\text { t16rec } \\
\text { [sec] }\end{array}$ & $\begin{array}{c}\mathrm{PV} \text { tripped } \\
{[\mathrm{MW}]}\end{array}$ & Collapse \\
\hline 1 & REGI_s1_f3npv & $\mathrm{s} 1$ & $\mathrm{f3}$ & No PV & 60.429 & 59.928 & 60.027 & 3.512 & \begin{tabular}{|l|}
1.016 \\
\end{tabular} & 1.085 & 0 & 1.015 & 0.116 & 0 & \\
\hline 2 & REGI_s2_f3_npv & s2 & f3 & No PV & 60.356 & 59.939 & 59.998 & 3.103 & 1.016 & 1.045 & 0 & 0.975 & 0.122 & 0 & \\
\hline 3 & REGI s3 f3 mps & $\mathrm{s} 3$ & f3 & undervoltage trip & 60.484 & 57.078 & 57.452 & 3.733 & 1.016 & 1.035 & 0 & 0.902 & 0.149 & 1827 & osc/volt \\
\hline 4 & REGI s4 f3 mps & $\mathrm{s} 4$ & f3 & undervoltage trip & 72.038 & 38.668 & 53.837 & 115.04 & 16.164 & 1.271 & 0 & 0.417 & 0.587 & 1827 & volt \\
\hline 5 & REGI_s5f3_mps & s5 & $\mathrm{f3}$ & undervoltage trip & 68.275 & 57.428 & 59.078 & 64.815 & 7.011 & 1.534 & 0 & 0.925 & 0.998 & 1827 & volt \\
\hline 6 & REGI s6 f3 mps & s6 & f3 & undervoltage trip & 60 & 54.756 & 54.756 & 147.31 & 1.016 & 0.992 & 0 & 0.572 & 19 & 1827 & $\begin{array}{l}\text { no volt } \\
\text { rec. }\end{array}$ \\
\hline 7 & REGI s7 f3 mps & s7 & f3 & undervoltage trip & 60.466 & \begin{tabular}{|l|l|}
58.267 \\
\end{tabular} & \begin{tabular}{|c|}
59.65 \\
\end{tabular} & \begin{tabular}{|l|}
3.581 .01 \\
\end{tabular} & 1.016 & 1.129 & 0 & 1.039 & 0.128 & $\begin{array}{l}1027 \\
1827\end{array}$ & OSC \\
\hline 8 & REGI_s8_f3_mps & s8 & f3 & undervoltage trip & 60.249 & 57.843 & 60.106 & 3.017 & 1.076 & 1.047 & 0 & 1.027 & 0.104 & 1827 & slow rec \\
\hline 9 & REGI s3 f3 mp & $\mathrm{s} 3$ & $\mathrm{f3}$ & IEEE1547 & 60.499 & 59.804 & 60.012 & 3.733 & 1.016 & 1.061 & 0 & 0.999 & 0.116 & 99 & \\
\hline 10 & REGI s4_f3 mp & $\mathrm{s} 4$ & $\mathrm{f} 3$ & IEEE1547 & 60.648 & 59.716 & 60.023 & 3.491 & 1.016 & 1.082 & 0 & 1.021 & 0.131 & 99 & \\
\hline 11 & REGI s5 f3 mp & s5 & $\mathrm{f} 3$ & IEEE1547 & 60.534 & 59.59 & 59.989 & 3.633 & 1.101 & 1.108 & 0 & 1.026 & 0.122 & 287 & \\
\hline 12 & REGI s6 f3 mp & s6 & f3 & & 60.326 & 59.35 & 59.592 & 147.31 & 1.016 & 1.26 & 0 & 0.593 & 19 & 782 & $\begin{array}{l}\text { no volt } \\
\text { rec. }\end{array}$ \\
\hline$\frac{12}{13}$ & REGI s7 f3 mp & s7 & $f 3$ & $\frac{T L E L}{I E E E}$ & \begin{tabular}{|l|}
60.508 \\
60.508
\end{tabular} & \begin{tabular}{|l|}
59.786 \\
\end{tabular} & \begin{tabular}{|l|l|}
59.996 \\
\end{tabular} & \begin{tabular}{|l|}
3.585 \\
\end{tabular} & 1.016 & 1.066 & 0 & 1.023 & 0.116 & $\frac{102}{99}$ & \\
\hline 14 & REGI s8 f3 mp & s8 & $\mathrm{f3}$ & IEEE1547 & $\begin{array}{l}60.287 \\
\end{array}$ & 59.751 & 59.999 & 2.225 & 1.131 & 1.053 & 0 & 1.012 & 0.101 & 99 & \\
\hline 15 & REGI s3 f3 mpl & $s 3$ & $f 3$ & Lvrt & 60.499 & 59.851 & \begin{tabular}{|l|}
60.02 \\
\end{tabular} & 3.733 & 1.016 & 1.067 & 0 & 1.004 & 0.116 & 0 & \\
\hline 16 & REGI s4 f3 mpl & $\mathrm{s} 4$ & $\mathrm{f} 3$ & & 60.648 & 59.778 & 60.055 & 3.491 & 1.016 & 1.091 & 0 & 1.026 & 0.131 & 0 & \\
\hline 17 & REGI s5 f3 mpl & s5 & $\mathrm{f3}$ & Lvrt & 60.534 & 59.764 & 59.981 & 3.633 & 1.101 & 1.115 & $\frac{0}{0}$ & 1.029 & 0.122 & 0 & \\
\hline 18 & REGI_s6 f3 mpl & $\mathrm{s} 6$ & $\mathrm{f} 3$ & Lvrt & 60.326 & 59.91 & 60.207 & 147.31 & 1.016 & 1.26 & 0 & 0.9 & 0.101 & 0 & \\
\hline 19 & REGI s7 f3 mpl & s7 & $\mathrm{f} 3$ & Lvrt & 60.508 & 59.837 & 60.005 & \begin{tabular}{|l|}
3.585 \\
\end{tabular} & 1.016 & 1.071 & 0 & 1.026 & 0.116 & 0 & \\
\hline 20 & REGI_s8_f3_mpl & s8 & f3 & Lvrt & 60.287 & 59.822 & 59.996 & 2.225 & 1.131 & 1.054 & 0 & 1.013 & 0.101 & 0 & \\
\hline 21 & REGI s3 f3 mplv & $\mathrm{s} 3$ & $f 3$ & Lvrt. Voltage c & 60.516 & 59.78 & 60.013 & \begin{tabular}{|l|}
3.736 \\
\end{tabular} & 1.016 & 1.057 & 0 & 1.005 & 0.113 & 0 & \\
\hline 22 & REGI $\mathrm{s} 4 \mathrm{f} 3 \mathrm{mplv}$ & s4 & 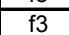 & Lvrt. Voltage cc & 60.575 & 59.734 & \begin{tabular}{|l|}
60.087 \\
\end{tabular} & \begin{tabular}{|l|}
4.99 \\
\end{tabular} & 1.101 & 1.088 & 0 & 1.031 & 0.125 & 0 & \\
\hline 23 & REGl_s5 f3 mplv & s5 & $\mathrm{f3}$ & Lvrt. Voltage cc & 60.538 & 59.69 & 60.049 & 3.725 & 1.016 & 1.102 & 0 & 1.019 & 0.119 & 0 & \\
\hline 24 & REGI s6 f3 mplv & $\mathrm{s} 6$ & $\mathrm{f3}$ & Lvrt. Voltage control & 60.147 & 59.89 & 60.147 & 497.57 & 1.016 & 1.002 & 0 & 0.977 & 0.1 & $\mathrm{c}$ & \\
\hline 25 & REGl_s7 f3_mplv & s7 & $\mathrm{f} 3$ & Lvrt. & 60.507 & 59.811 & 59.991 & 3.601 & 1.016 & 1.064 & 0 & 1.029 & 0.113 & c & \\
\hline 26 & REGl_s8_f3_mplv & s8 & $\mathrm{f} 3$ & Lvrt. Voltage control & 60.258 & 59.812 & 59.987 & 2.296 & 1.016 & 1.059 & 0 & 1.018 & 0.1 & c & \\
\hline 27 & REGI s3 f3 mpla & $\mathrm{s} 3$ & $f 3$ & Lvrt. Anti-ssanding & 60.525 & 59.838 & \begin{tabular}{|l|}
60.018 \\
\end{tabular} & \begin{tabular}{|l|}
3.632 \\
\end{tabular} & 1.016 & 1.065 & 0 & 1.004 & 0.116 & 0 & \\
\hline 28 & REGl s4 f3 mpla & $\mathrm{s} 4$ & $\mathrm{f3}$ & Lvrt. Anti-Islanding & 60.616 & \begin{tabular}{|l|}
59.773 \\
\end{tabular} & 60.052 & 3.442 & 1.016 & 1.086 & 0 & 1.026 & 0.122 & 0 & \\
\hline 29 & REGI s5 $\mathrm{f} 3 \mathrm{mpla}$ & s5 & $f 3$ & Lvrt. Anti-Islanding & 60.556 & 59.747 & 59.994 & $\begin{array}{ll}3.794 \\
\end{array}$ & 1.016 & 1.122 & 0 & 1.044 & 0.119 & $\bar{c}$ & \\
\hline 30 & REGI s6 f3 mpla & $\mathrm{s} 6$ & $\mathrm{f} 3$ & Lvrt. Anti-Islanding & \begin{tabular}{|l|}
60.24 \\
\end{tabular} & 59.901 & 60.205 & 303.02 & 1.016 & 1.08 & 0 & 0.901 & 0.104 & 0 & \\
\hline 31 & REGI s7 f3 mpla & s7 & $\mathrm{f3}$ & Lvrt. Anti-Islanding & 60.508 & \begin{tabular}{|l|}
59.826 \\
\end{tabular} & 60.002 & 3.333 & 1.101 & 1.069 & 0 & 1.026 & 0.116 & 0 & \\
\hline 32 & REGI s8 f3 mpla & s8 & $\mathrm{f} 3$ & Lvrt. Anti-Islanding & 60.314 & 59.819 & 59.993 & 2.325 & 1.131 & 1.06 & 0 & 1.013 & 0.101 & 0 & \\
\hline 33 & REGI s3 f3 mplm & $\mathrm{s} 3$ & $f 3$ & Lvrt. 30\% motor load & 61.135 & 59.997 & 60.179 & \begin{tabular}{|l|}
1.787 \\
\end{tabular} & 1.101 & 1.176 & 0 & 1.066 & 0.185 & 0 & \\
\hline 34 & REGI s4_f 3 mplm & $\mathrm{s} 4$ & $\mathrm{f} 3$ & Lvrt. 30\% motor load & 61.093 & 59.924 & 60.334 & 3.242 & 1.101 & 1.234 & 0 & 1.081 & 0.185 & 0 & \\
\hline 35 & REGI s5 f3 mplm & s5 & $\mathrm{f3}$ & Lvrt. 30\% motor load & 61.239 & 59.997 & 60.203 & 2.016 & 1.101 & 1.236 & 0 & 1.071 & 0.188 & 0 & \\
\hline 36 & REGl s6 $\mathrm{f} 3 \mathrm{mplm}$ & s6 & $\frac{\mathrm{f} 3}{3}$ & Lvrt. 30\% motor & 61.098 & 59.734 & 60.73 & \begin{tabular}{|l|}
8.224 \\
\end{tabular} & 1.101 & 1.127 & 0 & 1.085 & 0.185 & 0 & \\
\hline 37 & REGI s7 f3 mplm & s7 & $\frac{1}{f 3}$ & Lvrt. 30\% motor load & $\begin{array}{l}60.788 \\
\end{array}$ & \begin{tabular}{|l|l|}
59.997 \\
\end{tabular} & 60.069 & \begin{tabular}{|l|l|}
0.747 \\
1.747
\end{tabular} & 1.191 & 1.142 & 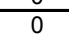 & 1.059 & 0.182 & 0 & \\
\hline 38 & REGI_s8_f3_mplm & $\mathrm{s} 8$ & f3 & Lvrt. 30\% motor load & 60.31 & 59.903 & 59.977 & 1.331 & 1.191 & 1.082 & 0 & 1.022 & 0.131 & 0 & \\
\hline
\end{tabular}

The observations from these cases follow:

- The considered fault does not result in significant frequency excursions or prolonged voltage sags for the cases without PV (cases 1 and 2). The red curves in Figure 3-6 and Figure 3-7 indicate system frequency and voltage in bus 16 for cases 1 and 2 .

- Sensitive undervoltage disconnection of PV can be detrimental to system reliability. Under the assumption that PV trips for undervoltage, according to IEEE 1547, faster than the maximum clearing time requirement (cases 3 to 8), all PV generation disconnects result in significant frequency excursions, voltage and dynamic stability system collapse. The peak load cases $(3,5$, and 7$)$ have oscillatory and voltage stability problems and the lower load cases $(4,6$ and 8$)$ have voltage recovery problems. The resulting generation deficit due to PV trips significantly aggravates the contingency. The green curves in Figure 3-6 indicate system frequency and voltage in bus 16 for cases 5 and 6 . 
- Under the assumption that PV trips for undervoltage according IEEE 1547 at maximum clearing time requirement (cases 9 to 14), the considered fault also results in larger frequency excursions than in the cases without PV. In these cases there are moderate PV trips and considerable frequency excursions, but without system collapse. The blue curves in Figure 3-6 and the green curves in Figure 3-7 indicate system frequency and voltage in bus 16 for these cases.

- In cases that assume LVRT (cases 15 to 20), the frequency drop is significantly less because no generation was lost. The PV active power is reduced during and after the fault becauses of the current limitation of their converters. Figure 3-10 presents the active power output of aggregated PV models and the sum of all PV models for case 15.

- Low load and high PV generation can result in poor voltage recovery if most conventional units are de-committed. In case 12 (associated with scenario s6), the voltage around the high-voltage bus 16 does not recover (green curves in Figure 3-7). Only two generating plants (G2 and G9) are dispatched. The voltage support available in the system is from these generators and the neighboring systems (G1). The area around bus 16 does not have electrically close generators and the system fails to recover. In case 18 (also associated with s6) the voltage at bus 16 does recover because there are no PV trips but only reaches $0.9 \mathrm{pu}$ (blue curves in Figure 3-7).

- Voltage control in PV generation can improve voltage recovery on severe faults. Figure 3-7 shows that case 24 with PV voltage control (black) presents better voltage performance than case 18 (blue).

- Oscillatory stability of the system can be affected with high PV penetration depending on de-committing criteria. The oscillatory stability of the system is negatively affected in cases with PV and scenario s5 (cases 11 and 17). In the frequency signal of Figure 3-6, the oscillatory component has less damping in cases 11 and 17 (blue and black) than in case 1 without PV (red). Figure 3-8 also shows that case 11 of scenario s5 with PV (green) has worse damping than case 13 of scenario s7 (blue). PV generators do not participate in these oscillations. The reduced number of large generators committed in scenario s5 resulted in lower damping of the electromechanical oscillations observed. That is, the unit commitment had a negative impact on system performance.

- Active anti-islanding can negatively affect oscillatory stability. Comparison of cases with (27 to 32 ) and without (15 to 20 ) active anti-islanding does not indicate a noticeable difference in frequency or voltage performance. Further exploration of different (but feasible) anti-islanding settings based on case 29 was performed. Figure 3-9 presents results of case 29 with different anti-islanding settings. The case with five times higher gain than case 29 results in dynamic instability (blue curve in Figure 3-9).

- Motor load in cases 33 to 38 include typical undervoltage tripping settings. Comparing cases 33 to 38 (with motor load) with cases 15 to 20 (without motor load) shows higher maximum voltages can be observed (V16max column in Table 3-6). The undervoltage motor tripping causes these overvoltages. 

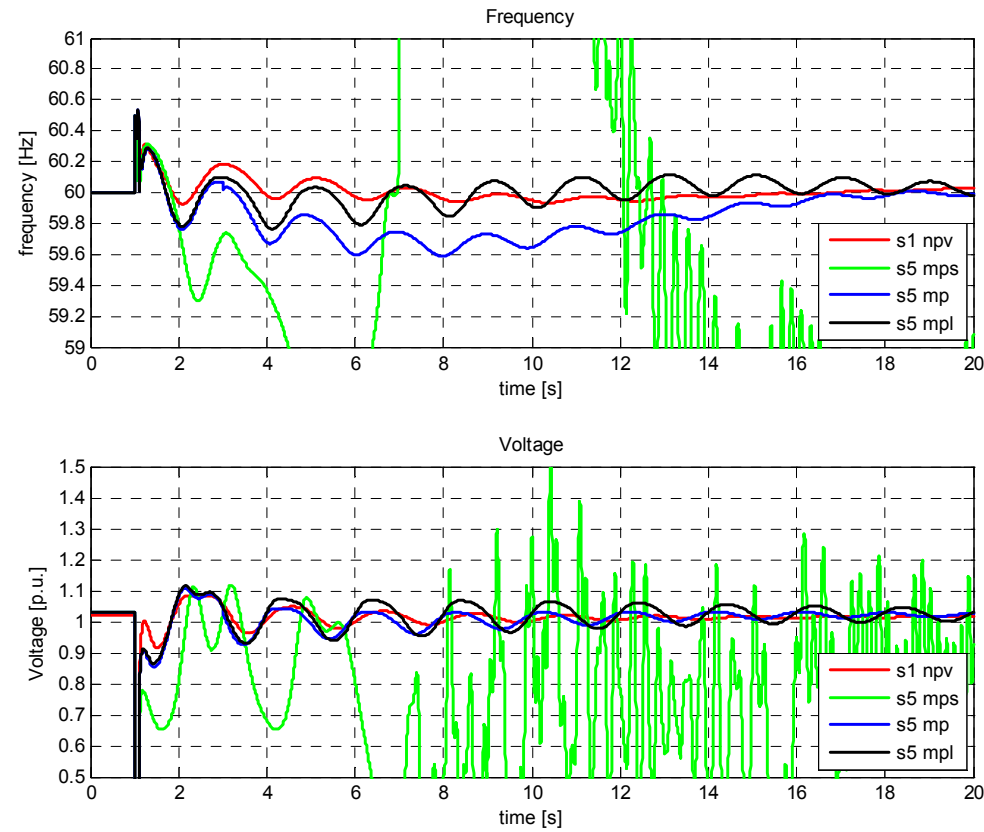

Figure 3-6. Peak load cases with different PV characteristics. Case 1 (red), case 5 (green), case 11 (blue), and case 17 (black).
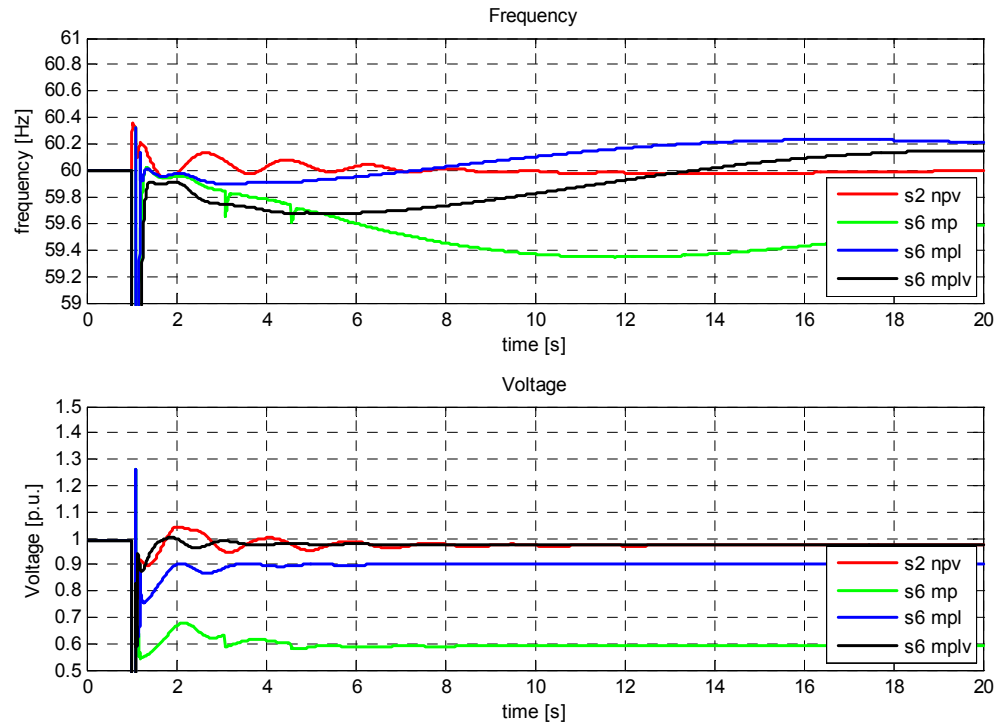

Figure 3-7. Lower load cases with different PV characteristics. Case 2 (red), case 12 (green), case 18 (blue), and case 24 (black). 

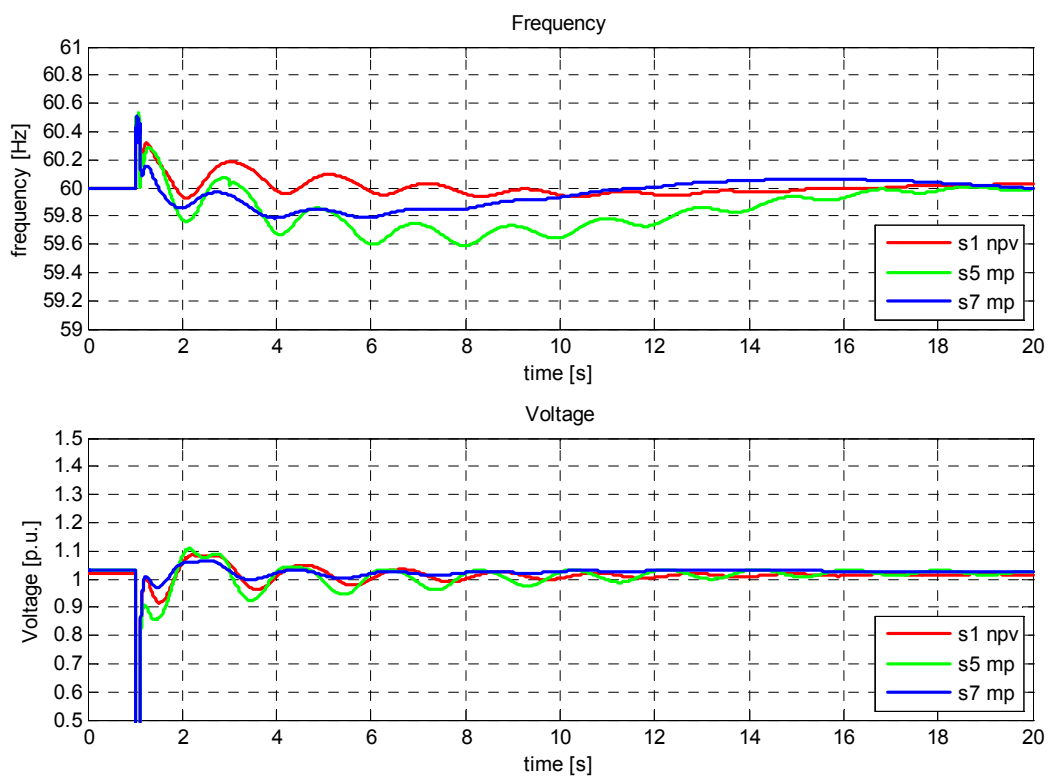

Figure 3-8. Peak load cases with different unit-commitment strategies. Case 1 (red), case 11 (green), and case 13 (blue).
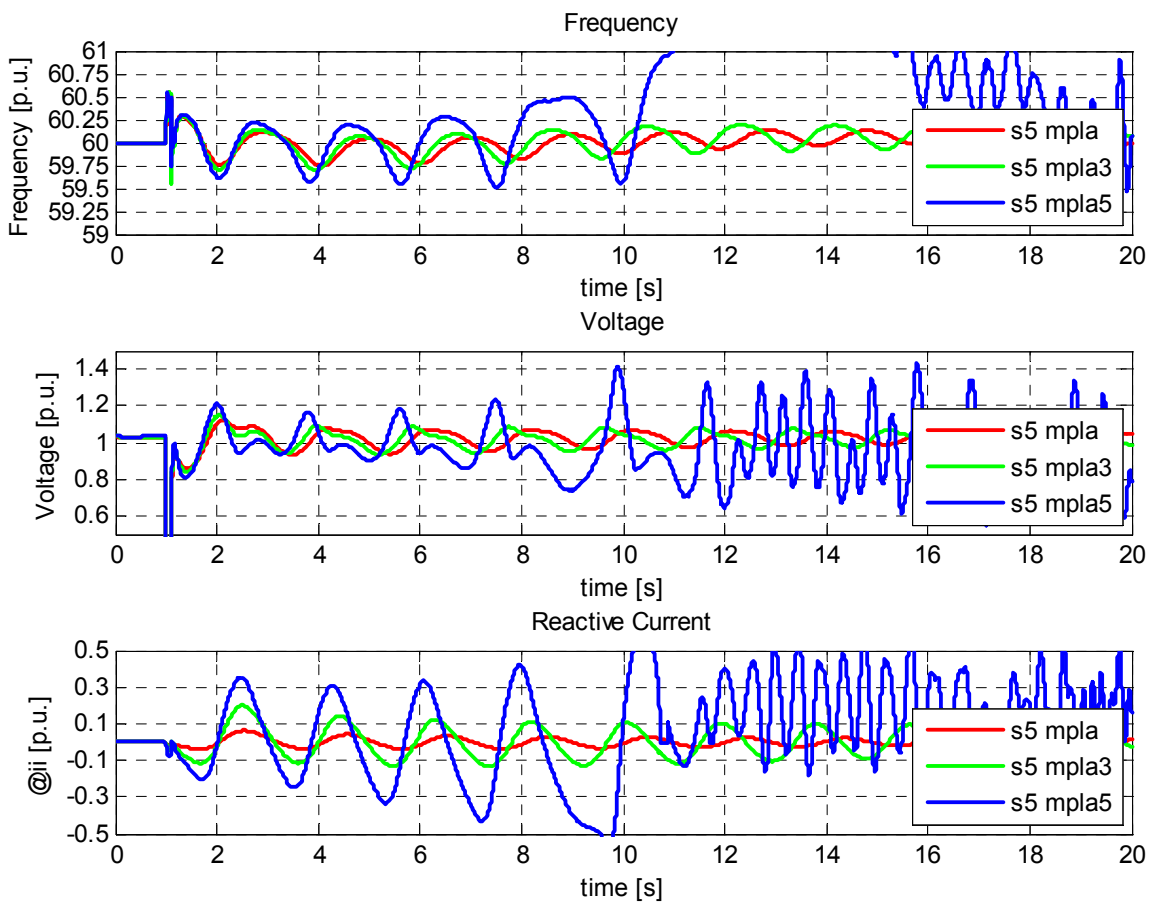

Figure 3-9. Peak load cases with different anti-islanding settings. Case 29 (red), case 29 with three times higher anti-islanding gain (green), and case 29 with five times higher gain (blue) 

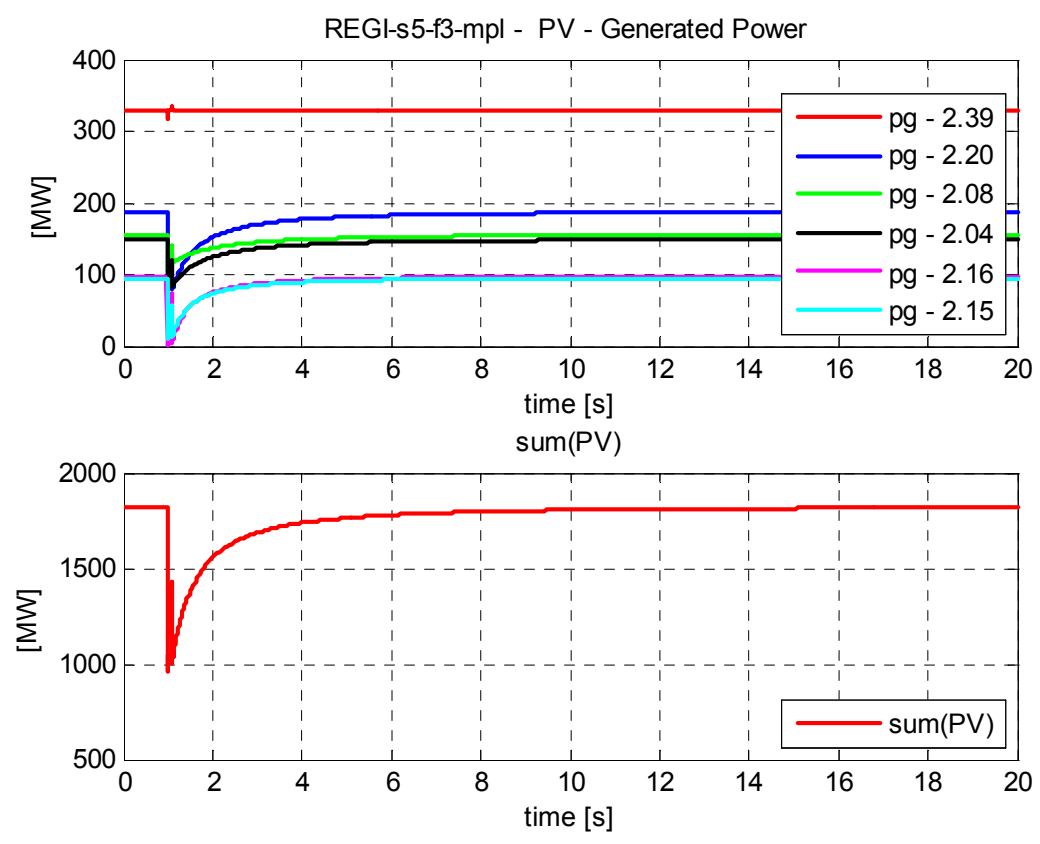

Figure 3-10. Power reduction of PV generation during and after faults (PV LVRT) 


\subsection{Gap Analysis}

The design and operation of systems with high PV penetration will require improved understanding of PV behavior during and after system faults. Present standards (IEEE 1547) assume relatively fast disconnection of PV. System planning should also consider systems that do not trip during faults and the performance that can be expected from PV technologies.

Unit commitment strategy has a significant impact on system performance at high PV penetration levels. A good understanding of the constraints on unit commitment caused by performance and generation flexibility is crucial to enable the operation of systems with high penetration of PV. Other critical gap is associated with understanding of potential additional regulation and load-following requirements because of $\mathrm{PV}$. 


\subsection{Recommendations for Future Research}

Recommended future research in this area includes:

- Develop models that are accurate enough to estimate aggregated behavior of PV systems for system planning. The behavior of aggregated PV during and after faults is most relevant. Converter technology and control can result in considerable differences between systems.

- Develop guidelines for enhancing transmission planning databases to accommodate such models, including aggregated representation of medium- and low-voltage networks.

- Improve understanding of and provide guidelines to quantify the performance and economic impact of PV penetration on regulation and load-following requirements.

- Develop methodologies for estimating the required flexibility of the generation assets to meet regulation and load-following requirements; in particular, the requirements for generating units to ramp production up or down and to stop and start.

- Develop a unit commitment and dispatch strategy for conventional units in systems with high-penetration PV. The proposed strategy should include reliability requirements, operational costs, regulation, and load-following costs. The use of PV forecasts in unit commitment is also instrumental to increase the value of PV generation for high penetration. The approach may require that part of the unit scheduling be done a few hours in advance (instead of 24 to 48 hours currently required) to improve PV production forecast accuracy. The extension of such research to systems with PV and wind generation is also recommended.

- Provide guidance to quantify the value in terms of performance and the economic benefit of potentially mitigating measures of PV power variability (modifications of control zone constraints, flexible conventional generation, centralized and local energy storage, forecast, etc.). These guidelines could be applied to different systems and generation resources. The extension of such research to systems with PV and wind generation is also recommended.

- Develop methods to reliably forecast PV generation at regional levels.

- Develop methods to estimate the actual PV generation to help with system operation.

- Develop active anti-islanding schemes that do not affect regional system performance.

- Develop a strategy and specification for PV voltage control.

- Develop potential remuneration mechanisms for ancillary services associated with voltage support. 


\subsection{Conclusions and Recommendations}

These are the observations from this effort:

\subsection{Observations of System Aspects}

- Unit commitment strategy has significant a impact on system performance at high PV penetration levels:

- System inertia and frequency regulation are reduced as conventional generation is de-committed. This results in power imbalances creating larger frequency excursions.

- Thermal units operate at less efficient load levels if conventional generation is not de-committed.

- Reactive power support in the transmission system is reduced as conventional generation is de-committed. This is of particular relevance for high PV generation and moderate load conditions. This results in longer voltage recovery times after faults and a higher risk of voltage collapse.

- Dynamic stability of the system can be affected.

- Transmission losses are lower with increased PV generation because PV is connected closer to the loads than is conventional generation.

- High-penetration PV will require flexible generation. The ability of a system to accommodate PV generation can be limited under moderate load conditions and conventional units with high technical minimum or stop/start limitations.

- With substantial PV penetration compliant with IEEE 1547, there is considerable reduction in system reliability. Additional risks are associated with the extensive loss of PV generation during transmission faults. It is recommended to:

- Require minimum undervoltage clearing times (instead of maximum clearing times) to avoid significant PV trips during, at least, transmission faults with primary clearing.

- Set underfrequency tripping below frequency load shedding stages.

- If PV performs frequency control, the steady-state frequency performance is similar to the system without PV. Depending on the bandwidth of the PV frequency control, minimum frequency excursions could be reduced. Frequency control in PV generation does not compensate for the reduced system inertia with PV generation.

- PV generation could provide primary frequency control for frequency excursions above nominal without significantly reducing energy production.

- PV generation could provide primary frequency control for frequency decrements as well, but it requires operation with a primary reserve. This could considerably reduce energy production if operation with a reserve is required frequently. There is also a communication challenge of accessing each PV system to require a specific operating point. 
- Anti-islanding schemes can affect the oscillatory stability of the bulk power system.

\subsection{Observations of Photovoltaics Potential Performance}

- The LVRT capability of PV would reduce the negative impact on the reliability of high-penetration PV.

- Even if the PV stays connected during and after a system fault, voltage sags may reduce prolonged PV power output. The power reduction depends on the specific converter/panel control and the voltage recovery in the system.

- For high PV penetration and if significant conventional generation is de-committed, PV voltage control can partially compensate for reduced voltage support in the transmission system.

- Voltage regulation tends to counteract the operation of anti-islanding schemes (of the type studied here). There is potential for voltage regulation to be tuned less responsively to ensure effective disconnection during islanding and steady-state voltage control.

\subsection{Relevant Aspects That Were not Analyzed}

- The dispatch of fewer regulating resources to accommodate variable PV generation can increase the requirement of load-following reserve in the system and for individual units. Additionally, the variability of PV generation may also increase load-following requirements.

- PV systems perform periodic sweeps to characterize the nonlinear relationship between the voltage and the current of the PV modules and the actual solar irradiation. The sweeps result in power output reductions between zero and maximum available power during many seconds. In some cases (depending on the PV system control), a sweep is also performed after significant voltage variations. Many PV systems simultaneously performing a sweep after a transient voltage sag can reduce transient generation considerably.

- The implementation of voltage control on individual PV systems is challenging. There is potential for undesirable interactions between PV systems connected to same feeder and phase and between PV systems and other voltage regulating devices.

- High penetration of PV in distribution feeders can complicate frequency load shedding. Present frequency load shedding schemes are based on frequency relays that disconnect complete feeders. The operation of such relays at times of the day when significant PV generation is produced will result in less effective megawatts of load disconnected. 


\section{References}

1. IEEE 39 Bus System Benchmark Model. Available at http://psdyn.ece.wisc.edu/IEEE_benchmarks/index.htm

2. GE PSLF Manual

3. Z.Ye, R.Walling, R.Zhou, L.Li, T.Wang: Study and Development of Anti-Islanding Control for Grid-Connected Inverter. General Electric Global Research Center, NREL/SR560-36243, 2004. Available at http://www.nrel.gov/docs/fy04osti/36243.pdf. 


\section{Appendix A: PSLF Load Flow Results}

Table A-1. Load Flow Results

\begin{tabular}{|c|c|c|c|c|c|c|c|c|c|}
\hline & \multicolumn{2}{|c|}{ PSLF } & \multicolumn{2}{c|}{ BENCHMARK } & & \multicolumn{2}{c|}{ PSLF } & \multicolumn{2}{c|}{ BENCHMARK } \\
\hline BUS-NO & V-PU & DEG & V (PU) & Angle (deg) & BUS-NO & V-PU & DEG & V (PU) & Angle (deg) \\
\hline $\mathbf{1}$ & 1.0474 & -10.03 & 1.047 & -8.44 & $\mathbf{2 1}$ & 1.0317 & -5.37 & 1.032 & -3.78 \\
\hline $\mathbf{2}$ & 1.0487 & -7.34 & 1.049 & -5.75 & $\mathbf{2 2}$ & 1.0498 & -0.92 & 1.05 & 0.67 \\
\hline $\mathbf{3}$ & 1.0302 & -10.19 & 1.03 & -8.6 & $\mathbf{2 3}$ & 1.0448 & -1.12 & 1.045 & 0.47 \\
\hline $\mathbf{4}$ & 1.0039 & -11.19 & 1.004 & -9.61 & $\mathbf{2 4}$ & 1.0373 & -7.66 & 1.037 & -6.07 \\
\hline $\mathbf{5}$ & 1.0053 & -10.2 & 1.005 & -8.61 & $\mathbf{2 5}$ & 1.0576 & -5.95 & 1.058 & -4.36 \\
\hline $\mathbf{6}$ & 1.0077 & -9.54 & 1.008 & -7.95 & $\mathbf{2 6}$ & 1.0521 & -7.11 & 1.052 & -5.53 \\
\hline $\mathbf{7}$ & 0.997 & -11.71 & 0.997 & -10.12 & $\mathbf{2 7}$ & 1.0377 & -9.08 & 1.038 & -7.5 \\
\hline $\mathbf{8}$ & 0.996 & -12.2 & 0.996 & -10.62 & $\mathbf{2 8}$ & 1.0501 & -3.6 & 1.05 & -2.01 \\
\hline $\mathbf{9}$ & 1.0282 & -11.91 & 1.028 & -10.32 & $\mathbf{2 9}$ & 1.0499 & -0.84 & 1.05 & 0.74 \\
\hline $\mathbf{1 0}$ & 1.0171 & -7.01 & 1.017 & -5.43 & $\mathbf{3 0}$ & 1.0475 & -4.92 & 1.048 & -3.33 \\
\hline $\mathbf{1 1}$ & 1.0127 & -7.87 & 1.013 & -6.28 & $\mathbf{3 1}$ & 0.982 & -1.59 & 0.982 & 0 \\
\hline $\mathbf{1 2}$ & 1.0001 & -7.83 & 1 & -6.24 & $\mathbf{3 2}$ & 0.9831 & 0.98 & 0.983 & 2.57 \\
\hline $\mathbf{1 3}$ & 1.0143 & -7.69 & 1.014 & -6.1 & $\mathbf{3 3}$ & 0.9972 & 2.61 & 0.997 & 4.19 \\
\hline $\mathbf{1 4}$ & 1.0117 & -9.24 & 1.012 & -7.66 & $\mathbf{3 4}$ & 1.0123 & 1.59 & 1.012 & 3.17 \\
\hline $\mathbf{1 5}$ & 1.0154 & -9.32 & 1.015 & -7.74 & $\mathbf{3 5}$ & 1.0493 & 4.04 & 1.049 & 5.63 \\
\hline $\mathbf{1 6}$ & 1.0318 & -7.77 & 1.032 & -6.19 & $\mathbf{3 6}$ & 1.0635 & 6.74 & 1.064 & 8.32 \\
\hline $\mathbf{1 7}$ & 1.0335 & -8.89 & 1.034 & -7.3 & $\mathbf{3 7}$ & 1.0278 & 0.83 & 1.028 & 2.42 \\
\hline $\mathbf{1 8}$ & 1.0309 & -9.81 & 1.031 & -8.22 & $\mathbf{3 8}$ & 1.0265 & 6.22 & 1.027 & 7.81 \\
\hline $\mathbf{1 9}$ & 1.0499 & -2.61 & 1.05 & -1.02 & $\mathbf{3 9}$ & 1.03 & -11.64 & 1.03 & -10.05 \\
\hline $\mathbf{2 0}$ & 0.9912 & -3.6 & 0.991 & -2.01 & & & & & \\
\hline & & & & & & & & & \\
\hline
\end{tabular}




\section{Appendix B: Dynamic models}

Table B-1. Generator Dynamic Data

\begin{tabular}{|c|c|c|c|c|c|c|c|c|c|c|c|c|c|c|c|c|c|c|}
\hline no. & bus & kv & Mbase & Ld & Lpd & Lppd & Lq & Lpq & Lppq & LI & $\mathbf{R a}$ & Tpdo & Tppdo & Tpqo & Tppqo & S1 & S12 & $\mathrm{H}$ \\
\hline 10 & 30 & 22 & 1290 & 1.29 & 0.4 & 0.082 & 0.89 & 0.103 & 0.082 & 0.013 & 0 & 10.2 & 0.03 & 0.2 & 0.04 & 0.05 & 0.3 & 3.255 \\
\hline 2 & 31 & 22 & 574 & 1.693 & 0.4 & 0.2 & 1.618 & 0.976 & 0.2 & 0.035 & 0 & 6.56 & 0.03 & 1.5 & 0.04 & 0.05 & 0.3 & 5.28 \\
\hline 3 & 32 & 22 & 753 & 1.879 & 0.4 & 0.2 & 1.785 & 0.66 & 0.2 & 0.03 & 0 & 5.7 & 0.03 & 1.5 & 0.04 & 0.05 & 0.3 & 4.75 \\
\hline 4 & 33 & 22 & 917 & 2.403 & 0.4 & 0.2 & 2.367 & 1.523 & 0.2 & 0.03 & 0 & 5.69 & 0.03 & 1.5 & 0.04 & 0.05 & 0.3 & 3.117 \\
\hline 5 & 34 & 22 & 303 & 2.03 & 0.4 & 0.2 & 1.879 & 0.503 & 0.2 & 0.054 & 0 & 5.4 & 0.03 & 0.44 & 0.04 & 0.05 & 0.3 & 8.58 \\
\hline 6 & 35 & 22 & 800 & 2.032 & 0.4 & 0.2 & 1.928 & 0.651 & 0.2 & 0.022 & 0 & 7.3 & 0.03 & 0.4 & 0.04 & 0.05 & 0.3 & 4.35 \\
\hline 7 & 36 & 22 & 816 & 2.408 & 0.4 & 0.2 & 2.384 & 1.518 & 0.2 & 0.032 & 0 & 5.66 & 0.03 & 1.5 & 0.04 & 0.05 & 0.3 & 3.23 \\
\hline 8 & 37 & 22 & 702 & 2.035 & 0.4 & 0.2 & 1.965 & 0.639 & 0.2 & 0.028 & 0 & 6.7 & 0.03 & 0.41 & 0.04 & 0.05 & 0.3 & 3.46 \\
\hline 9 & 38 & 22 & 702 & 1.478 & 0.4 & 0.2 & 1.439 & 0.411 & 0.2 & 0.03 & 0 & 4.79 & 0.03 & 1.96 & 0.04 & 0.05 & 0.3 & 4.92 \\
\hline \multicolumn{19}{|c|}{ Representation of connection to large grid } \\
\hline 1 & 39 & 1 & 6667 & 1.333 & 0.4 & 0.2 & 1.267 & 0.533 & 0.2 & 0.003 & 0 & 7 & 0.03 & 0.7 & 0.04 & 0.05 & 0.3 & 7.5 \\
\hline
\end{tabular}

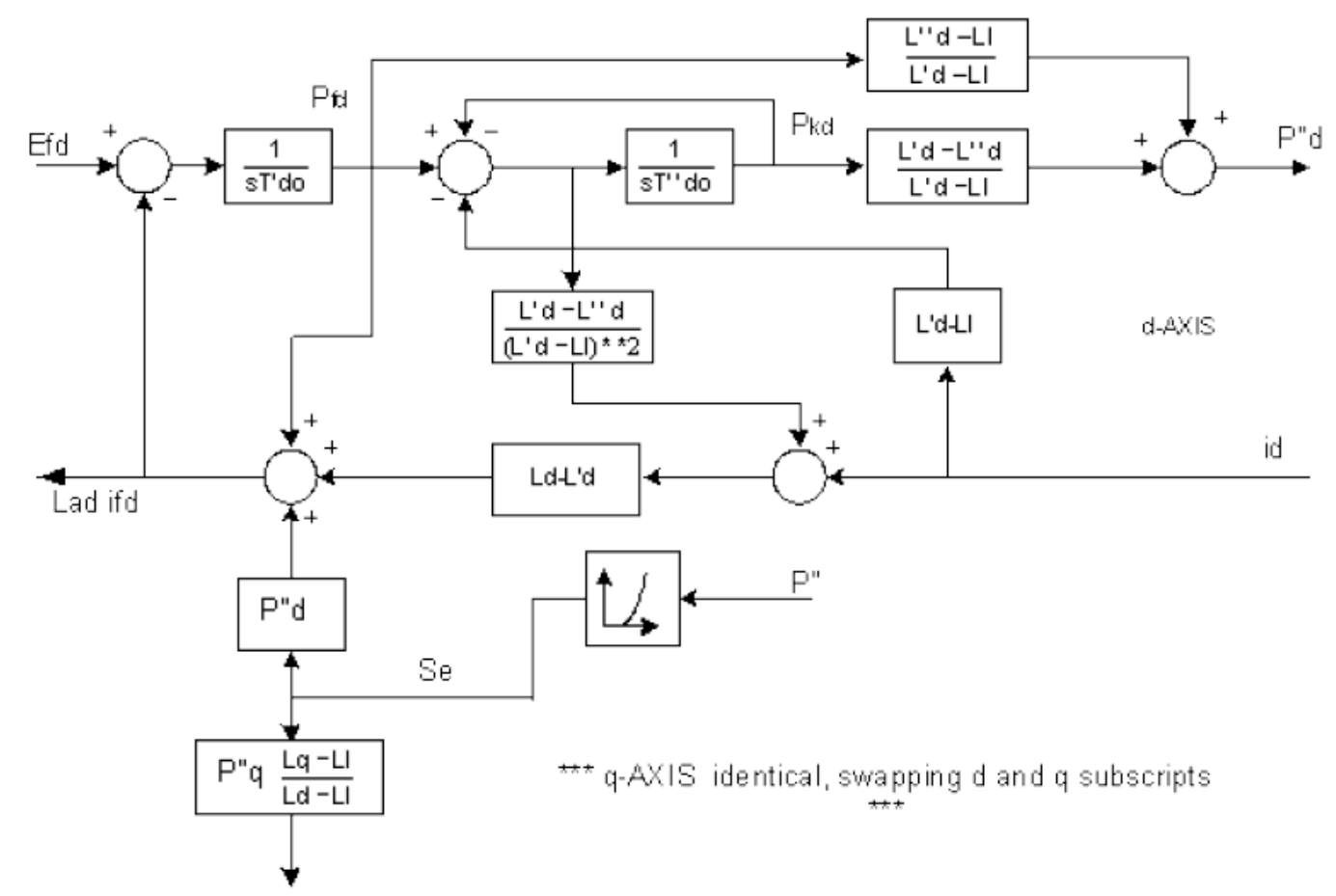

Figure B-1. D-component of PSLF - "genrou” model 
Table B-2. AVR Parameters

\begin{tabular}{|c|c|c|c|c|c|c|c|c|c|c|c|c|c|c|}
\hline Unit No. & Ta/Tb & Tb & $\mathbf{K}$ & Te & Emin & Ema & Kc & Tc & Edfmin & Edfmax & Tr & & Ta & Vref \\
\hline $\mathbf{1}$ & 0.1 & 10 & 200 & 0.015 & -5 & 5 & 0.08 & 0 & -5 & 5 & 0.01 & & 1 & 1.03 \\
\hline $\mathbf{2}$ & 0.1 & 10 & 200 & 0.015 & -5 & 5 & 0.08 & 0 & -5 & 5 & 0.01 & & 1 & 0.982 \\
\hline $\mathbf{3}$ & 0.1 & 10 & 200 & 0.015 & -5 & 5 & 0.08 & 0 & -5 & 5 & 0.01 & & 1 & 0.9831 \\
\hline $\mathbf{4}$ & 0.1 & 10 & 200 & 0.015 & -5 & 5 & 0.08 & 0 & -5 & 5 & 0.01 & & 1 & 0.9972 \\
\hline $\mathbf{5}$ & 0.1 & 10 & 200 & 0.015 & -5 & 5 & 0.08 & 0 & -5 & 5 & 0.01 & & 1 & 1.0123 \\
\hline $\mathbf{6}$ & 0.1 & 10 & 200 & 0.015 & -5 & 5 & 0.08 & 0 & -5 & 5 & 0.01 & 1 & 1.0493 \\
\hline $\mathbf{7}$ & 0.1 & 10 & 200 & 0.015 & -5 & 5 & 0.08 & 0 & -5 & 5 & 0.01 & & 1 & 1.0635 \\
\hline $\mathbf{8}$ & 0.1 & 10 & 200 & 0.015 & -5 & 5 & 0.08 & 0 & -5 & 5 & 0.01 & & 1 & 1.0278 \\
\hline $\mathbf{9}$ & 0.1 & 10 & 200 & 0.015 & -5 & 5 & 0.08 & 0 & -5 & 5 & 0.01 & & 1 & 1.0265 \\
\hline $\mathbf{1 0}$ & 0.1 & 10 & 200 & 0.015 & -5 & 5 & 0.08 & 0 & -5 & 5 & 0.01 & 1 & 1.0475 \\
\hline
\end{tabular}

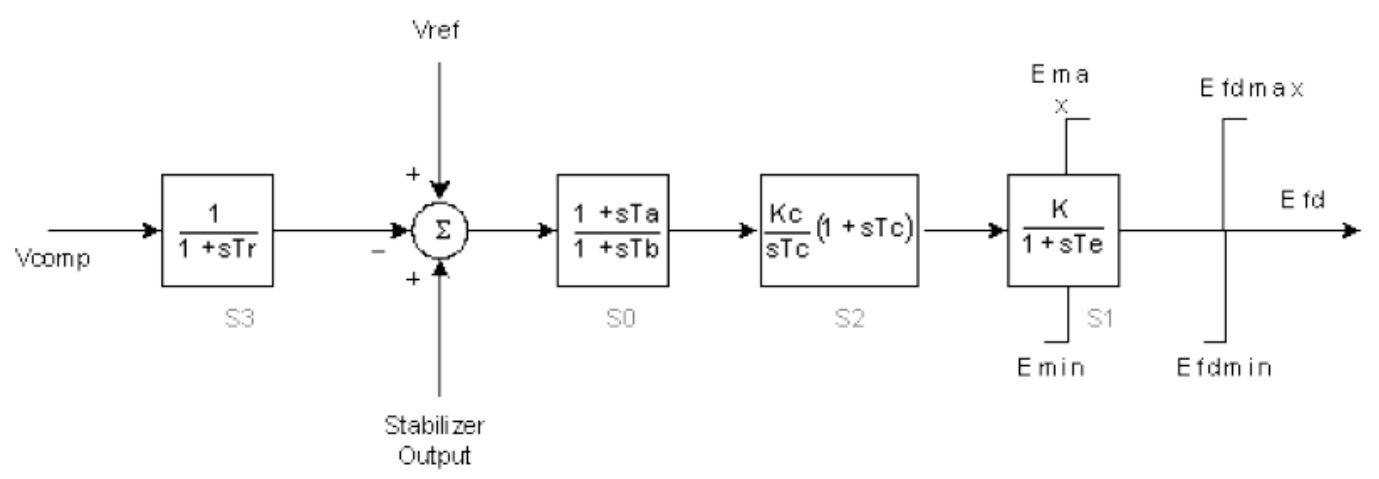

Figure B-2. PSLF - AVR model 
Table B-3. Stabilizer Parameters

\begin{tabular}{|c|c|c|c|c|c|c|c|c|c|c|c|c|c|c|c|c|c|c|c|c|c|c|c|c|c|c|}
\hline $\begin{array}{l}\text { Unit } \\
\text { No. }\end{array}$ & \begin{tabular}{|l|} 
J1 \\
\end{tabular} & K1 & \begin{tabular}{|l|}
$\mathrm{J} 2$ \\
\end{tabular} & K2 & Tw1 & Tw2 & Tw3 & $\mid$ Tw4 & \begin{tabular}{|l|l} 
T6 \\
\end{tabular} & \begin{tabular}{|l|l|} 
T7 \\
\end{tabular} & Ks2 & Ks4 & T8 & T9 & n & $\mathbf{m}$ & Ks1 & T1 & T2 & T3 & T4 & $\begin{array}{c}\text { Vst } \\
\max \end{array}$ & $\begin{array}{l}\text { Vst } \\
\text { min }\end{array}$ & $\mathbf{a}$ & & $\begin{array}{l}T \\
b\end{array}$ \\
\hline 1 & 1 & 0 & 3 & 0 & 10 & 0 & 2 & 0 & 0 & 0 & 0 & 0 & 0.5 & 0.1 & 0 & 0 & 1 & 5 & 0.6 & 3 & 0.5 & 0.2 & -0.2 & 11 & 0 & 0 \\
\hline 2 & 1 & 0 & 3 & 0 & 10 & 0 & 2 & 0 & 0 & 0 & 0 & 0 & 0.5 & 0.1 & 0 & 0 & 0.5 & 5 & 0.4 & 1 & 0.1 & 0.2 & -0.2 & 1 & \begin{tabular}{l|l} 
\\
\end{tabular} & 0 \\
\hline 3 & 1 & 0 & 3 & 0 & 10 & 0 & 2 & 0 & 0 & 0 & 0 & 0 & 0.5 & 0.1 & 0 & 0 & 0.5 & 3 & 0.2 & 2 & 0.2 & 0.2 & -0.2 & 1 & 0 & 0 \\
\hline 4 & 1 & 0 & 3 & 0 & 10 & 0 & 2 & 0 & 0 & 0 & 0 & 0 & 0.5 & 0.1 & 0 & 0 & 2 & 1 & 0.1 & 1 & 0.3 & 0.2 & -0.2 & 1 & 0 & 0 \\
\hline 5 & 1 & 0 & 3 & 0 & 10 & 0 & 2 & 0 & 0 & 0 & 0 & 0 & 0.5 & 0.1 & 0 & 0 & 1 & 1.5 & 0.2 & 1 & 0.1 & 0.2 & -0.2 & $\sqrt{1}$ & 0 & 0 \\
\hline 6 & 1 & 0 & 3 & 0 & 10 & $\overline{0}$ & 2 & 0 & 0 & 0 & 0 & 0 & 0.5 & 0.1 & 0 & 0 & 4 & 0.5 & 0.1 & 0.5 & 0.05 & 0.2 & -0.2 & 1 & \begin{tabular}{l|l}
0 \\
\end{tabular} & 0 \\
\hline 7 & 1 & 0 & 3 & 0 & 10 & 0 & 2 & 0 & 0 & 0 & 0 & 0 & 0.5 & 0.1 & 0 & 0 & 7.5 & 0.2 & 0.02 & 0.5 & 0.1 & 0.2 & -0.2 & 1 & \begin{tabular}{l|l} 
\\
\end{tabular} & 0 \\
\hline 8 & 1 & 0 & 3 & 0 & 10 & 0 & 2 & 0 & 0 & 0 & 0 & 0 & 0.5 & 0.1 & 0 & 0 & 2 & 1 & 0.2 & 1 & 0.1 & 0.2 & -0.2 & 1 & \begin{tabular}{l|l}
0 \\
\end{tabular} & 0 \\
\hline 9 & 1 & 0 & 3 & 0 & 10 & 0 & 2 & 0 & 0 & 0 & 0 & 0 & 0.5 & 0.1 & 0 & 0 & 2 & 1 & 0.5 & 2 & 0.1 & 0.2 & -0.2 & 1 & 0 & 0 \\
\hline 10 & 1 & 0 & 3 & 0 & 10 & $\overline{0}$ & 2 & 0 & 0 & 0 & 0 & 0 & 0.5 & 0.1 & 0 & 0 & 1 & 1 & 0.05 & 3 & 0.5 & 0.2 & -0.2 & 1 & 0 & 0 \\
\hline
\end{tabular}

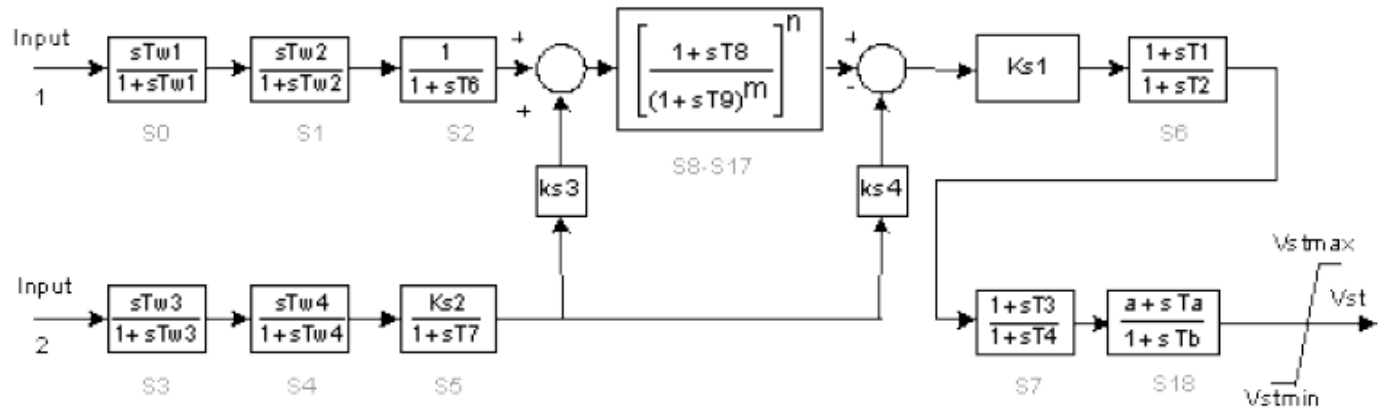

Figure B-3. PSLF - "pss2a" model

$$
\begin{aligned}
& \mathrm{P}=\mathrm{Po}(\mathrm{p} 1 \mathrm{v} 2+\mathrm{p} 2 \mathrm{v}+\mathrm{p} 3+\mathrm{p} 4(1+\mathrm{lpd} \mathrm{f})) \\
& \mathrm{Q}=\mathrm{Qo}(\mathrm{q} 1 \mathrm{v} 2+\mathrm{q} 2 \mathrm{v}+\mathrm{q} 3+\mathrm{q} 4(1+\mathrm{lqd}))
\end{aligned}
$$

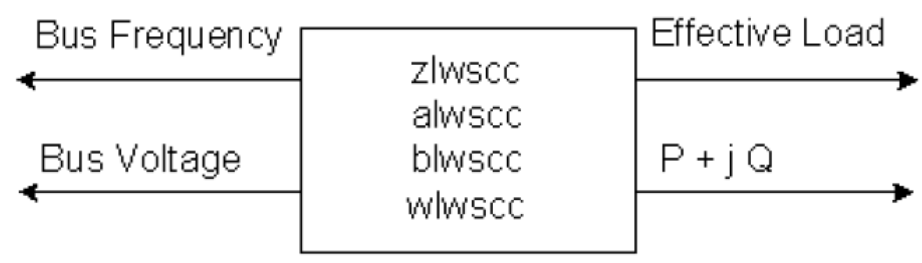

Figure B-4. PSLF - "wlwscc" load model polynomial representation 


\section{Appendix C: Modifications to IEEE 39 Bus System}

\section{Load Flow Results of Extended Model}

Table C-1. Load Flow Result of Extended Model

\begin{tabular}{|c|c|c|c|c|c|c|c|c|c|}
\hline & \multicolumn{3}{|c|}{ PSLF } & \multicolumn{2}{|r|}{ IEEE } & & \multicolumn{3}{|c|}{ PSLF } \\
\hline BUS-NO & KV & V-PU & DEG & $\mathbf{V}(\mathrm{PU})$ & Angle (deg) & BUS-NO & KV & V-PU & DEG \\
\hline 1 & 345 & 1.0479 & -20.78 & 1.0474 & -8.44 & 103 & 22 & 1.0489 & -24.34 \\
\hline 2 & 345 & 1.0501 & -18.16 & 1.0487 & -5.75 & 203 & 0.44 & 1.0603 & -29.12 \\
\hline 3 & 345 & 1.0312 & -20.65 & 1.0302 & -8.6 & 104 & 22 & 1.0371 & -23.48 \\
\hline 4 & 345 & 1.0007 & -20.1 & 1.0039 & -9.61 & 204 & 0.44 & 1.0175 & -27.06 \\
\hline 5 & 345 & 0.9993 & -17.73 & 1.0053 & -8.61 & 107 & 22 & 1.0412 & -22.76 \\
\hline 6 & 345 & 1.0013 & -16.71 & 1.0077 & -7.95 & 207 & 0.44 & 1.023 & -26.34 \\
\hline 7 & 345 & 0.9911 & -19.39 & 0.997 & -10.12 & 108 & 22 & 1.0416 & -23.48 \\
\hline 8 & 345 & 0.9904 & -20.08 & 0.996 & -10.62 & 208 & 0.44 & 1.0249 & -27.15 \\
\hline 9 & 345 & 1.0254 & -21.5 & 1.0282 & -10.32 & 115 & 22 & 1.0036 & -23.47 \\
\hline 10 & 345 & 1.0134 & -15.02 & 1.0172 & -5.43 & 215 & 0.44 & 0.9709 & -26.83 \\
\hline 11 & 345 & 1.0082 & -15.61 & 1.0127 & -6.28 & 116 & 22 & 1.0458 & -22.72 \\
\hline 12 & 100 & 0.9961 & -15.84 & 1.0002 & -6.24 & 216 & 0.44 & 1.0484 & -27.24 \\
\hline 13 & 345 & 1.0106 & -15.97 & 1.0143 & -6.1 & 118 & 22 & 1.0385 & -24.36 \\
\hline 14 & 345 & 1.0087 & -18.25 & 1.0117 & -7.66 & 218 & 0.44 & 1.032 & -28.63 \\
\hline 15 & 345 & 1.0157 & -20.03 & 1.0154 & -7.74 & 120 & 22 & 1.0314 & -19.42 \\
\hline 16 & 345 & 1.034 & -19.06 & 1.0318 & -6.19 & 220 & 0.44 & 1.0258 & -23.85 \\
\hline 17 & 345 & 1.0355 & -20.07 & 1.0336 & -7.3 & 121 & 22 & 1.0264 & -20.26 \\
\hline 18 & 345 & 1.0327 & -20.75 & 1.0309 & -8.22 & 221 & 0.44 & 1.0017 & -23.7 \\
\hline 19 & 345 & 1.051 & -14.37 & 1.0499 & $\begin{array}{l}-1.02 \\
\end{array}$ & 123 & 22 & 1.0445 & -16.11 \\
\hline 20 & 100 & 0.9922 & -15.72 & 0.9912 & -2.01 & 223 & 0.44 & 1.028 & -19.74 \\
\hline 21 & 345 & 1.0338 & -16.88 & 1.0318 & -3.78 & 124 & 22 & 1.031 & -22.31 \\
\hline 22 & 345 & 1.0512 & -12.5 & 1.0498 & 0.67 & 224 & 0.44 & 1.004 & -25.48 \\
\hline 23 & 345 & 1.0465 & -12.74 & 1.0448 & 0.47 & 125 & 22 & 1.0207 & -20.74 \\
\hline 24 & 345 & 1.0406 & -19.06 & 1.0373 & -6.07 & 225 & 0.44 & 1.0093 & -25.1 \\
\hline 25 & 345 & 1.0569 & -17.03 & 1.0576 & -4.36 & 126 & 22 & 1.0205 & -22.54 \\
\hline 26 & 345 & 1.0532 & -18.72 & 1.0521 & -5.53 & 226 & 0.44 & 1.0166 & -27.23 \\
\hline 27 & 345 & 1.0396 & -20.58 & 1.0377 & -7.5 & 127 & 22 & 1.0412 & -24.08 \\
\hline 28 & 345 & 1.0509 & -15.69 & 1.0501 & -2.01 & 227 & 0.44 & 1.0292 & -28.02 \\
\hline 29 & 345 & 1.0506 & -12.97 & 1.0499 & 0.74 & 128 & 22 & 1.0184 & -19.52 \\
\hline 30 & 22 & 1.0475 & -15.74 & 1.0475 & -3.33 & 228 & 0.44 & 1.0131 & -24.18 \\
\hline 31 & 22 & 0.982 & -1.59 & 0.982 & 0 & 129 & 22 & 1.0195 & -16.82 \\
\hline 32 & 22 & 0.9831 & -7 & 0.9831 & 2.57 & 229 & 0.44 & 1.018 & -21.62 \\
\hline 33 & 22 & 0.9972 & -9.16 & 0.9972 & 4.19 & 131 & 22 & 1.036 & -4.78 \\
\hline 34 & 22 & 1.0123 & -10.53 & 1.0123 & 3.17 & 231 & 0.44 & 1.009 & -7.82 \\
\hline 35 & 22 & 1.0493 & -7.54 & 1.0493 & 5.63 & 139 & 22 & 1.0333 & -25.96 \\
\hline 36 & 22 & 1.0635 & -4.9 & 1.0635 & 8.32 & 239 & 0.44 & 1.023 & -30.14 \\
\hline 37 & 22 & 1.0278 & -10.24 & 1.0278 & 2.42 & & & & \\
\hline 38 & 22 & 1.0265 & -5.91 & 1.0265 & 7.81 & & & & \\
\hline 39 & 345 & 1.03 & -22.35 & 1.03 & -10.05 & & & & \\
\hline
\end{tabular}




\section{Governors}

Table C-2. Modified Governor Mbase Values

\begin{tabular}{|c|c|c|c|c|c|}
\hline BUS-NO & ID & PGEN & IREG & MBASE & MBGOV \\
\hline 30 & 10 & 250 & 2 & 1290 & $\mathbf{3 4 9}$ \\
\hline 31 & 2 & 520.8 & 6 & 573.9 & $\mathbf{6 6 5}$ \\
\hline 32 & 3 & 650 & 10 & 753.3 & $\mathbf{8 1 1}$ \\
\hline 33 & 4 & 632 & 19 & 917.4 & $\mathbf{7 9 7}$ \\
\hline 34 & 5 & 508 & 20 & 303 & $\mathbf{6 1 2}$ \\
\hline 35 & 6 & 650 & 22 & 800 & $\mathbf{8 1 6}$ \\
\hline 36 & 7 & 560 & 23 & 816.3 & $\mathbf{6 7 6}$ \\
\hline 37 & 8 & 540 & 25 & 701.8 & $\mathbf{6 4 2}$ \\
\hline 38 & 9 & 830 & 29 & 701.8 & $\mathbf{9 8 7}$ \\
\hline 39 & 1 & 1000 & 39 & 6666.7 & $\mathbf{1 1 9 4}$ \\
\hline
\end{tabular}


Appendix D: Single Line Diagrams of Starting Scenarios 


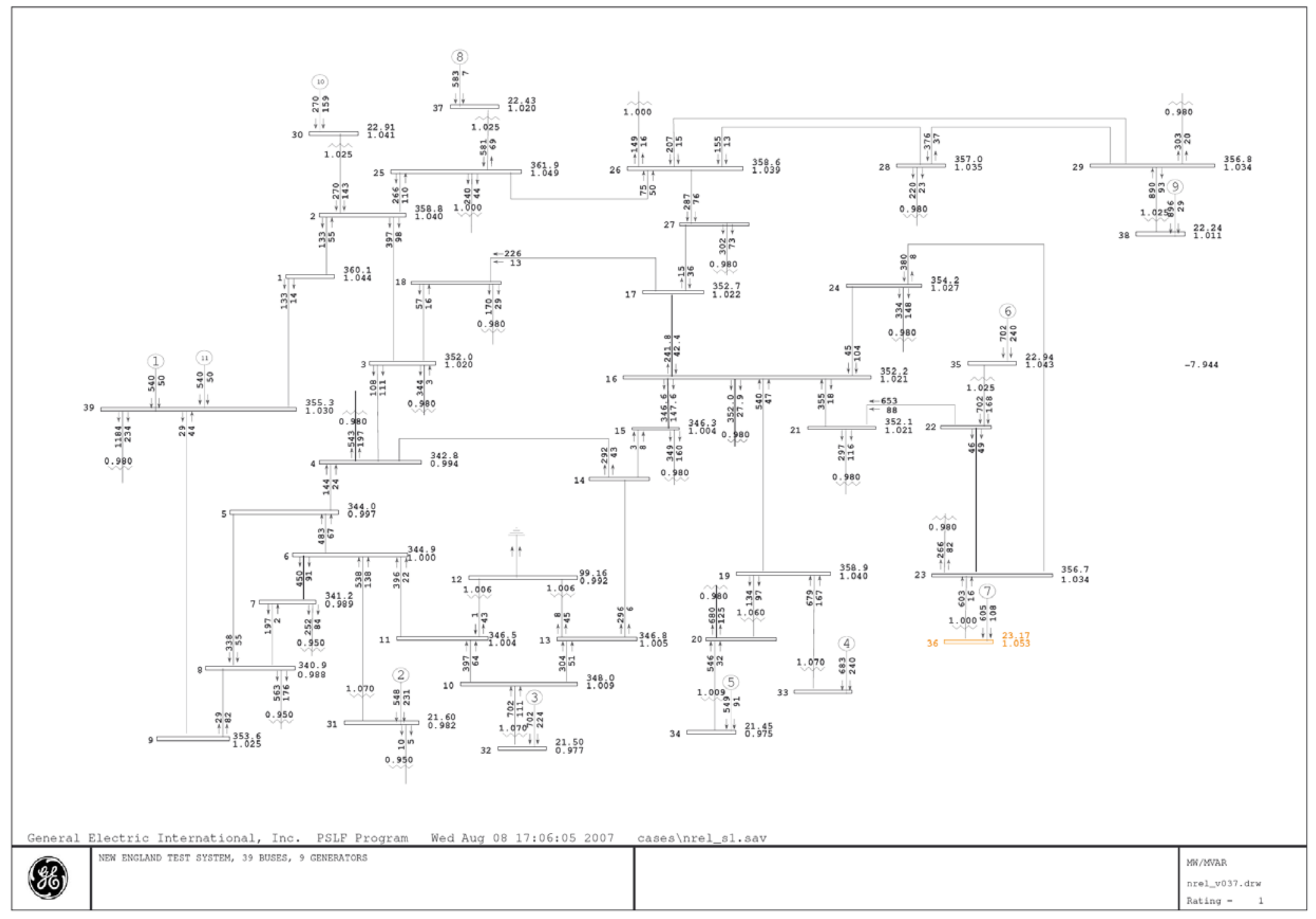

Figure D-1. Scenario s1 peak load (IEEE benchmark load). No PV generation. 


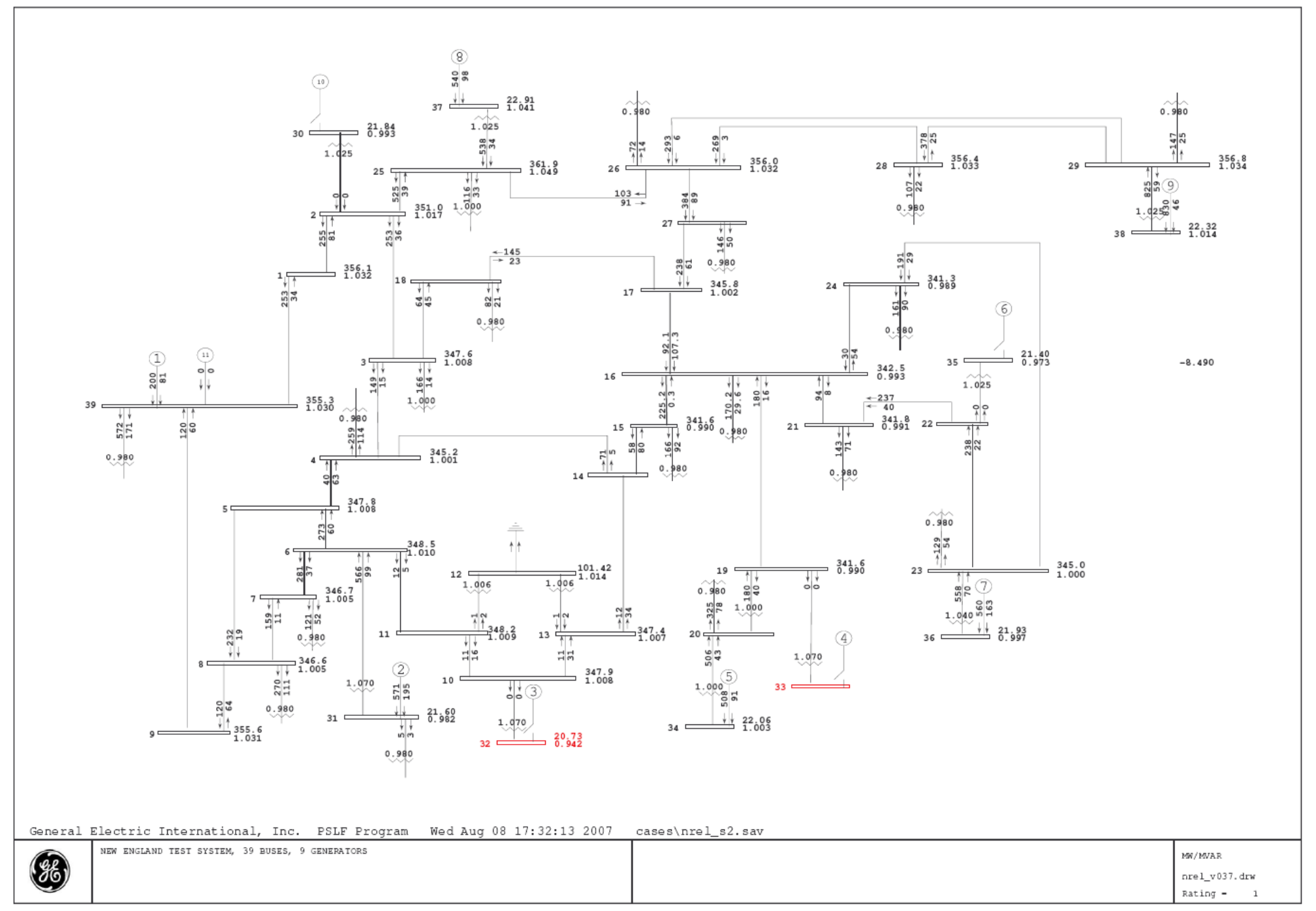

Figure D-2. Scenario s2 low load (50\% of peak). No PV generation. 


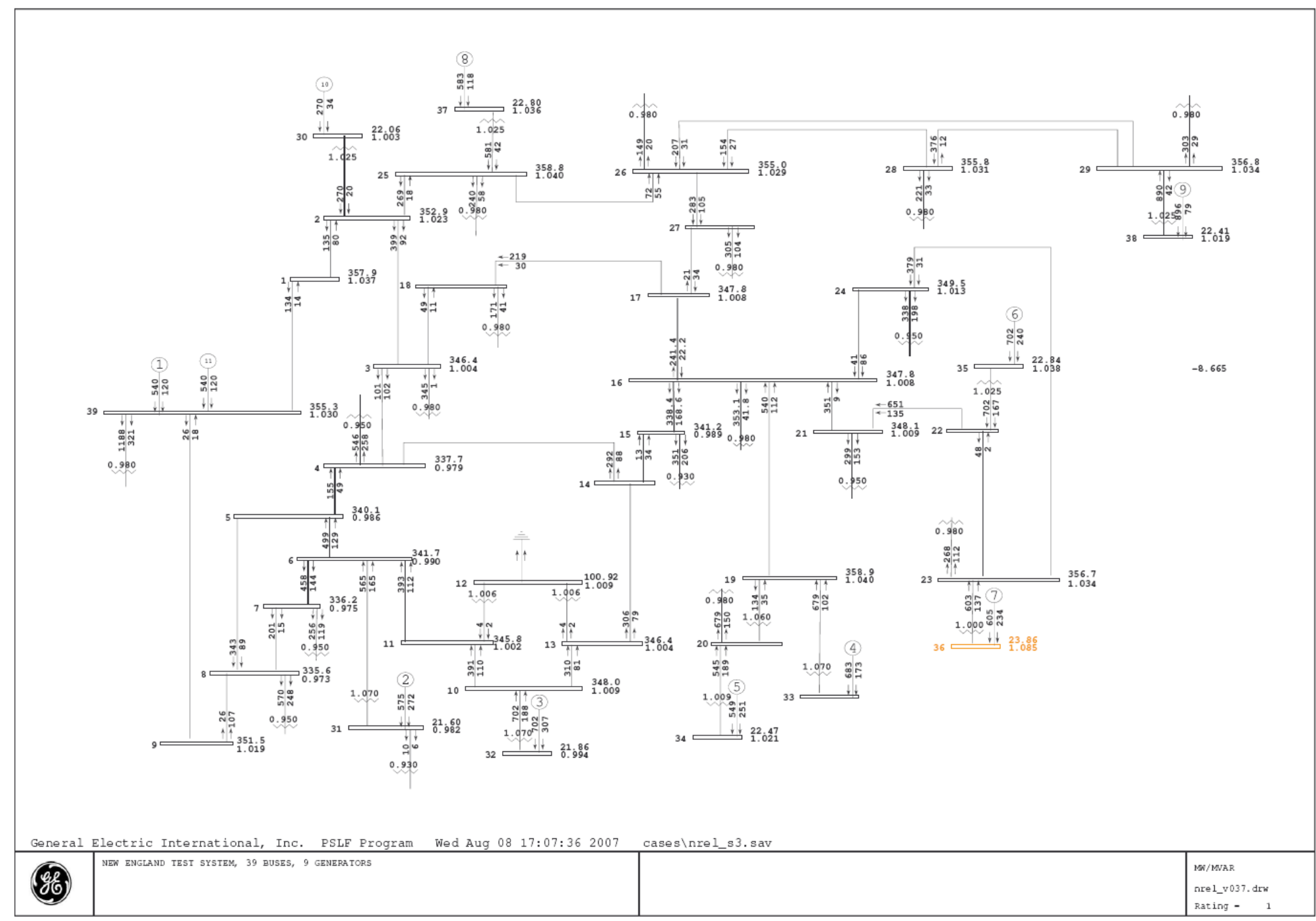

Figure D-3. Scenario s3 peak (plus 30\%). 30\% PV generation. 


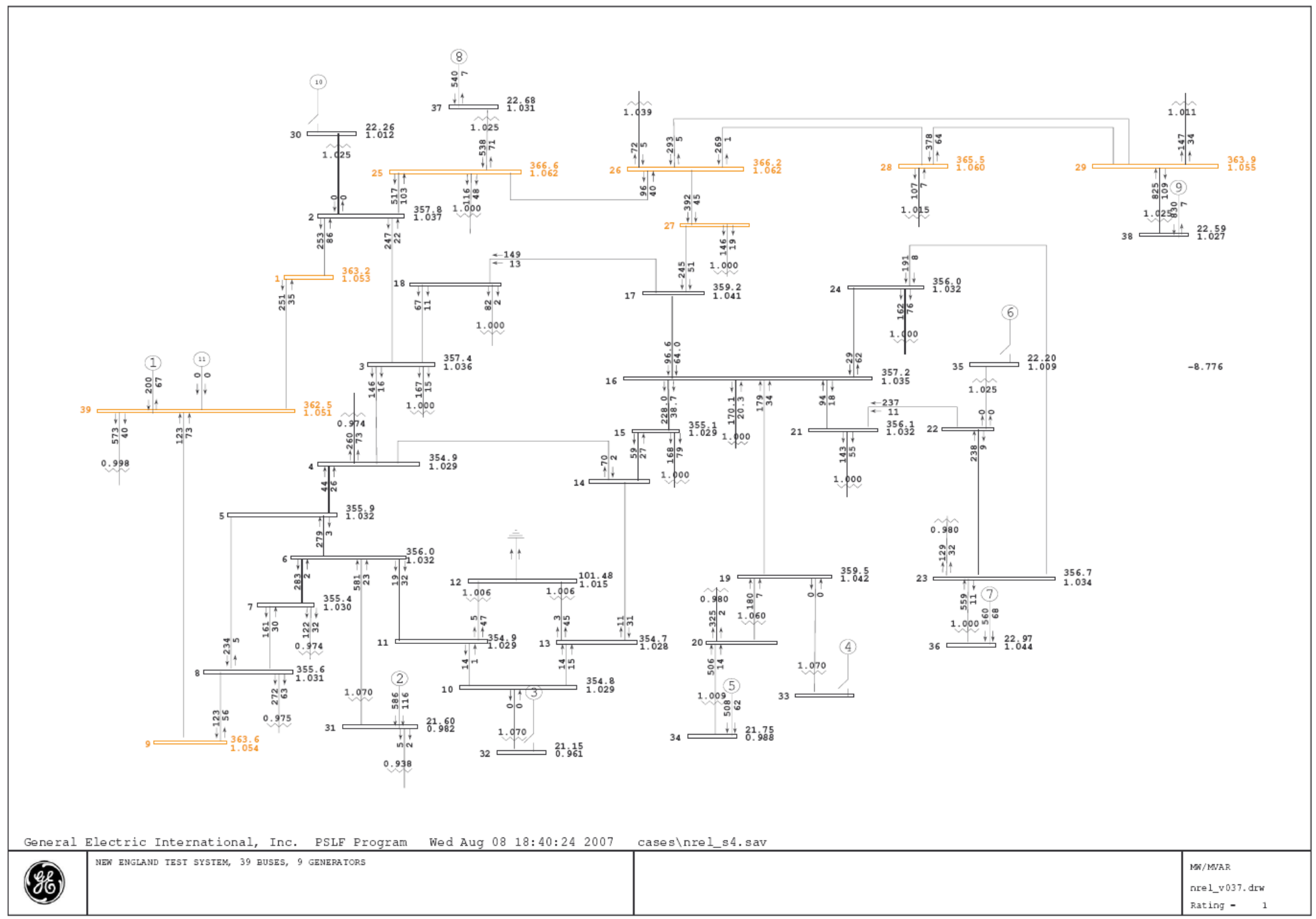

Figure D-4. Scenario s4 low load plus 30\%. 30\% PV generation. 


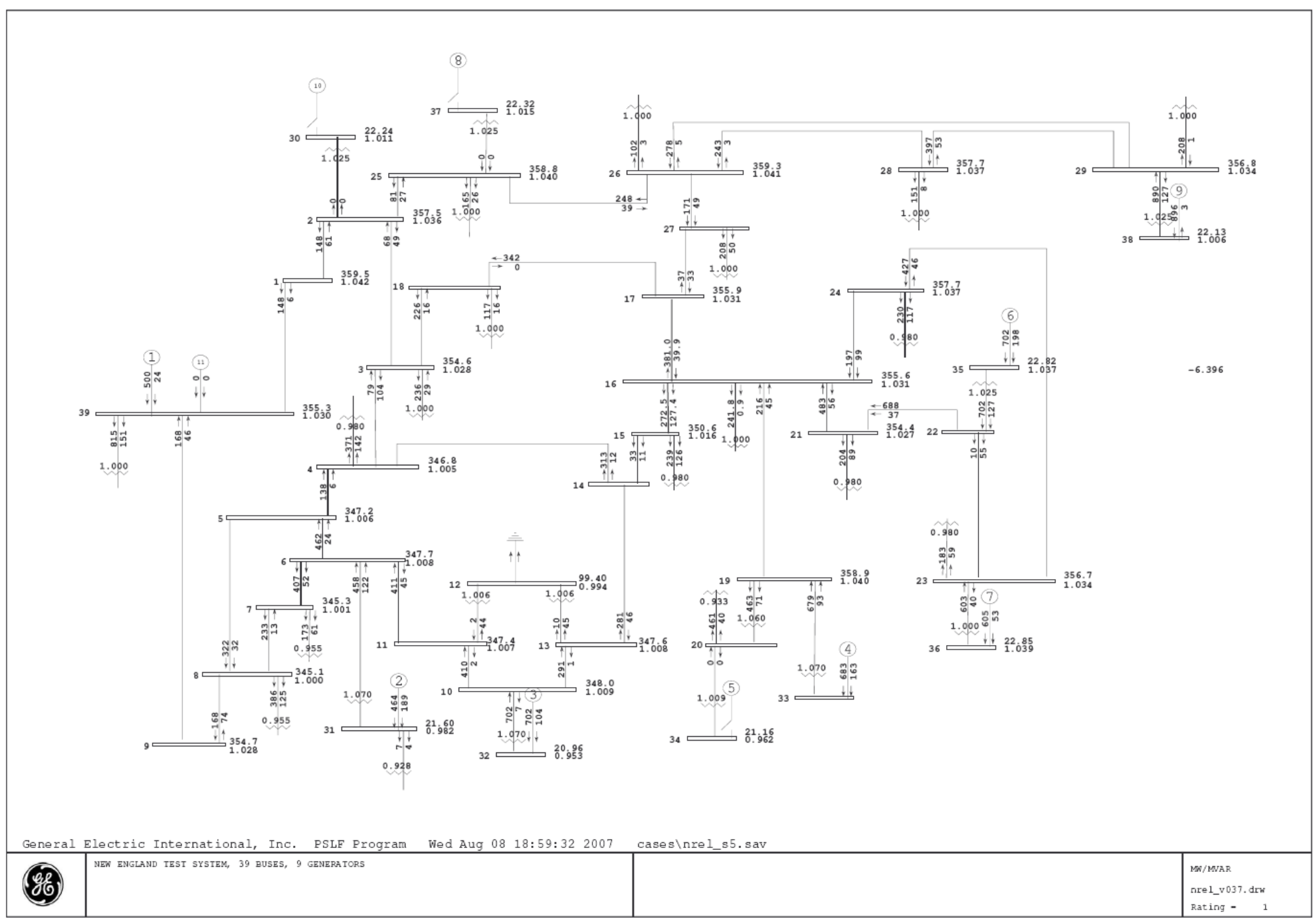

Figure D-5. Scenario s5 peak load. 30\% PV generation. Conventional generation de-committed. 


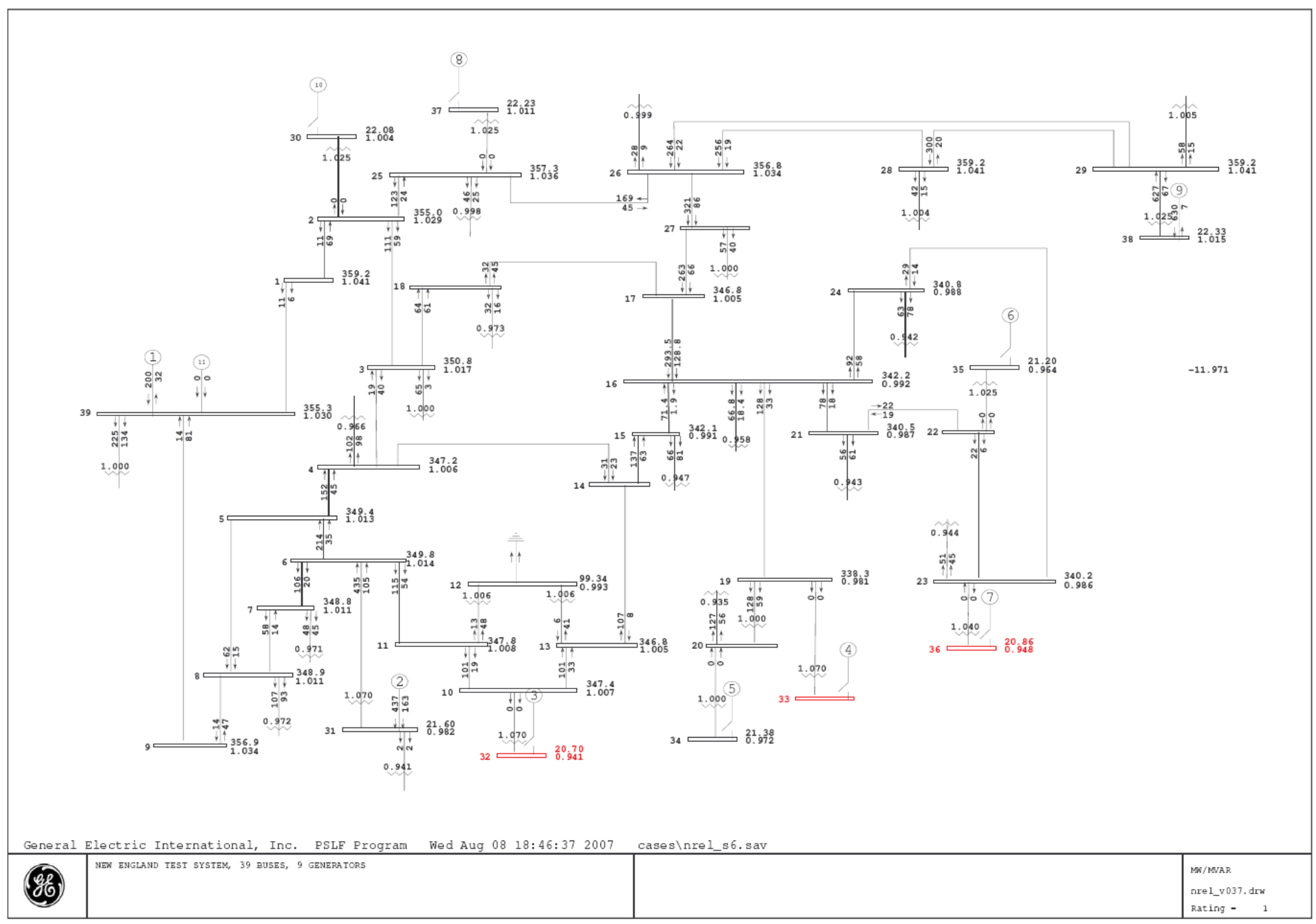

Figure D-6. Scenario s6 low load. 30\% PV generation. Conventional generation de-committed. 


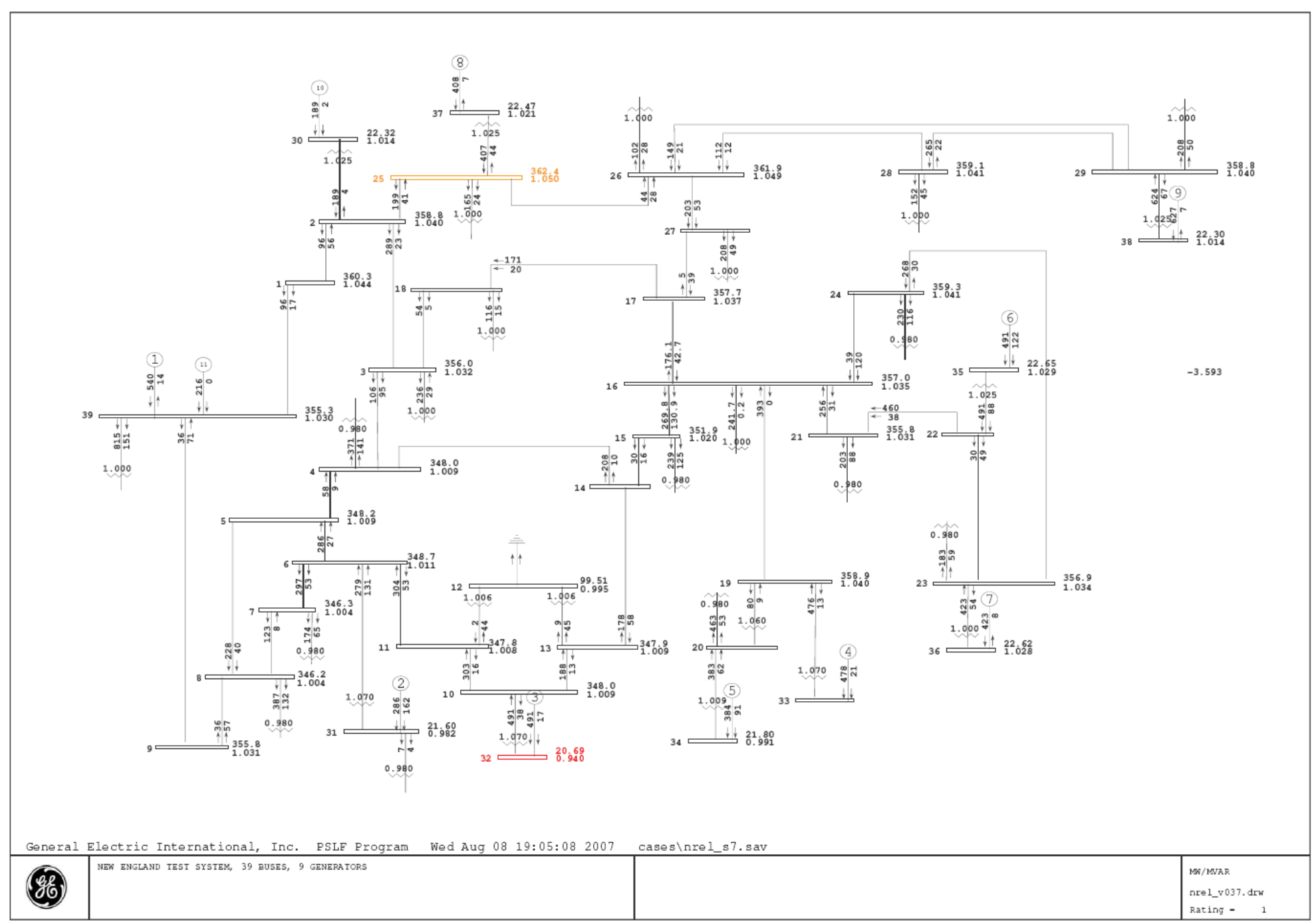

Figure D-7. Scenario s7 peak load. 30\% PV generation. Conventional generation not de-committed. 


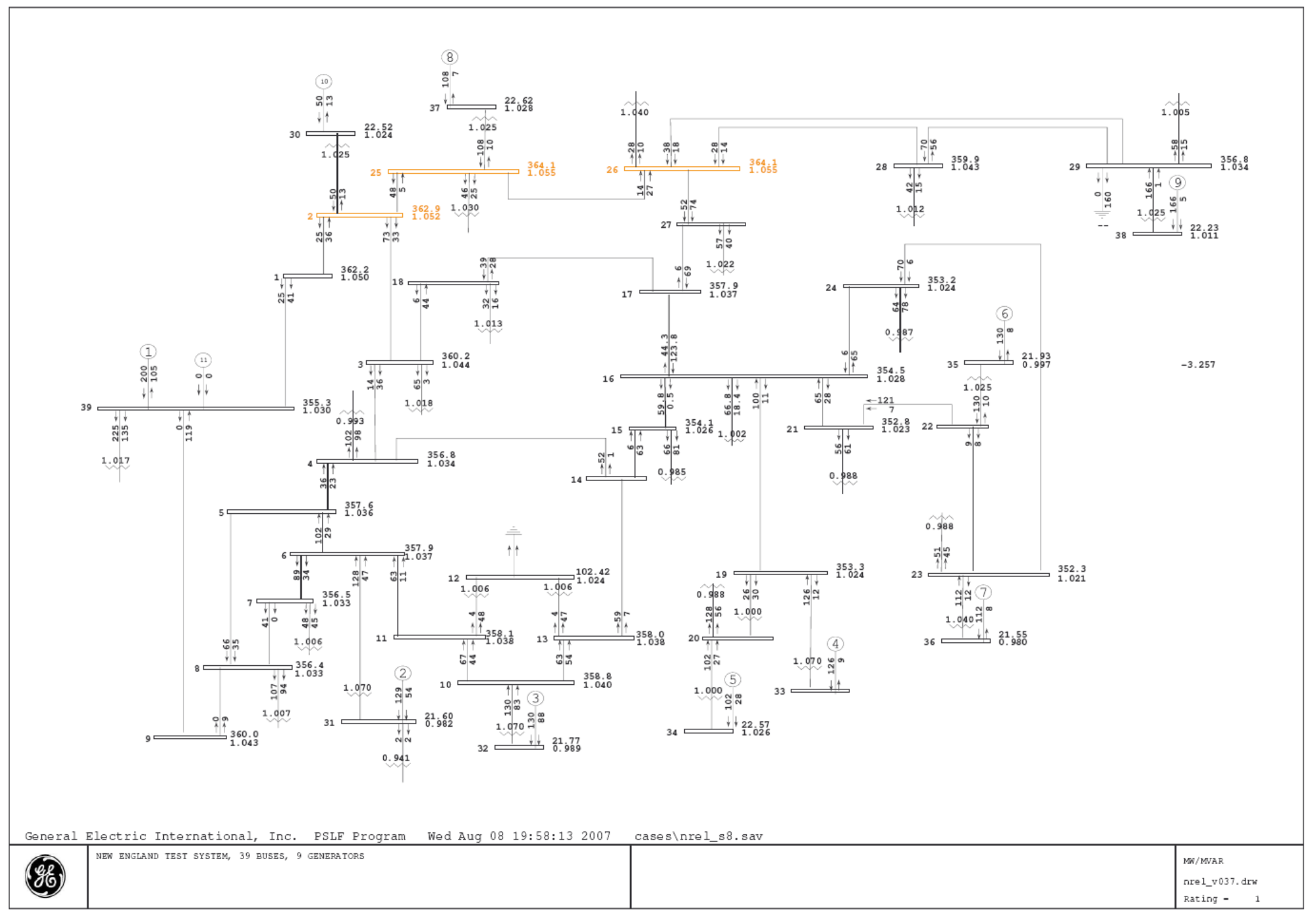

Figure D-8. Scenario s8 low load. 30\% PV generation. Conventional generation not de-committed. 


\section{Appendix E: PV Model Verification}

Figure E-1 shows the simple simulation system used to test the model and controls of the PV model. The source is a generator significantly larger than the PV. Loads were also included in the setup as needed to create frequency excursions needed in the analysis.

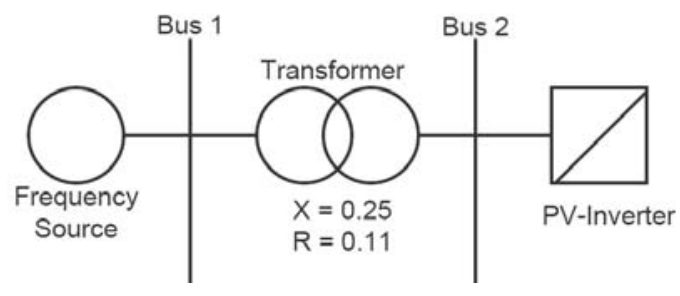

Figure E-1. PV-model test 


\section{Maximum Power Point Tracking}

Step changes of solar irradiation were simulated to calibrate the responsiveness of the MPP tracking loop. The results of a step change from 0.6 to 1 pu are presented in Figure E-2. It takes about three seconds to reach 0.96 pu power output ( $90 \%$ of requested change).

Significantly more time is required to achieve the final value (1 pu) due to the non-linear relationship between power and the voltage of the panel (section 0$)$. The signals presented are system frequency $\left(F_{P V}\right), \mathrm{PV}$ voltage $\left(V_{P V}\right), \mathrm{PV}$ power $\left(P_{P V}\right)$, active current component $\left(I_{r}\right)$ and reactive current component $\left(I_{i}\right)$
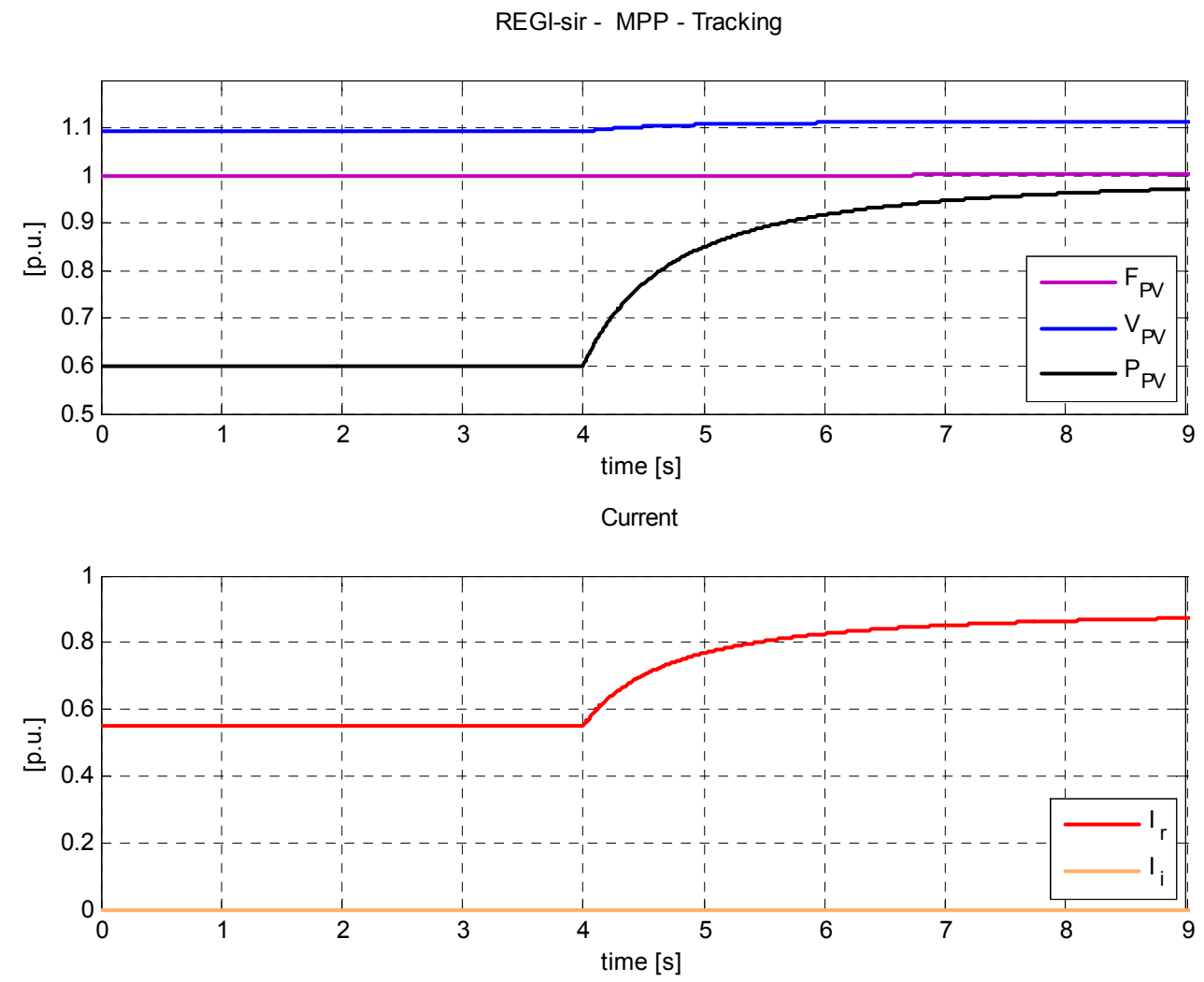

Figure E-2. MPP-tracking response to a step change in solar irradiation 


\section{Frequency Control}

Frequency ramps were applied to the PV system to test the frequency control response.

Figure E-3 presents the response of the system to a frequency increase after 2 seconds and a later frequency reduction (starting at 5 seconds). The signals presented are system frequency $\left(F_{P V}\right)$, PV voltage $\left(V_{P V}\right)$, PV power $\left(P_{P V}\right)$, active current component $\left(I_{r}\right)$ and reactive current component $\left(I_{i}\right)$, control output to achieve maximum available power $\left(k_{P A C}\right)$, MPP control output, frequency control output $\left(k_{F C}\right)$, active current limit output $\left(k_{A C L}\right)$, and control mode $(C M)$. The control mode signal is 1 for frequency control, -1 for MPP control, and 0 for current limiter control. The control signals refer to Figure 2-9. The PV frequency control was set to reach steady state in 2 to 3 seconds.
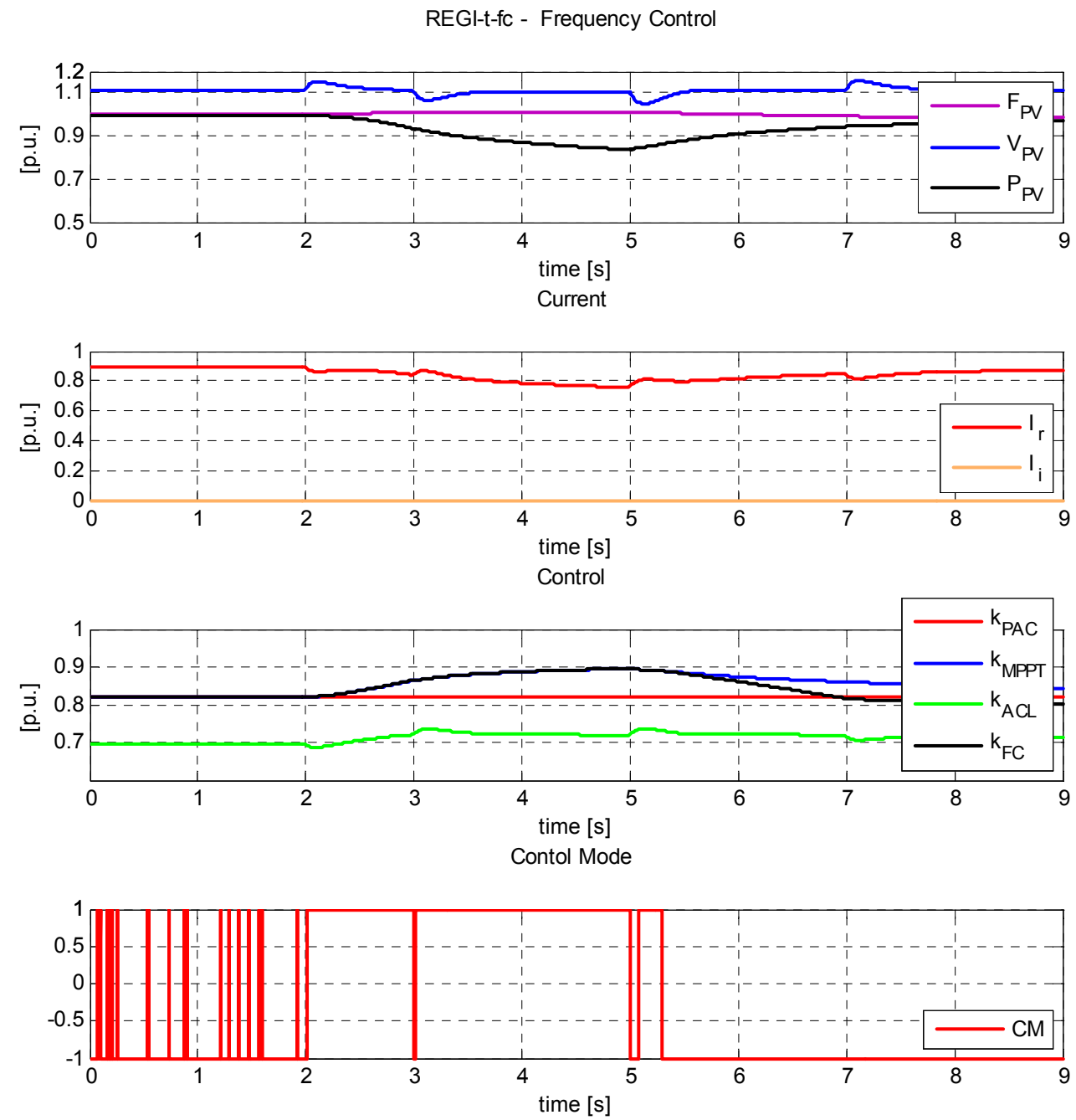

Figure E-3. PV response to frequency changes 
A similar run with initial reserve is presented in Figure E-4. The initial power is $20 \%$ below available power.
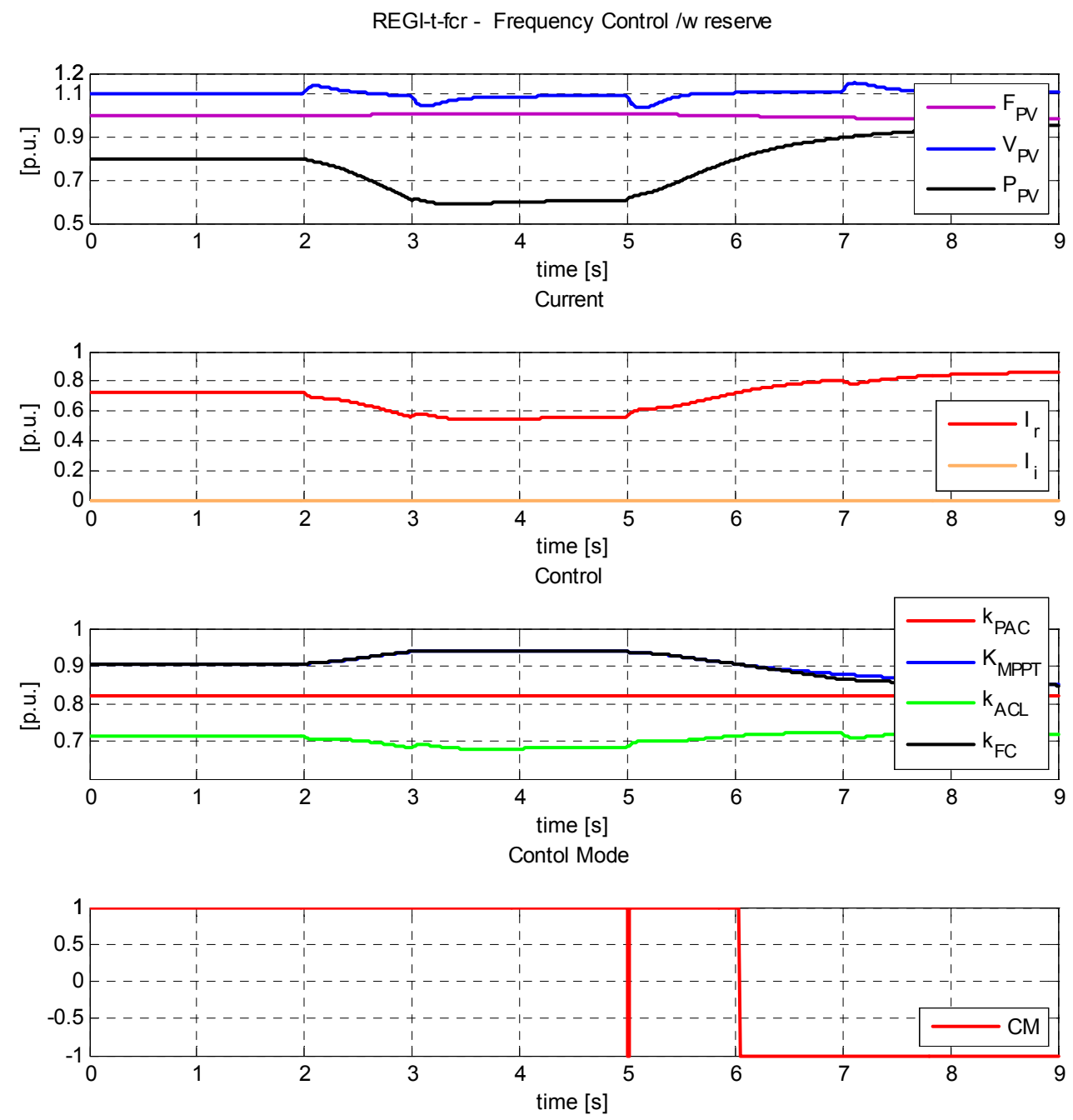

Figure E-4. PV response to frequency changes with initial reserve 


\section{Voltage Control}

Step changes in voltage reference were performed to test the voltage control. Figure E-5 and Figure E- 6 present the responses for two different settings. PV voltage $\left(V_{P V}\right)$ and reactive current component $\left(I_{i}\right)$ are presented. The different settings are used later in the anti-islanding section.
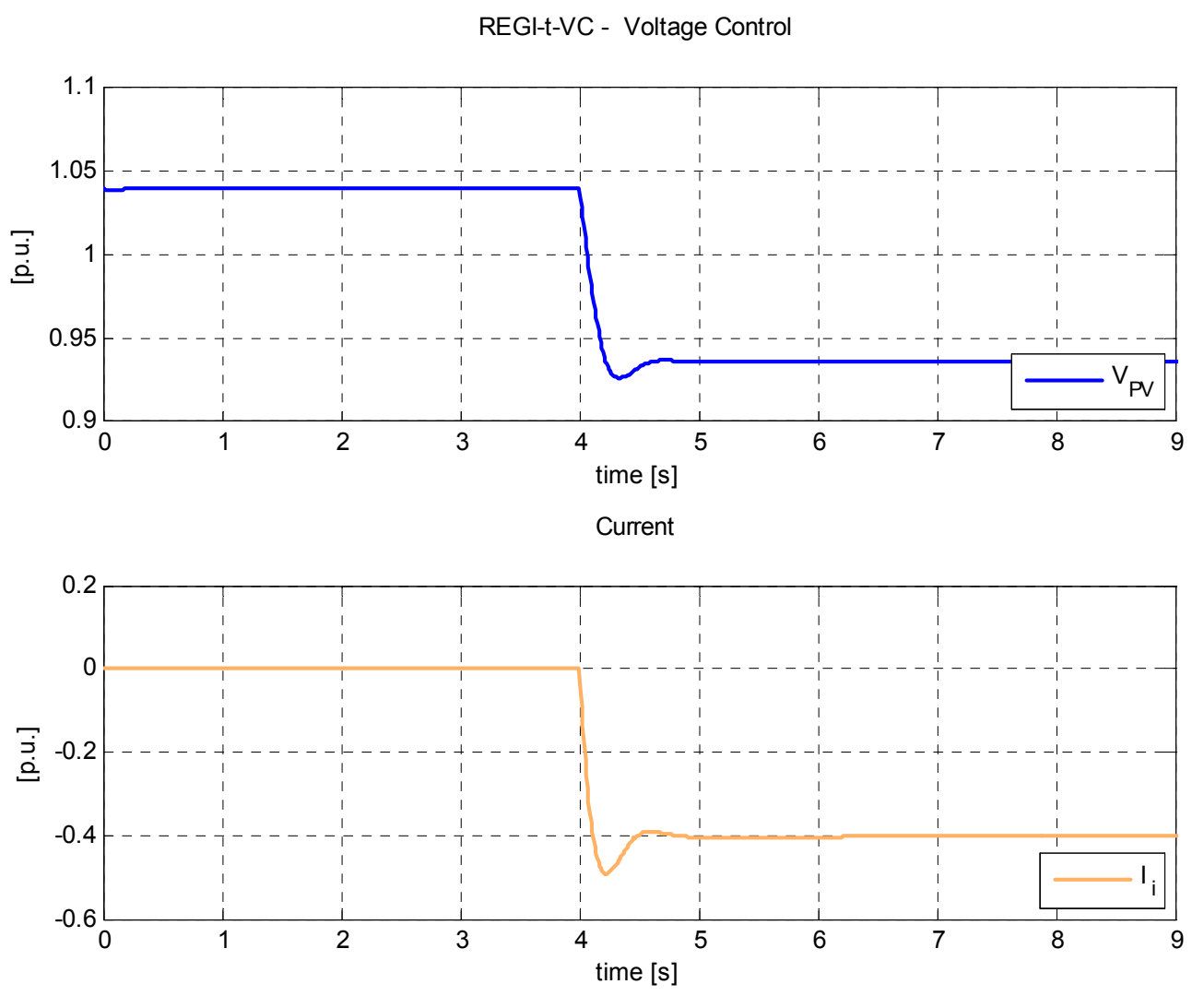

Figure E-5. Response to voltage reference step change 

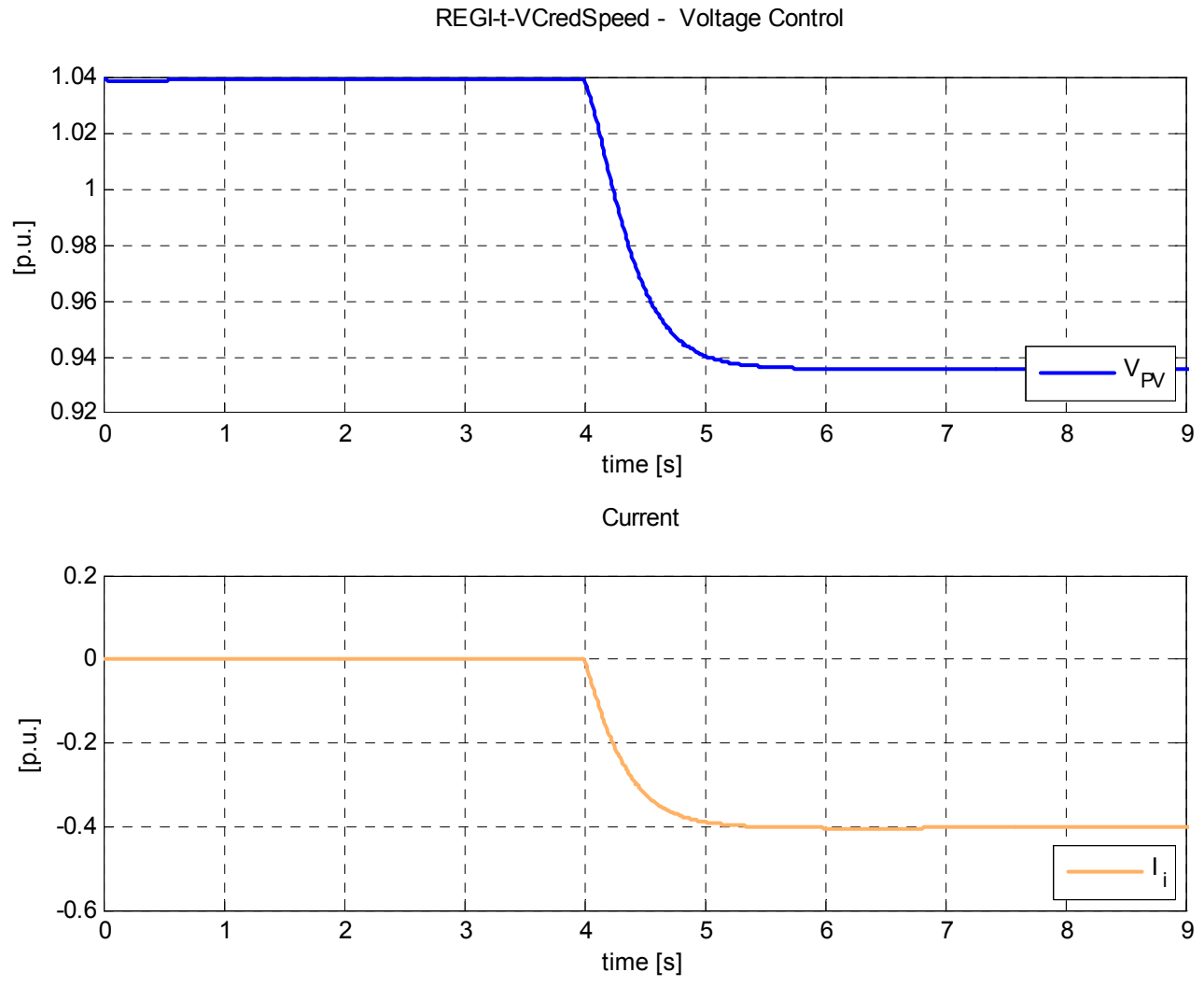

Figure E-6. Response to voltage reference step change, slower settings 


\section{Fault Response}

Different faults were applied to the test system to verify the PV response. All these cases assumed that the PV does not trip for voltage sags. Figure E-7 presents the response to a bus fault applied after two seconds and cleared one second later. MPP tracking and an active current limiter are active as presented in Figure 2-8. PV active power is reduced during the fault to limit the current (ACL control in Figure 2-8). The MPP tracking control brings the active power back to its initial value after the fault.

REGI-t-fau-ma - MPPT + ACL
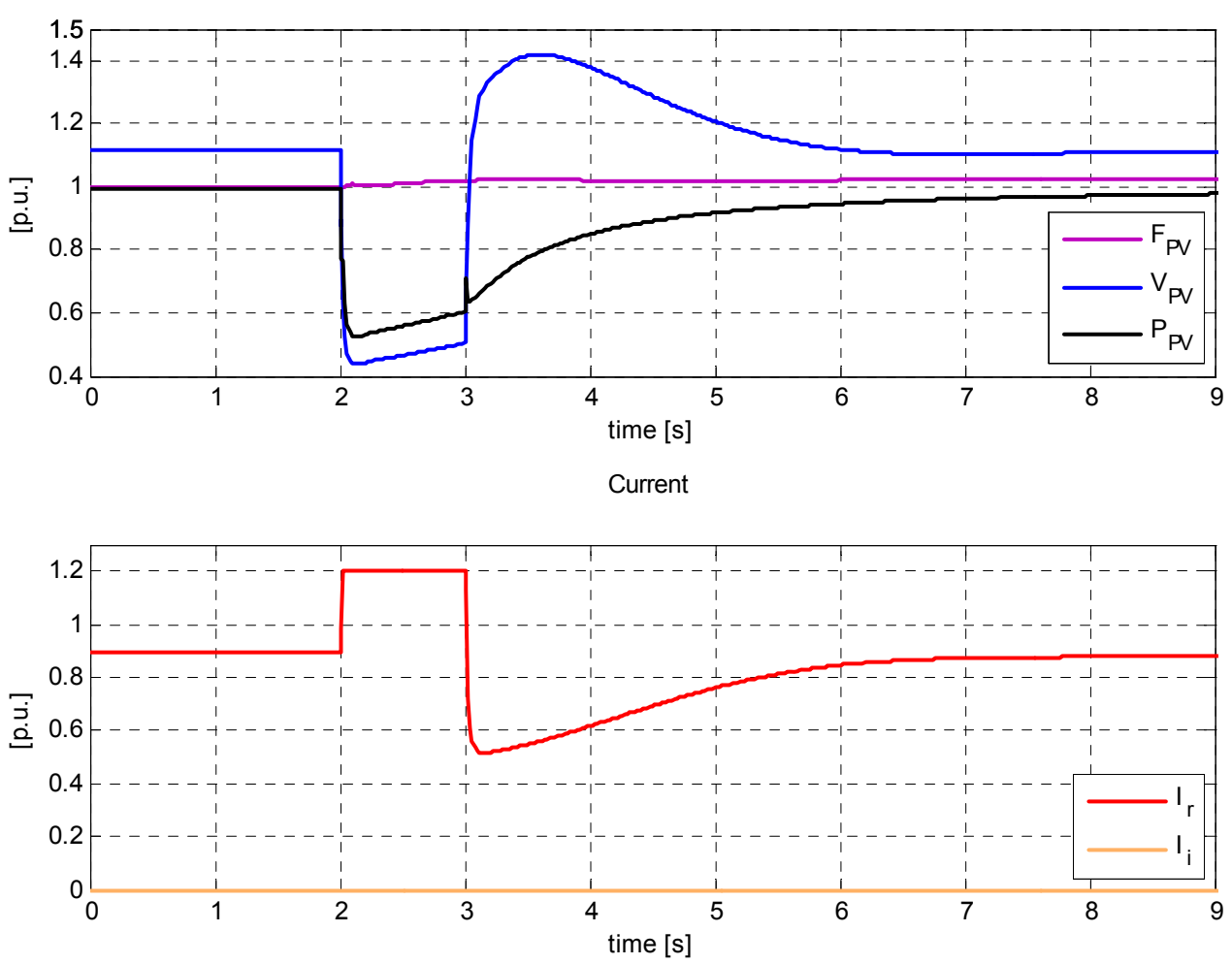

Figure E-7. PV response to voltage sag

Figure E-8 presents the response to the same fault with the frequency control active $(F C$ in Figure 2-9). The signals presented are system frequency $(F P V)$, PV voltage $\left(V_{P V}\right)$, PV power $\left(P_{P V}\right)$, active current component $\left(I_{r}\right)$ and reactive current component $\left(I_{i}\right)$, control output to achieve maximum available power $\left(k_{P A C}\right)$, MPP control output, frequency control output $\left(k_{F C}\right)$, active current limit output $\left(k_{A C L}\right)$, and control mode $(C M)$. The control mode signal is 1 for frequency control, -1 for MPP control, and 0 for current limiter control. The control signals refer to Figure 2-9. The frequency increase at the end of the simulation results in the frequency control governing the module. All control mode transitions are smooth. 

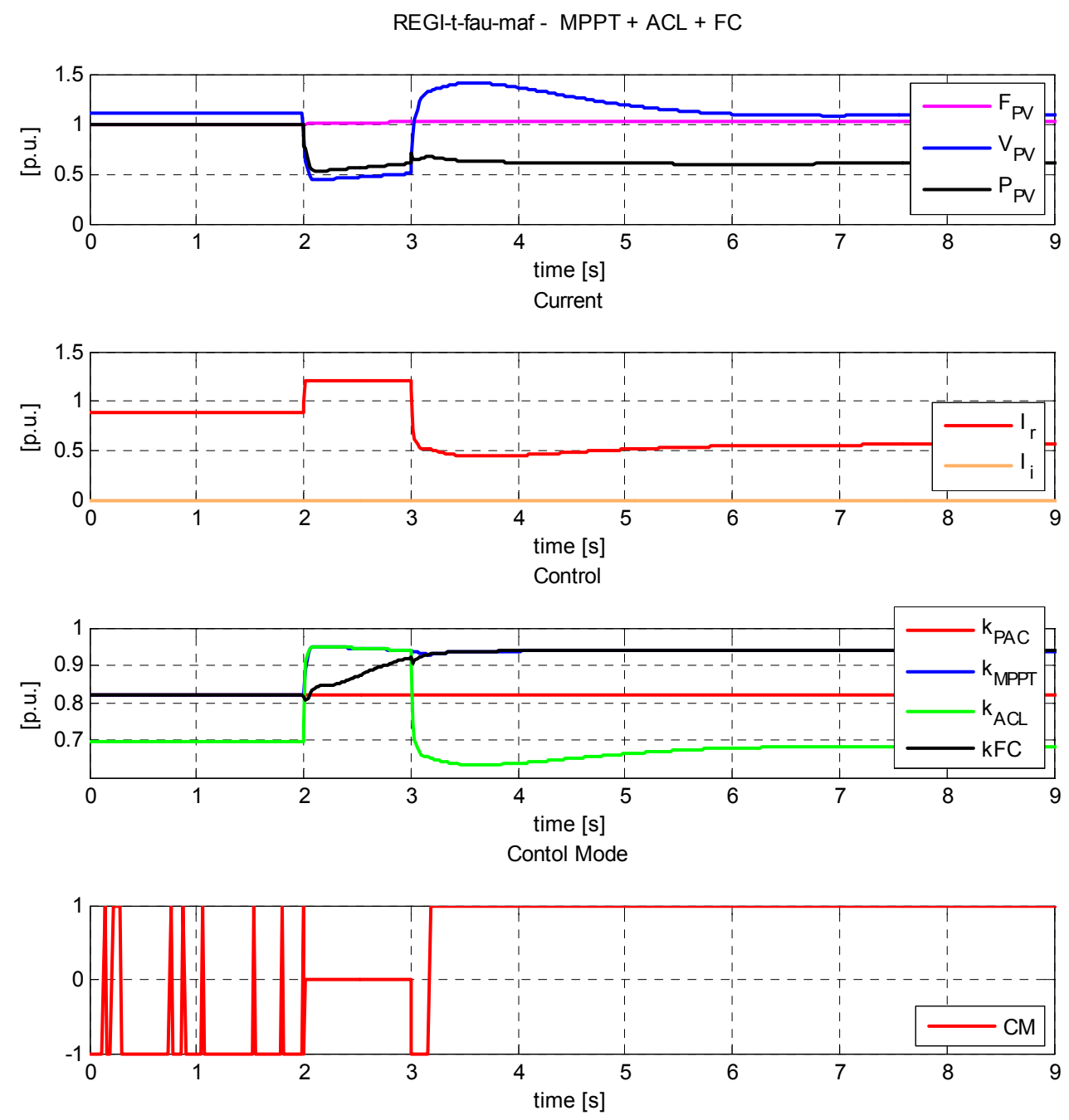

Figure E-8. PV response to voltage sag

As mentioned in section 2.2.8, a system without fast DC link control was considered. Figure E-9 presents the response to the same fault with a PV converter more sensitive to voltage changes. After the fault, the power output drops to zero because the DC voltage increases proportionally with the terminal voltage, bringing the module to the open circuit voltage. The PV power-out recovers relatively fast when the terminal voltage returns to its initial value. 
REGl-t-fau-md - MPPT + ACL + VD
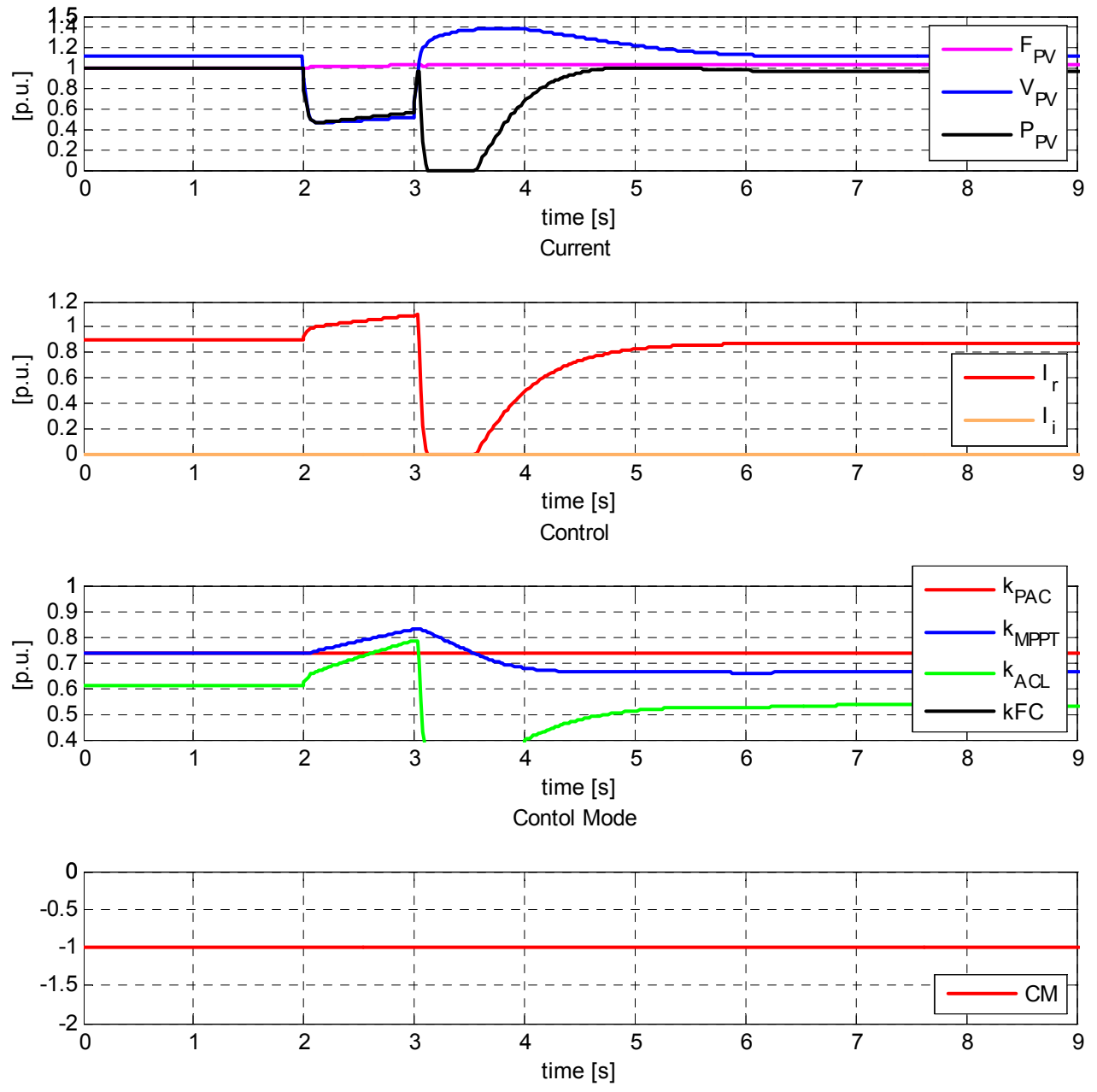

Figure E-9. PV response to voltage sag without fast DC link voltage control 


\section{Active Anti-Islanding}

The PV was islanded with a motor load equal to the PV output to evaluate tune the antiislanding loop in Figure 2-9. Figure E-10 presents the PV response without anti-islanding. The PV remains in stable operation after disconnection from bulk system (after 2 seconds).
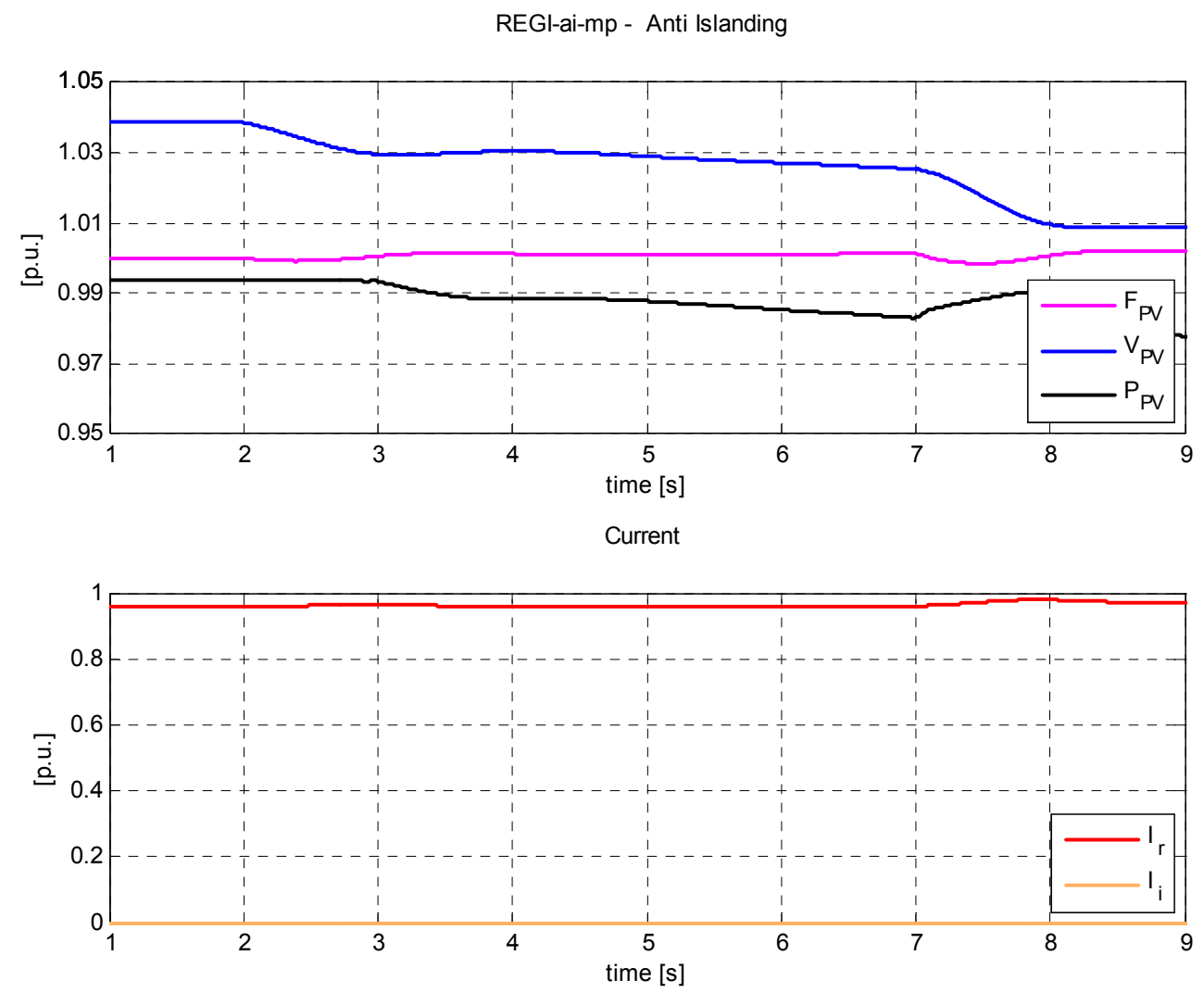

Figure E-10. PV islanding without active anti-islanding

Figure E-11 presents the response with the anti-islanding loop enabled. The PV trips about 0.6 seconds after disconnection from bulk system. The anti-islanding action effectively increases the voltage, destabilizing the frequency. 

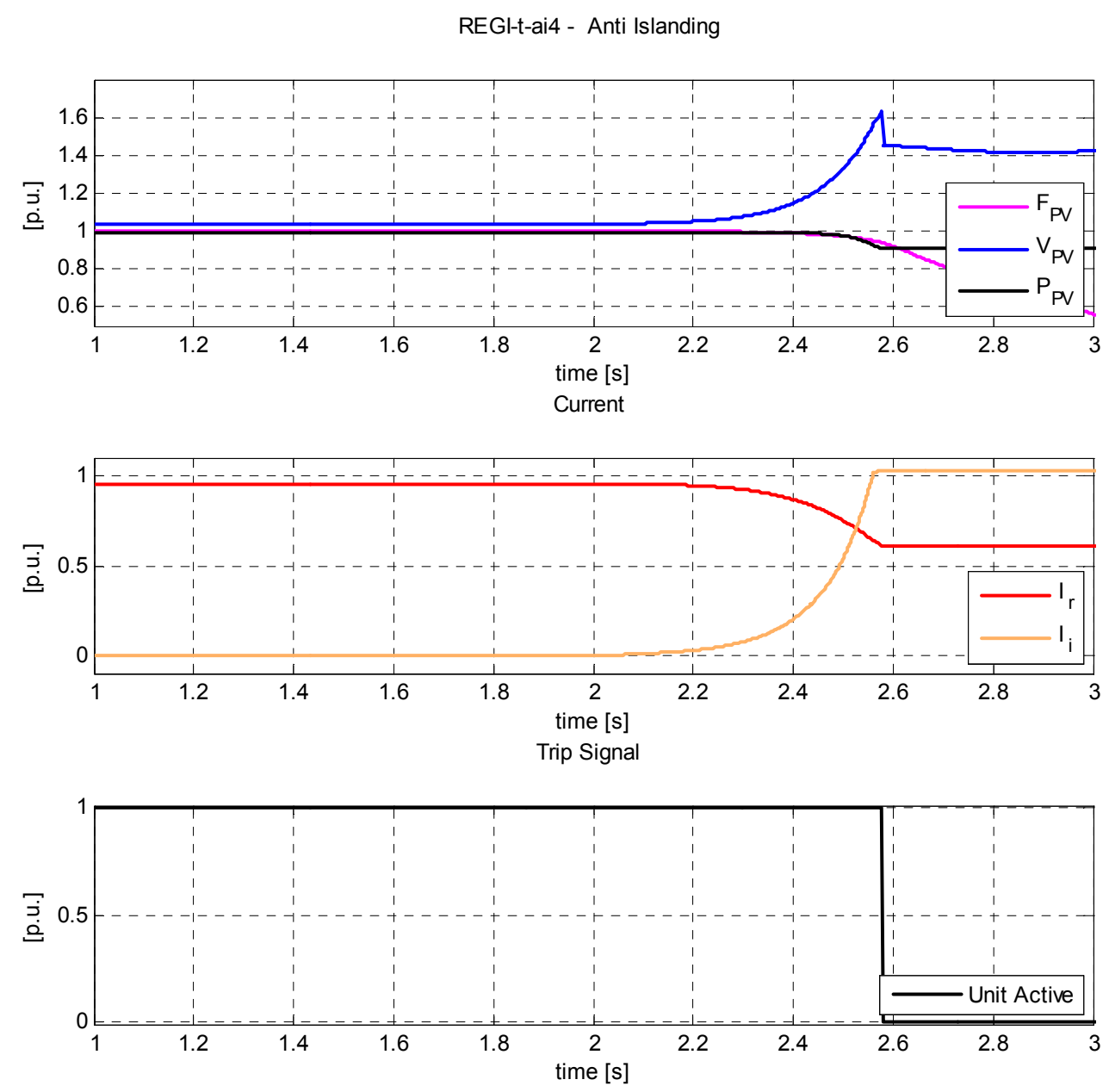

Figure E-11. PV islanding with active anti-islanding

Figure E-12 presents the response with active anti-islanding and voltage control enabled. The PV does not trip. The voltage control compensates the anti-islanding reactive current request. 

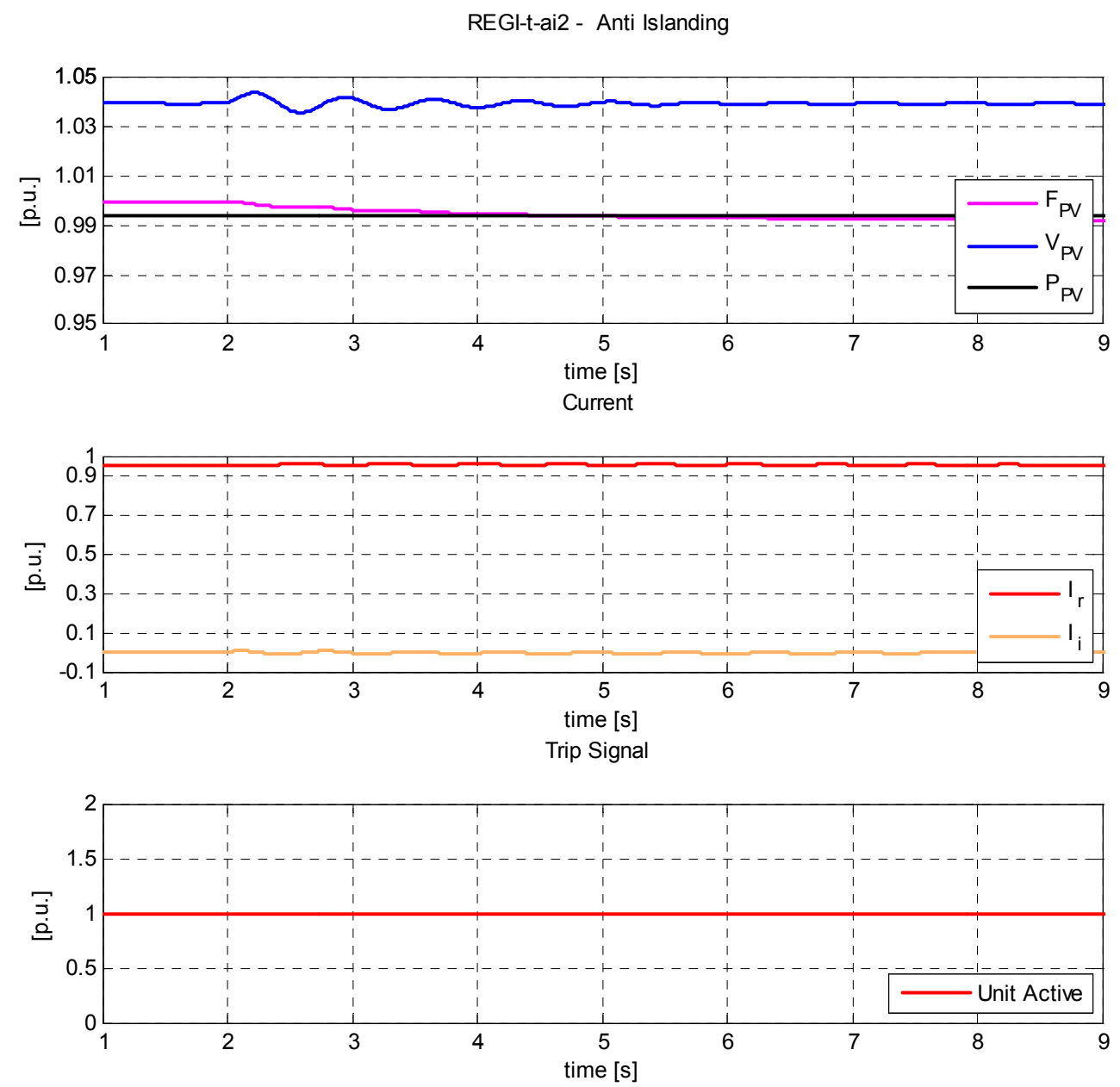

Figure E-12. PV islanding with active anti-islanding and voltage control

Figure E-13 presents the response with active anti-islanding and voltage control enabled. The voltage control is set slower (as in Figure E-6). The PV trips in about 0.6 seconds. The voltage control is slower and cannot compensate for the anti-islanding destabilizing request. Figure E-14 presents a similar case with five times higher gain than the anti-islanding loop. The PV trips in about 0.3 seconds. 
REGI-t-ai3 - Anti Islanding
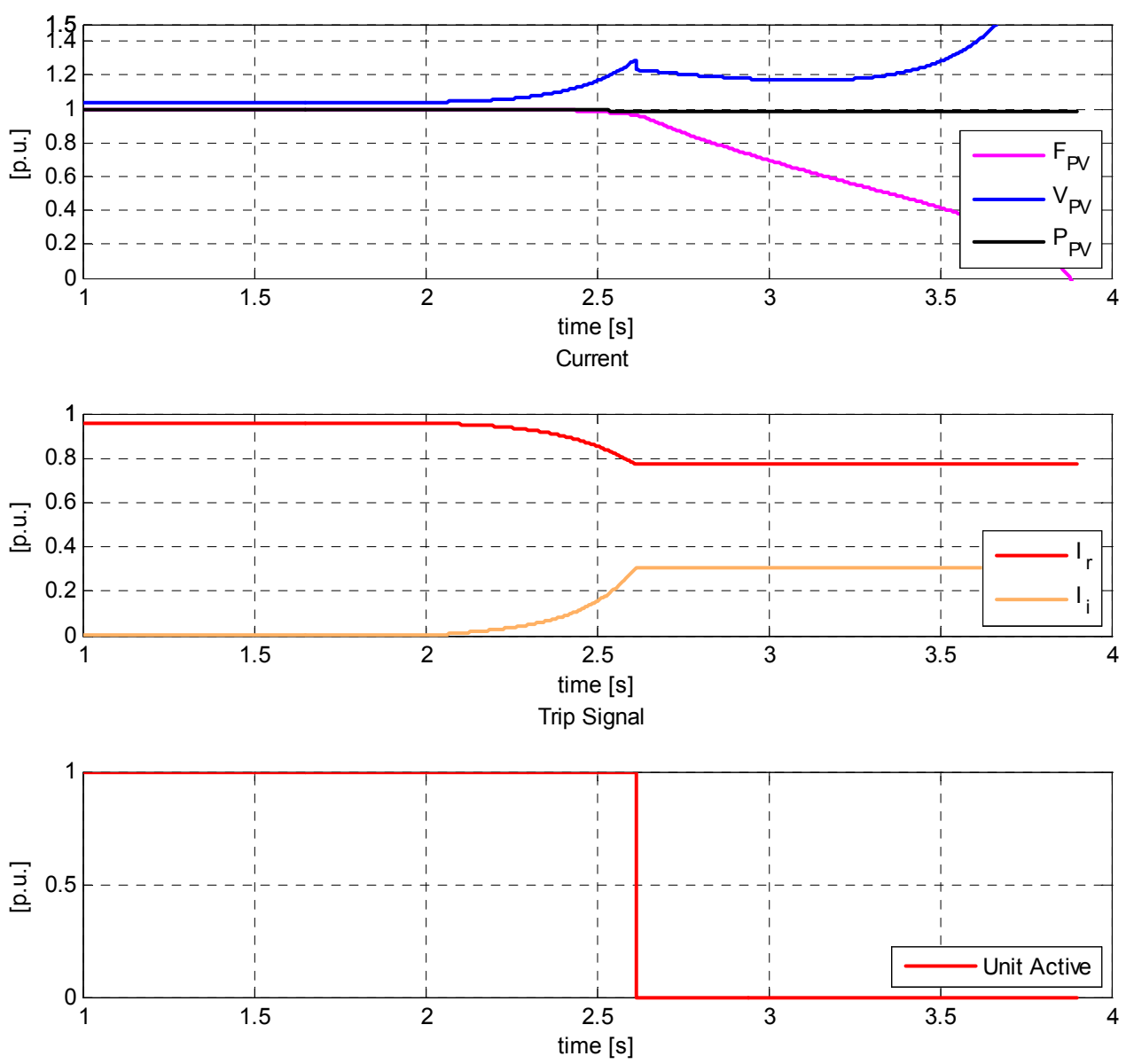

Figure E-13. PV islanding with active anti-islanding and slower voltage control 
REGI-t-ai5 - Anti Islanding
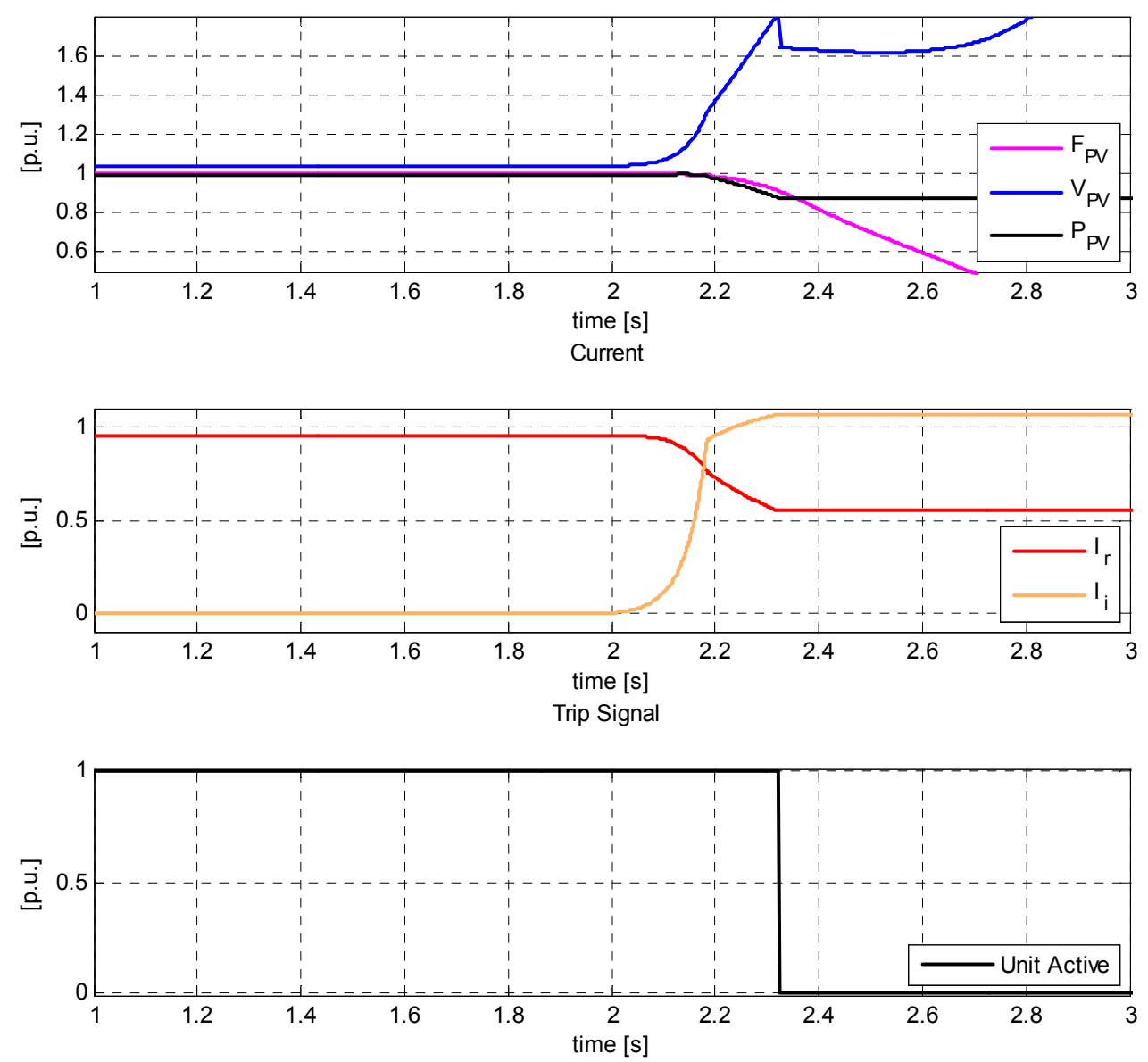

Figure E-14. PV islanding with active anti-islanding (higher gain) and slower voltage control 


\section{REPORT DOCUMENTATION PAGE}

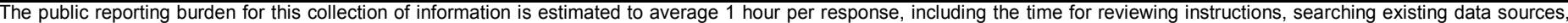

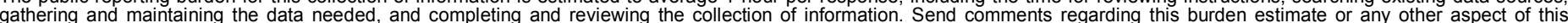

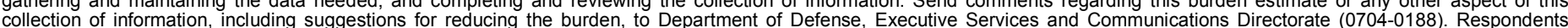

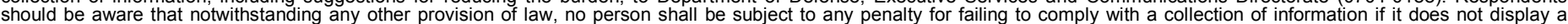

should be aware that notwithstanding

PLEASE DO NOT RETURN YOUR FORM TO THE ABOVE ORGANIZATION.

\begin{tabular}{l|l|l|l} 
1. REPORT DATE $(D D-M M-Y Y Y Y)$ & 2. REPORT TYPE & 3. DATES COVERED (FrOm - TO)
\end{tabular}

February 2008

Subcontract report

4. TITLE AND SUBTITLE

Transmission System Performance Analysis for High-Penetration

Photovoltaics 5a. CONTRACT NUMBER

DE-AC36-99-G010337

5b. GRANT NUMBER

5c. PROGRAM ELEMENT NUMBER

5d. PROJECT NUMBER

NREL/SR-581-42300

5e. TASK NUMBER

PVB7.6401

5f. WORK UNIT NUMBER

7. PERFORMING ORGANIZATION NAME(S) AND ADDRESS(ES)

GE Global Research

1 Research Circle

8. PERFORMING ORGANIZATION REPORT NUMBER

Niskayuna, NY 12309

ADC-7-77032-01

9. SPONSORING/MONITORING AGENCY NAME(S) AND ADDRESS(ES)

National Renewable Energy Laboratory

1617 Cole Blvd.

Golden, CO 80401-3393

10. SPONSOR/MONITOR'S ACRONYM(S)

NREL

11. SPONSORING/MONITORING AGENCY REPORT NUMBER NREL/SR-581-42300

12. DISTRIBUTION AVAILABILITY STATEMENT

National Technical Information Service

U.S. Department of Commerce

5285 Port Royal Road

Springfield, VA 22161

13. SUPPLEMENTARY NOTES

NREL Technical Monitor: Ben Kroposki

14. ABSTRACT (Maximum 200 Words)

This study is an assessment of the potential impact of high levels of penetration of photovoltaic (PV) generation on transmission systems. The effort used stability simulations of a transmission system with different levels of PV generation and load.

\section{SUBJECT TERMS}

photovoltaics; PV; transmission; renewable systems interconnection; GE Global Research; National Renewable Energy Laboratory; NREL

16. SECURITY CLASSIFICATION OF:
\begin{tabular}{|l|l|l|}
\hline a. REPORT & b. ABSTRACT & c. THIS PAGE \\
Unclassified & Unclassified & Unclassified \\
& & \\
\hline
\end{tabular}

\begin{tabular}{l|l} 
17. LIMITATION \\
OF ABSTRACT \\
UL
\end{tabular}

19a. NAME OF RESPONSIBLE PERSON

19b. TELEPHONE NUMBER (Include area code) 